\title{
Modeling Renewable Energy Resources in Integrated Resource Planning
}

D. Logan, C. Neil, and A. Taylor RCG/Hagler, Bailly, Inc.

Boulder, Colorado

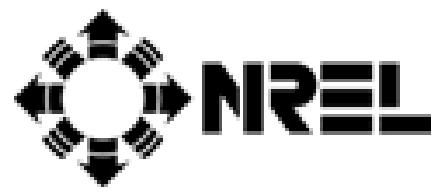

National Renewable Energy Laboratory 1617 Cole Boulevard Golden, Colorado 80401-3393

A national laboratory of the U.S. Department of Energy Managed by Midwest Research Institute for the U.S. Department of Energy under contract No. DE-AC36-83CH10093 


\section{Modeling Renewable Energy Resources in Integrated Resource Planning}

D. Logan, C. Neil, and A. Taylor RCG/Hagler, Bailly, Inc.

Boulder, Colorado

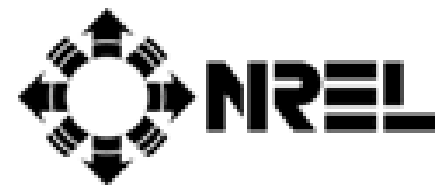

National Renewable Energy Laboratory 1617 Cole Boulevard Golden, Colorado 80401-3393

A national laboratory of the U.S. Department of Energy Managed by Midwest Research Institute for the U.S. Department of Energy under contract No. DE-AC36-83CH10093

Prepared under Task No. AAE-3-13371-01

June 1994 


\section{NOTICE}

This report was prepared as an account of work sponsored by an agency of the United States government. Neither the United States government nor any agency thereof, nor any of their employees, makes any warranty, express or implied, or assumes any legal liability or responsibility for the accuracy, completeness, or usefulness of any information, apparatus, product, or process disclosed, or represents that its use would not infringe privately owned rights. Reference herein to any specific commercial product, process, or service by trade name, trademark, manufacturer, or otherwise does not necessarily constitute or imply its endorsement, recommendation, or favoring by the United States government or any agency thereof. The views and opinions of authors expressed herein do not necessarily state or reflect those of the United States government or any agency thereof. 


\section{Foreword}

One of the obstacles to a wider use of renewable energy lies in the reliance of utilities on planning models that were not designed to account for the particular attributes of renewables. This report reviews the important attributes of renewables and describes modeling methodologies that capture the impact of these attributes on the value of renewables to utilities. Since no single model captures all of the impacts, the report presents a framework for using multiple models within an integrated resource planning process. The report also describes further methodological development that is necessary to improve the representation of renewables.

RCG/Hagler, Bailly, Inc. produced this report under subcontract from the Analytic Studies Division of the National Renewable Energy Laboratory with funding from the Integrated Planning Program at the U. S. Department of Energy. 


\section{Acknowledgments}

The authors are grateful to Joe Iannucci of Distributed Utility Associates and Connie Smyser and Lew Rubin of the Electric Power Research Institute for thoughtful comments on an earlier draft of this report. We also acknowledge the benefit we received from stimulating discussions with Peter Lilienthal and Blair Swezey of the National Renewable Energy Laboratory and Jill Baylor of RCG/Hagler Bailly throughout the course of this project. We remain responsible, however, for any errors and omissions. This work was performed under Subcontract No. AAE-3-13371-01 to the National Renewable Energy Laboratory. 


\section{Contents}

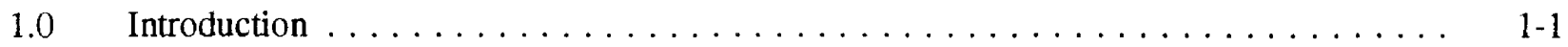

$1.1 \quad$ Review Methodology . . . . . . . . . . . . . . . . . . . $1-1$

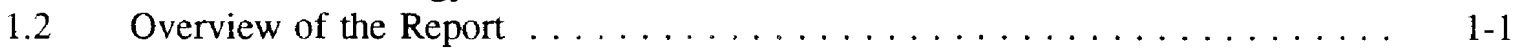

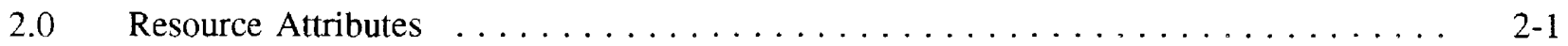

2.1 Overview of Resource Attributes . . . . . . . . . . . . . 2-1

2.2 Key Attributes of Renewable Resources . . . . . . . . . . . . . . . . 2-8

3.0 Utility Planning Processes and Models $\ldots \ldots \ldots \ldots \ldots \ldots \ldots \ldots \ldots \ldots$ 3-1

3.1 The Logic of Utility Planning . . . . . . $\ldots \ldots \ldots \ldots \ldots \ldots \ldots \ldots$

3.2 Utility Planning Models . . . . . . . . . . . $\ldots \ldots \ldots \ldots \ldots \ldots$ 3-6

3.3 Resource Attributes in the Planning Process $\ldots \ldots \ldots \ldots \ldots \ldots \ldots \ldots$

$4.0 \quad$ Modeling of Resource Attributes $\ldots \ldots \ldots \ldots \ldots \ldots \ldots \ldots \ldots \ldots$. $\ldots \ldots \ldots$

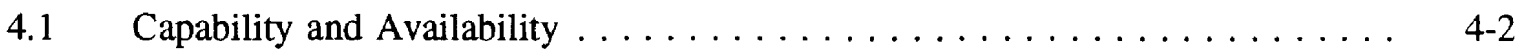

4.1 .1 Concept ........................ 4-2

4.1 .2 Modeling Techniques $\ldots \ldots \ldots \ldots \ldots \ldots \ldots \ldots \ldots$ 4-5

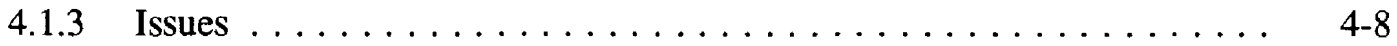

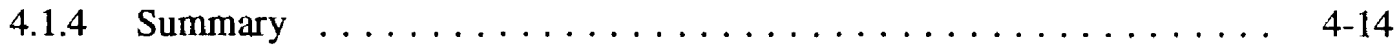

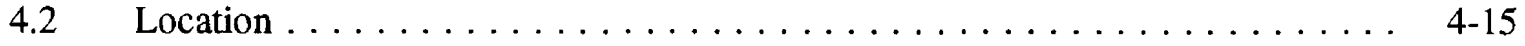

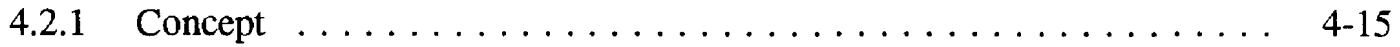

4.2.2 Modeling Techniques $\ldots \ldots \ldots \ldots \ldots \ldots \ldots \ldots \ldots$ 4-16

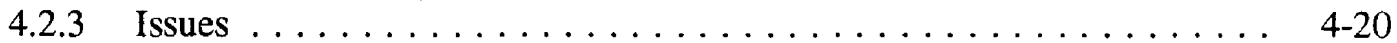

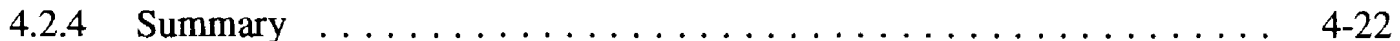

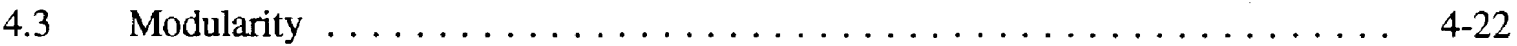

4.3.1 Concept ............................ 4-22

4.3.2 Modeling Techniques . . . . . . . . . . . . . . . . . . . 4 4-24

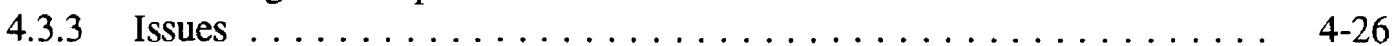

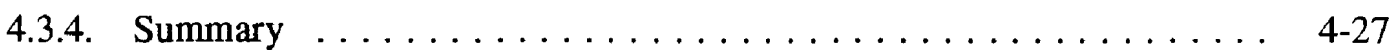

$4.4 \quad$ Risk Diversity . . . . . . . . . . . . . . . . . . . . . . 4-28

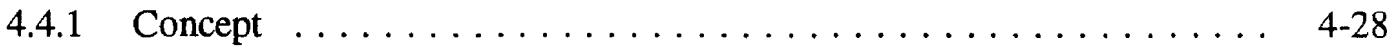

4.4 .2 Modeling Techniques $\ldots \ldots \ldots \ldots \ldots \ldots \ldots \ldots \ldots \ldots$ 4-30

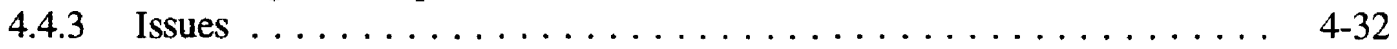

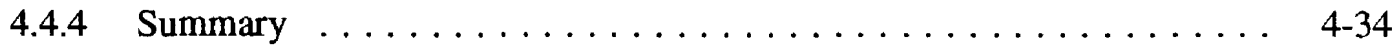

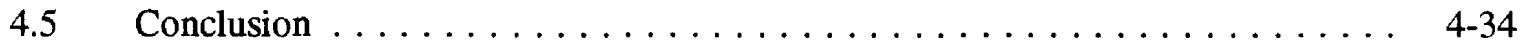

5.0 A Framework for Evaluating Renewable Resources Using Current Models $\ldots \ldots \ldots$. . . 5-1

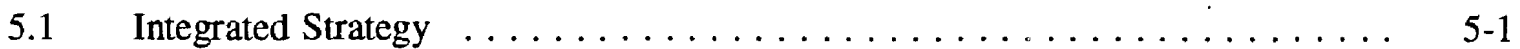

$5.2 \quad$ Integrated Strategy Development Process . . . . . . . . . . . . . . . . . 5-2

5.3 Tasks in the Integrated Strategy Development Process . . . . . . . . . . . . 5-2

5.4 Discussion . . . . . . . . . . . . . . . . . . . . . . . . . $5-10$

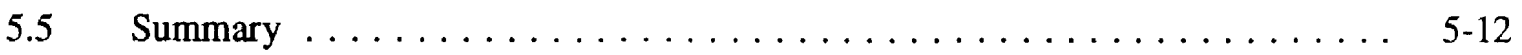




\section{Contents (Concluded)}

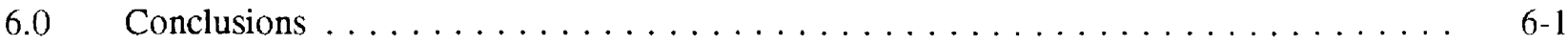

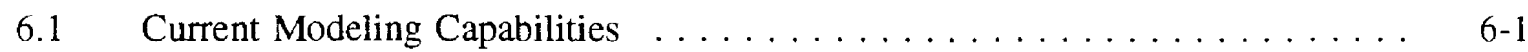

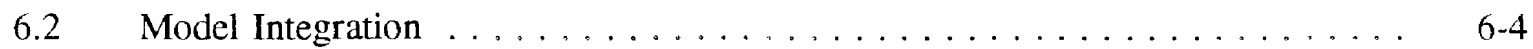

6.3 Recommendations for Methodology Development . . . . . . . . . . . . $6-5$

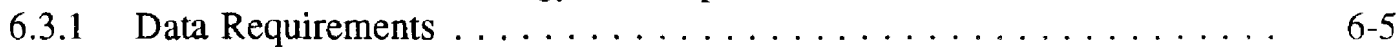

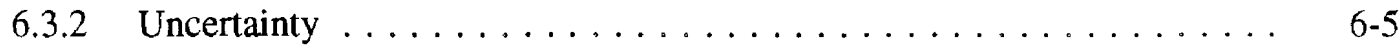

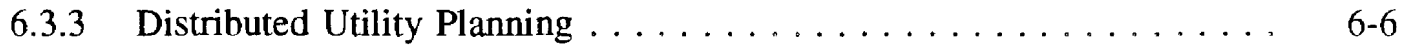

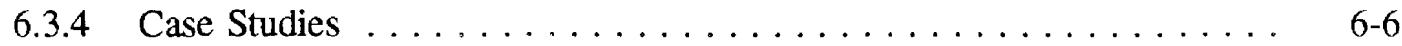

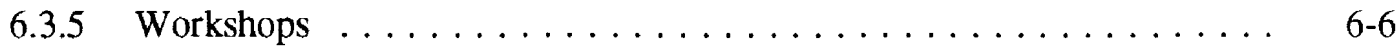

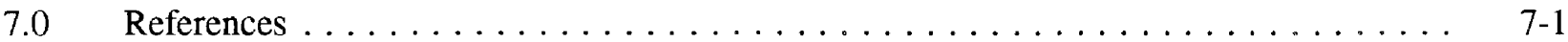

Appendix A: Selection of Models for Review $\ldots \ldots \ldots \ldots \ldots \ldots \ldots \ldots \ldots \ldots$ A-1

Appendix B: Technical Analysis of Risk Preference Functions . . . . . . . . . . . . B-1

Appendix C: Descriptions of Models Reviewed $\ldots \ldots \ldots \ldots \ldots \ldots \ldots \ldots \ldots \ldots$

Appendix D: Models Considered for Review $\ldots \ldots \ldots \ldots \ldots \ldots \ldots \ldots \ldots \ldots \ldots \ldots \ldots$ 


\section{List of Figures}

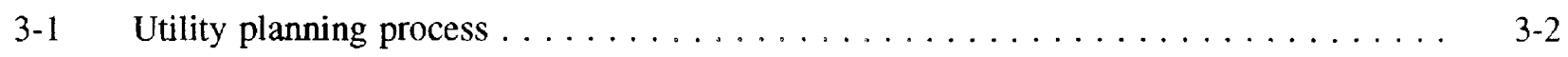

4-1 Renewable resource power delivery profile $\ldots \ldots \ldots \ldots \ldots \ldots \ldots$ 4-7

4-2 Multiple-scenario power delivery profiles $\ldots \ldots \ldots \ldots \ldots \ldots \ldots \ldots \ldots$

4-3 The distributed utility planning process $\ldots \ldots \ldots \ldots \ldots \ldots \ldots \ldots \ldots$

4-4 Calculation of diversity premium $\ldots \ldots \ldots \ldots \ldots \ldots \ldots \ldots \ldots \ldots \ldots \ldots$

5-1 Integrated strategy development process - conceptual approach $\ldots \ldots \ldots \ldots$

5-2 Integrated strategy development process-key tasks $\ldots \ldots \ldots \ldots \ldots \ldots$

$5-3 \quad$ Triggering mechanism $\ldots \ldots \ldots \ldots \ldots \ldots \ldots \ldots \ldots \ldots \ldots \ldots \ldots$

5-4 Probabilistic cost-effectiveness analysis $\ldots \ldots \ldots \ldots \ldots \ldots \ldots \ldots \ldots \ldots \ldots$

B-1 Risk preference function for annual electric bill $\ldots \ldots \ldots \ldots \ldots \ldots \ldots \ldots \ldots$ B-2 


\section{List of Tables}

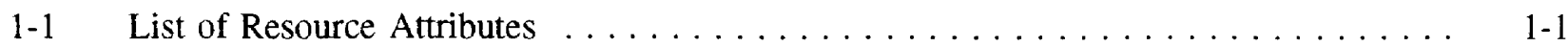

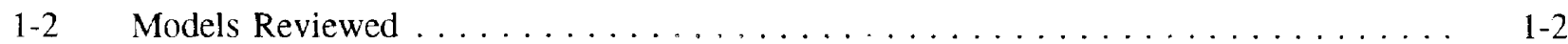

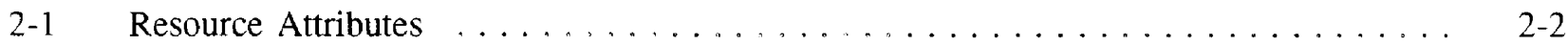

3-1 Description of Model Types $\ldots \ldots \ldots \ldots \ldots \ldots \ldots \ldots \ldots \ldots \ldots \ldots$

3-2 Representation of Resource Attributes within Utility Planning Models . . . . . . . . . 3-9

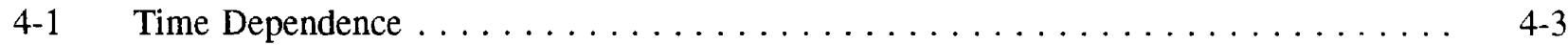

4-2 Comparison of the Impact on Commitment Decisions of Modeling Renewable Resources as Generating Units or Load Modifiers . . . . . . . . . . . . . . . . . . 4-14

4-3 Location $\ldots \ldots \ldots \ldots \ldots \ldots \ldots \ldots \ldots \ldots \ldots \ldots \ldots \ldots \ldots \ldots \ldots$

6-1 Summary of Model Capabilities $\ldots \ldots \ldots \ldots \ldots \ldots \ldots \ldots \ldots \ldots \ldots$. $\ldots \ldots \ldots$

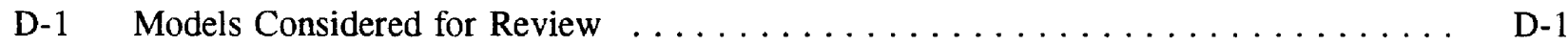




\subsection{Introduction}

Including renewable energy resources in integrated resource planning (IRP) requires that utility planning models properly consider the relevant attributes of the different renewable resources in addition to conventional supply-side and demand-side options. Otherwise, a utility's resource plan is unlikely to have an appropriate balance of the various resource options. The current trend toward regulatory set-asides for renewable resources is motivated in part by the perception that the capabilities of current utility planning models are inadequate with regard to renewable resources. Adequate modeling capabilities and utility planning practices are a necessary prerequisite to the long-term penetration of renewable resources into the electric utility industry's resource mix.

This report presents a review of utility planning models conducted for the National Renewable Energy Laboratory (NREL). The review examines the capabilities of utility planning models to address key issues in the choice between renewable resources and other options. The purpose of this review is to provide a basis for identifying high priority areas for advancing the state of the art.

\subsection{Review Methodology}

This review focuses on methodology and issues related to modeling several key attributes that are most significant in the comparison of renewable resources and other resource options. Our review started by identifying and defining the comprehensive list of resource attributes in Table 1-1. These attributes are defined in Section 2. The list was shortened to focus on the key attributes for renewable resources identified by asterisks in Table 1-1. We also identified a long list of models that have a role in IRP and the primary functions of these models. The short list of models to review was derived from this long list in two stages. We first identified the types of models that address the key attributes, then selected 11 models that either are advanced in their treatment of these attributes, used by utilities, or are generally available. These models are listed in Table 1-2, with their sources, primary functions, and pertinent attributes and issues. Models sponsored by the Electric Power Research Institute (EPRI) are identified in Table 1-2. The process of selecting these models is described in greater detail in Appendix A.

\subsection{Overview of the Report}

The report is organized as follows. Section 2 describes and categorizes the attributes of various kinds of resources and identifies the key attributes for renewables that are the focus of the remainder of the report. Section 3 presents an overview of utility planning processes and models. Section 4 is the heart of the

\begin{tabular}{|c||}
\hline $\begin{array}{c}\text { Table 1-1 } \\
\text { List of Resource Attributes }\end{array}$ \\
\hline Capability* \\
Availability* \\
Efficiency \\
Dispatchability \\
Location ${ }^{*}$ \\
Modularity* \\
Costs \\
Incentives \\
Risk-Diversity \\
External Costs \\
\hline *Key attributes for renewable resources \\
\hline
\end{tabular}


report. It defines the key attributes in greater detail, describes modeling concepts, and discusses the state of the art in modeling these attributes. Section 5 presents a framework for integrating a comprehensive evaluation of renewable resources into IRP using existing models with their current capabilities. Section 6 concludes the report with a summary of our findings and recommendations.

Appendix A describes the process by which we selected the models to be reviewed. Appendix B presents some mathematical details on modeling the diversity attribute. Appendix $\mathrm{C}$ provides brief descriptions of the selected models and consolidates the observations pertaining to each model that appear elsewhere in the report. Appendix D contains the list of models considered.

\begin{tabular}{|c|c|c|c|}
\hline \multicolumn{4}{|c|}{ Table 1-2. Models Reviewed } \\
\hline Model & Developer (Sponsor) & Primary Functions & Key Attributes \\
\hline Delta & Pacific Gas \& Electric & Location benefits & $\begin{array}{l}\text { Capability } \\
\text { Location }\end{array}$ \\
\hline DYNAMICS & $\begin{array}{l}\text { Decision Focus, Inc. } \\
\text { (EPRI) }\end{array}$ & $\begin{array}{l}\text { Chronological production } \\
\text { simulation }\end{array}$ & Capability \\
\hline $\begin{array}{l}\text { EGEAS/IRP } \\
\text { Workstation }\end{array}$ & $\begin{array}{l}\text { Stone \& Webster } \\
\text { Engineering Corporation } \\
\text { (EPRI) }\end{array}$ & $\begin{array}{l}\text { Production simulation } \\
\text { Resource planning } \\
\text { Generation reliability }\end{array}$ & $\begin{array}{l}\text { Capability } \\
\text { Modularity }\end{array}$ \\
\hline Elfin & $\begin{array}{l}\text { Environmental Defense } \\
\text { Fund }\end{array}$ & $\begin{array}{l}\text { Production simulation } \\
\text { Resource planning }\end{array}$ & $\begin{array}{l}\text { Capability } \\
\text { Modularity }\end{array}$ \\
\hline IRP-Manager & $\begin{array}{l}\text { Electric Power Software } \\
\text { (EPRI) }\end{array}$ & $\begin{array}{l}\text { Production simulation } \\
\text { Resource planning } \\
\text { Uncertainty analysis }\end{array}$ & Capability \\
\hline ISAAC & $\begin{array}{l}\text { Bonneville Power } \\
\text { Administration }\end{array}$ & Production simulation & $\begin{array}{l}\text { Capability } \\
\text { Modularity } \\
\text { Risk diversity }\end{array}$ \\
\hline MABS & Pacific Gas \& Electric & $\begin{array}{l}\text { Project economic analysis } \\
\text { Probabilistic analysis }\end{array}$ & $\begin{array}{l}\text { Capability } \\
\text { Location } \\
\text { Modularity } \\
\text { Risk diversity }\end{array}$ \\
\hline MIDAS & $\begin{array}{l}\text { M.S. Gerber \& } \\
\text { Associates (EPRI) }\end{array}$ & $\begin{array}{l}\text { Uncertainty analysis } \\
\text { Production simulation } \\
\text { Resource planning }\end{array}$ & $\begin{array}{l}\text { Capability } \\
\text { Modularity } \\
\text { Risk diversity }\end{array}$ \\
\hline PROMOD III & $\begin{array}{l}\text { Energy Management } \\
\text { Associates }\end{array}$ & $\begin{array}{l}\text { Production simulation } \\
\text { Generation reliability }\end{array}$ & $\begin{array}{l}\text { Capability } \\
\text { Availability }\end{array}$ \\
\hline $\begin{array}{l}\text { PROSCREEN II/ } \\
\text { PROVIEW }\end{array}$ & $\begin{array}{l}\text { Energy Management } \\
\text { Associates }\end{array}$ & $\begin{array}{l}\text { Production simulation } \\
\text { Resource planning } \\
\text { Capital expenditures } \\
\text { Financialrates }\end{array}$ & $\begin{array}{l}\text { Capability } \\
\text { Availability } \\
\text { Modularity }\end{array}$ \\
\hline UPLAN III & LCG Consulting & $\begin{array}{l}\text { Chronological production } \\
\text { Simulation } \\
\text { Resource planning } \\
\text { FinanciaVrates }\end{array}$ & $\begin{array}{l}\text { Capability } \\
\text { Availability }\end{array}$ \\
\hline
\end{tabular}




\subsection{Resource Attributes}

The range of technologies currently available to utilities for consideration as resource options to balance future supply and demand is vast. Utilities must consider the important differences between these technologies. This section identifies and categorizes the resource attributes that are relevant to utility decisions among three broad options and the attributes that are particularly significant to renewable resources.

\subsection{Overview of Resource Attributes}

Table 2-1 lists the attributes that are relevant to comparing and ranking resource options. The broad categories of resource options in Table 2-1 are defined as follows:

1. Conventional generation and storage-combustion turbine (CT), combined cycle (CC), fossil-fired steam turbine, nuclear, fossil-fired cogeneration, diesel, fuel cell, pumped hydro, battery, and compressed air energy storage

2. Renewable-wind, solar, geothermal, hydro, biomass, municipal solid waste (MSW), and end-use renewable

3. Demand-side management (DSM)—efficiency improvements and direct load control.

These categories are defined in this way simply to facilitate the discussion in this report. The lists of resources in each category are intended to be illustrative rather than exhaustive.

Ten general attributes and the characteristics or subattributes that define them are presented in Table 2-1. The table also summarizes the relevance of these attributes for the three resource categories and for specific options within the categories. The remainder of this subsection briefly discusses the 10 general attributes. ${ }^{1}$

Capability refers to limits on the ability of an option to supply power or to reduce demand in a given period under normal conditions. These limits include:

- The capacity rating

- Any limit on the total amount of energy that can be generated in the period owing, for example, to fuel supply constraints for a fossil station or to water constraints for a hydro station

- Contractual limits on the number of operations of a direct load control program.

The capability of an option may vary between time periods because of parameters such as seasonal variations in ambient temperatures that affect the capacity of a thermal unit.

1 The attributes of renewable resources are also described in Hamrin and Rader (1993) and in Wan and Parsons (1993). 


\begin{tabular}{|c|c|c|c|}
\hline Attribute & $\begin{array}{l}\text { Conventional Supply-Side } \\
\text { and Storage Options }\end{array}$ & $\begin{array}{l}\text { Renewable Energy } \\
\text { Technologies }\end{array}$ & $\begin{array}{l}\text { Demand-Side Management } \\
\text { Options }\end{array}$ \\
\hline $\begin{array}{l}\text { CAPABILITY } \\
\text { Peak capability } \\
\text { Energy capability } \\
\text { Seasonal profile } \\
\text { Hourly profile }\end{array}$ & May have mild seasonal profiles. & $\begin{array}{l}\text { Hydro, solar, and wind options } \\
\text { typically have pronounced } \\
\text { seasonal profiles. Solar and wind } \\
\text { options also have pronounced } \\
\text { hourly profiles. }\end{array}$ & $\begin{array}{l}\text { Pronounced seasonal and hourly } \\
\text { profiles. }\end{array}$ \\
\hline $\begin{array}{l}\text { AVAILABILITY } \\
\text { Intermittence } \\
\text { Forced outages } \\
\text { Maintenance requirements } \\
\text { Correlation with: } \\
\text { - Weather } \\
\text { - Hydrological conditions } \\
\text { - System demand }\end{array}$ & $\begin{array}{l}\text { No intermittence. } \\
\text { Maintenance requirements may } \\
\text { be coordinated with other plants. }\end{array}$ & $\begin{array}{l}\text { Hydro capability is dependent on } \\
\text { hydrological conditions. Plants on } \\
\text { the same river system are tightly } \\
\text { correlated. } \\
\\
\text { Wind and solar are intermittent. } \\
\text { Units in the same area are } \\
\text { correlated with each other and } \\
\text { may be correlated with the } \\
\text { weather-sensitive component of } \\
\text { system demand. }\end{array}$ & $\begin{array}{l}\text { Demand impacts are correlated } \\
\text { with both the weather-sensitive } \\
\text { component of system demand } \\
\text { and long-term demand growth. }\end{array}$ \\
\hline $\begin{array}{l}\text { EFFICIENCY } \\
\text { Heat rate }\end{array}$ & $\begin{array}{l}\text { Efficiency is a major determinant } \\
\text { of total cost, particularly for } \\
\text { technologies that use higher cost } \\
\text { fuels. }\end{array}$ & $\begin{array}{l}\text { Efficiency is generally not an } \\
\text { issue for renewables because } \\
\text { they typically rely on zero- or low- } \\
\text { cost energy sources. }\end{array}$ & Not applicable. \\
\hline
\end{tabular}




\begin{tabular}{|c|c|c|c|}
\hline Attribute & $\begin{array}{l}\text { Conventional Supply-Side } \\
\text { and Storage Options }\end{array}$ & $\begin{array}{l}\text { Renewable Energy } \\
\text { Technologies }\end{array}$ & $\begin{array}{c}\text { Demand-Side Management } \\
\text { Options }\end{array}$ \\
\hline $\begin{array}{l}\text { DISPATCHABILITY } \\
\text {. Fully dispatchable } \\
\text {. Curtailable } \\
\text {. Base-loaded } \\
\\
\text { Constraints: } \\
\text { - Ramp rate } \\
\text {. Minimum output } \\
\text {. Minimum up time } \\
\text {. Minimum downtime }\end{array}$ & $\begin{array}{l}\text { Fossil-fired noncogeneration } \\
\text { options are typically fully } \\
\text { dispatchable, subject to minimum } \\
\text { load, minimum downtime, and } \\
\text { ramp rate constraints. } \\
\text { Nuclear generation is base-loaded } \\
\text { but may be curtailable. } \\
\text { Cogeneration may be built to } \\
\text { accommodate any level of } \\
\text { dispatchability. }\end{array}$ & $\begin{array}{l}\text { Run-of-river hydro is } \\
\text { nondispatchable. Pondage hydro } \\
\text { is dispatchable, subject to energy } \\
\text { and flow constraints. } \\
\text { Wind is nondispatchable. } \\
\text { Solar thermal with thermal } \\
\text { storage is dispatchable. Other } \\
\text { solar options are nondispatchable. } \\
\text { Biomass, landfill methane, and } \\
\text { MSW options are typically } \\
\text { nondispatchable. } \\
\text { Geothermal is typically } \\
\text { nondispatchable. }\end{array}$ & $\begin{array}{l}\text { Direct load control and } \\
\text { interruptible load are fully } \\
\text { dispatchable, subject to } \\
\text { contractual constraints on } \\
\text { maximum number and duration } \\
\text { of operations. All other DSM } \\
\text { options are nondispatchable. }\end{array}$ \\
\hline $\begin{array}{l}\text { LOCATION } \\
\text { Delivery point: substation } \\
\text { feeder }\end{array}$ & Connected at transmission level. & $\begin{array}{l}\text { Connected at transmission or } \\
\text { distribution level. Can be } \\
\text { targeted to defer transmission or } \\
\text { distribution upgrades. }\end{array}$ & $\begin{array}{l}\text { Connected at transmission (for } \\
\text { large industrial customers) or } \\
\text { distribution level (for other } \\
\text { customers). Can be targeted to } \\
\text { defer transmission or distribution } \\
\text { upgrades. }\end{array}$ \\
\hline
\end{tabular}




\begin{tabular}{|c|c|c|c|}
\hline Attribute & $\begin{array}{l}\text { Conventional Supply-Side } \\
\text { and Storage Options }\end{array}$ & $\begin{array}{l}\text { Renewable Energy } \\
\text { Technologies }\end{array}$ & $\begin{array}{l}\text { Demand-Side Management } \\
\text { Options }\end{array}$ \\
\hline $\begin{array}{l}\text { MODULARITY } \\
\text { Incremental size } \\
\text { Pre-construction lead time } \\
\text { Construction lead time }\end{array}$ & $\begin{array}{l}\text { Incremental sizes of fossil-fired } \\
\text { options vary between } 15 \mathrm{MW} \text { (for } \\
\text { small CTs) to } 1000 \mathrm{MW} \text { (for large } \\
\text { coal-fired steam units). } \\
\text { Incremental sizes of nuclear units } \\
\text { vary between } 300 \mathrm{MW} \text { (for future } \\
\text { advanced design units) and } 1200 \\
\text { MW (for current technology). } \\
\text { Pre-construction lead times of } \\
\text { fossil-fired options vary between } 1 \\
\text { year (for CTs) and } 4 \text { years (for } \\
\text { coal-fired units). Pre-construction } \\
\text { lead times of nuclear units are } 6 \\
\text { years. } \\
\text { Construction lead times of fossil- } \\
\text { fired options vary between } 1 \text { year } \\
\text { (for CTs) and } 6 \text { years (for large } \\
\text { coal-fired units). Construction } \\
\text { lead times of nuclear units vary } \\
\text { between } 4 \text { years (for advanced } \\
\text { design units) and } 6 \text { years (for } \\
\text { current technology). }\end{array}$ & $\begin{array}{l}\text { Incremental sizes and lead times } \\
\text { of RETs, except for MSW, are } \\
\text { typically smaller and shorter than } \\
\text { for conventional options. } \\
\text { Pre-construction lead times for } \\
\text { MSW are } 3 \text { to } 4 \text { years. }\end{array}$ & $\begin{array}{l}\text { DSM options have no minimum } \\
\text { incremental size, but the } \\
\text { maximum size of a DSM option } \\
\text { is limited. DSM programs may } \\
\text { be implemented with a lead time } \\
\text { of only } 1 \text { year. However, the } \\
\text { demand impacts of DSM } \\
\text { programs may take } 10 \text { years to } \\
\text { build up. }\end{array}$ \\
\hline
\end{tabular}




\begin{tabular}{|c|c|c|c|}
\hline Attribute & $\begin{array}{l}\text { Conventional Supply-Side } \\
\text { and Storage Options }\end{array}$ & $\begin{array}{l}\text { Renewable Energy } \\
\text { Technologies }\end{array}$ & $\begin{array}{c}\text { Demand-Side Management } \\
\text { Options }\end{array}$ \\
\hline $\begin{array}{l}\text { COSTS } \\
\text { Construction } \\
\text { Operating and maintenance } \\
\text { Fuel } \\
\text { Decommissioning } \\
\text { Correlation with other } \\
\text { system costs }\end{array}$ & $\begin{array}{l}\text { Correlation of fuel costs is } \\
\text { significant. }\end{array}$ & $\begin{array}{l}\text { Typically no fuel costs. These } \\
\text { tech-nologies provide } \\
\text { diversification of the fuel supply } \\
\text { portfolio. }\end{array}$ & $\begin{array}{l}\text { DSM options often involve } \\
\text { participants bearing some costs. }\end{array}$ \\
\hline $\begin{array}{l}\text { INCENTIVES } \\
\text { Tax } \text { credits }^{2} \\
\text { Shareholder incentives }{ }^{2} \\
\text { Emission allowance } \\
\text { incentives }\end{array}$ & None. & $\begin{array}{l}\text { The } 1992 \text { National Energy Policy } \\
\text { Act provides a } 1.5 \text { cents/kWh tax } \\
\text { credit for renewable energy } \\
\text { producers. The } 1990 \text { Clean Air } \\
\text { Act Amendments provide bonus } \\
\text { emission credits for renewable } \\
\text { energy production. }\end{array}$ & $\begin{array}{l}\text { Some jurisdictions have } \\
\text { established shareholder } \\
\text { incentives for utility DSM } \\
\text { accomplishments. }\end{array}$ \\
\hline $\begin{array}{l}\text { RISK } \\
\text { Start-up delay } \\
\text { Construction cost overrun } \\
\text { Fuel costs } \\
\text { O\&M costs } \\
\text { Reliability problems } \\
\text { Premature retirement }\end{array}$ & $\begin{array}{l}\text { Fossil fuel costs have been } \\
\text { volatile over the past two } \\
\text { decades. } \\
\text { Environmental requirements may } \\
\text { become more stringent and } \\
\text { thereby increase operating costs. }\end{array}$ & $\begin{array}{l}\text { Less mature technologies may } \\
\text { have greater construction and } \\
\text { operating risks than conventional } \\
\text { technologies. }\end{array}$ & $\begin{array}{l}\text { Persistence of DSM impacts is } \\
\text { an open issue. }\end{array}$ \\
\hline
\end{tabular}




\begin{tabular}{|c|c|c|c|}
\hline Attribute & $\begin{array}{l}\text { Conventional Supply-Side } \\
\text { and Storage Options }\end{array}$ & $\begin{array}{l}\text { Renewable Energy } \\
\text { Technologies }\end{array}$ & $\begin{array}{l}\text { Demand-Side Management } \\
\text { Options }\end{array}$ \\
\hline $\begin{array}{l}\text { RISK (cont.) } \\
\text { Diversity }\end{array}$ & $\begin{array}{l}\text { Contribution to diversity depends } \\
\text { on fuel and technology mix of } \\
\text { entire system. } \\
\text { Correlation of fossil fuel prices is } \\
\text { major issue. }\end{array}$ & $\begin{array}{l}\text { Renewable resources generally } \\
\text { enhance diversity, except for } \\
\text { hydro additions to a } \\
\text { predominantly hydro system. }\end{array}$ & $\begin{array}{l}\text { DSM options add diversity, } \\
\text { because they are generally } \\
\text { independent of generation } \\
\text { options. }\end{array}$ \\
\hline $\begin{array}{l}\text { EXTERNAL COSTS } \\
\text { Air/water emissions } \\
\text { Land use } \\
\text { Waste disposal } \\
\text { Public safety }\end{array}$ & $\begin{array}{l}\text { Air emissions are a significant } \\
\text { issue for fossil-fired generation. } \\
\text { Waste disposal is a significant } \\
\text { issue for coal and nuclear } \\
\text { generation. } \\
\text { Public safety is an issue for } \\
\text { nuclear generation. }\end{array}$ & $\begin{array}{l}\text { Land use and fish habitats are } \\
\text { significant issues for hydro } \\
\text { generation. Noise and visual } \\
\text { impacts are issues for wind } \\
\text { energy resources. }\end{array}$ & $\begin{array}{l}\text { Air emissions are created in } \\
\text { manufacturing insulation. } \\
\text { Chlorinated fluorocarbons may } \\
\text { be released by disposal of old } \\
\text { refrigerators and air conditioners }\end{array}$ \\
\hline \multicolumn{4}{|c|}{$\begin{array}{l}\text { Notes: } \\
\text { 1. There is no current experience to validate the lead times for nuclear units. } \\
\text { 2. } \\
\text { 3. } \\
\text { 4. Explernale only to investor-owned utilities. } \\
\text { Cost-benefit framework must account for avoided externalities from existing generation. }\end{array}$} \\
\hline
\end{tabular}


Availability is defined as the opposite of unavailability, which is any reduction in the capability of a resource to generate electric power from what it is under normal conditions. This heading includes any reductions resulting from maintenance requirements or random outages.

Generation from some renewable options, primarily wind and solar, is intermittent. The definition of "intermittence" has not been standardized in the industry, and the variation in hourly output from these options creates some ambiguity between capability and availability. We use intermittence in this report to refer to random fluctuations in the energy source, distinct from whatever predictable patterns characterize the energy source. We account for intermittence under the heading of availability, and we account for predictability under capability, although capability and availability are discussed together in Section 4. Consider, for example, the hourly profile of photovoltaic generation at a specific location. There is a predictable hourly profile of generation on a typical day since the sun shines during the day but not at night. On any given day, insolation may follow the predictable profile of what we are loosely calling a typical day, or it may be reduced by clouds. This cloud effect is what we are calling intermittence. The predictable profile is an important characteristic of the capability of the photovoltaic plant. Its intermittence is a key component of its availability.

Intermittence is sometimes defined to encompass every aspect of variability in output from a renewable resource, including the predictable profile as well as random departures from the predictable profile. Our definition includes only the random departures. Yet another definition of intermittence applies the term to variations of output within an hour resulting, for example, from clouds scudding across the sky over a photovoltaic plant. We discuss this in Section 4 under the heading of short-term fluctuation.

Efficiency. The heat rate, a standard measure of efficiency, is an important parameter in the economics of most resources because the cost of fuel is a major component of the total cost of power for these options.

Dispatchability refers to the degree of control that the utility has over the hour-by-hour and minute-byminute output of a resource. A fully dispatchable resource is one over which the utility has complete control throughout the range from zero to maximum capacity. Full dispatchability is preferable because it provides the utility the greatest operating flexibility. A nondispatchable resource is one over which the utility has no control. The utility must take the output from such a resource whenever it is generated. A schedulable resource is one for which the utility can specify the hourly output in advance. Depending on contractual terms and physical limitations, the utility may specify the scheduled output 1,8 , or 24 hours in advance, for example. A curtailable resource is one over which the utility has no control except under specified minimum load conditions, when the utility has the right to curtail output from the resource or receive the output at zero energy cost.

Dispatchable resources can be used to respond to fluctuations in load in real time. A resource under direct digital control can be operated with a portion of its capacity held as spinning reserve to cover sudden outages of other resources. However, full dispatchability is less important for a resource with low or zero incremental cost, as long as this resource can be curtailed under minimum load conditions. Also, dispatchability is less important for resources with an hourly capability profile that is significantly correlated with system loads, such as photovoltaics, whose generation is strongly correlated with air conditioning loads in the summer. The value of a resource to the system is greater if its hourly output is sufficiently predictable to allow the utility to reduce the total amount of load-following capacity committed and on line in any given hour.

Location determines the effect of an option on the total cost of future transmission and distribution reinforcements, on costs associated with losses, and on the overall reliability of service to a local area. In general, integrating a large central station into the system, particularly at a new site, requires significant 
transmission additions. Smaller options that can be installed at a substation can reduce transmission costs by deferring transmission reinforcements. Generating options that can be installed at customers' premises and DSM options can defer distribution as well as transmission reinforcements. Options installed at a substation or at customers' premises can improve local reliability even if they do not defer reinforcements.

Modularity is the opposite of "lumpiness," or the large unit sizes of some technologies. Modular options come in relatively small blocks of incremental capacity with short lead times. This provides advantages to utilities by avoiding the temporary overcapacity that results when a large unit is commissioned and by minimizing both the risks of individual projects and the systemwide risks resulting from demand uncertainty.

Costs. Various resources have unique cost elements. It is important to account fully for all costs in order to make a fair comparison between the options. Whether or not the costs of one resource are correlated with those of other resources determines the cost diversification the resource provides to the total portfolio of resources.

Incentives to promote particular options have been established by legislation and regulation to tip the balance of resource decision making toward these options. It is important to understand who benefits from these incentives-ratepayers, shareholders, or someone else-and to account properly for the allocation of the benefits in ranking the options.

Risk. There is some degree of risk involved in all the attributes. There is also substantial uncertainty in various planning assumptions such as demand growth and the prices of fuel burned in existing units that determine the benefits of resource options. Obviously, these risks must be accounted for in ranking the options.

A subattribute of risk is the diversification that an option may provide to the utility's resource portfolio. This subattribute is different from others in that it is not entirely inherent in the candidate option itself, but depends on the mix of technologies and fuels in the rest of the utility's system. Risks involving a single option that are independent of the risks affecting other options are diversified away when combined in a portfolio with other resources. An option can provide diversity benefits if it is independent of the risks affecting other options that make up a significant share of the utility's resource mix. But risks that are positively correlated with other options will increase the risk of the total portfolio.

External costs refer to costs (or benefits) borne by others as a consequence of decisions made by the utility for which the others receive no compensation (or make no payment). These "externalities" include environmental impacts (as a cost) and may include regional economic impacts (as a benefit). A proper evaluation of resource options from a societal perspective must include consideration of external costs. But care must be taken to avoid double-counting externalities that may actually already be accounted for in the utility's cost structure, such as sulfur dioxide emissions.

\subsection{Key Attributes of Renewable Resources}

The following five attributes are particularly important for renewable resources:

$\begin{array}{ll}- & \text { Capability } \\ - & \text { Availability } \\ \text { - } & \text { Modularity } \\ \text { - } & \text { Location } \\ & \text { Risk diversity. }\end{array}$


Capability-which refers to the typical or normal pattern of generation from a resource-and availability-which refers to departures from normal-are both important because some renewable resources such as solar and wind are markedly different from conventional generation resources in these categories. These differences pose special challenges in system operation and in modeling these resources in the planning process. For conventional resources and some renewable resources, capability is the rated output of a unit. There may be a slight adjustment for seasonal weather effects. But the output of some renewable resources is determined primarily by weather conditions. Although listed separately above, capability and availability are combined in Section 4 because of their close relationship in the context of renewable resources.

Modularity is potentially a key advantage for some renewable resources because of their small incremental sizes and short lead times. However, the state of the art in modeling modularity for conventional as well as renewable resources is not well developed.

Location is a key attribute for renewable resources in considering both integration cost and system benefits. For some renewable resources, the energy source is remote from loads; therefore, additional costs must be incurred to integrate the resource into the system and deliver the output of these resources to the load center. Other renewable resources are suitable for dispersed deployment and can therefore be given credit for system benefits, which include both avoiding or deferring transmission and distribution reinforcements that would otherwise be required and improving local reliability. A key practical issue is the large number of locations for which benefits must be calculated for a complete evaluation of the location attribute.

Risk diversity is a potential benefit of renewable resources, particularly for systems that are predominately fossil fired. Diversity cuts across several attributes in Table 2-1, including availability and costs. Diversity includes both fuel diversity and technology diversity. It represents the mitigation of risks that can be realized by having a large number of types of resources, each having only a small share of the total resource mix.

The other attributes listed in Table 2-1 do not present particular challenges for evaluating renewable resources. Dispatchability of renewable resources can be evaluated within the degrees of dispatchability afforded by conventional generation options. A more critical issue is properly modeling the impact of the capability and availability of renewable resources on the dispatch of conventional resources. This will be addressed under capability and availability.

The costs of renewable resources are covered by the various cost components already recognized for conventional resources. The key issue for renewables is making sure that none of the relevant cost components for either renewable or conventional resources is overlooked and that cost estimates for both types of resources are developed on a consistent basis. Incentives also can be accommodated within conventional cost and financial analyses.

The risks inherent in renewable resources can be addressed similarly to conventional resource risks. Again, the key concern for renewable resources is that these risks are evaluated in a symmetrical fashion for renewable and conventional resources. The simplest decision analysis techniques are adequate for most of the risks involved in the analysis of individual resource options. ${ }^{2}$ Exceptions are risks having a broad impact on the entire system, such as demand growth and fuel prices. We address these risks under modularity and diversity.

2 Logan (1990); Temple, Barker \& Sloane, Inc. (1987). 
Although the evaluation of external costs is a topic of vigorous debate, analytical devices for incorporating these values into the planning process are well established. The issue for renewable resources is to assure that no relevant component is overlooked. 


\subsection{Utility Planning Processes and Models}

Utility planning is a multifaceted activity. In this review, planning is defined to include more than what has traditionally been regarded as generation planning, and even resource planning, because the potential for distributed applications of renewable generation and demand-side technologies requires incorporation of transmission and distribution planning into the IRP framework as well. This section provides an overview of utility planning processes and models. It also identifies the points at which the various attributes of renewable and other types of resources enter the planning process.

\subsection{The Logic of Utility Planning}

The IRP process consists of five kinds of activities:

1. Forecasting

2. Assessing options

3. Constructing a plan

4. Evaluating a plan

5. Reviewing the plan.

These activities are linked by a logic that is shown in Figure 3-1. The quality of IRP depends on how well these logical linkages are observed as well as on the quality of the data and analysis used within each activity. ${ }^{3}$

Forecasting includes forecasting the prices of fuels, labor, equipment, and capital, as well as demand, or the levels of energy services that the homes, businesses, institutions, and industries in the utility's service area will demand in the future. These forecasts affect the utility's resource commitments in several ways. First, demand forecasts determine the overall need for new resources. Second, price forecasts determine the relative competitiveness of the various resource options. Third, price forecasts also determine the competitiveness of the various resource options relative to the resources that make up the existing system.

Assessing options is a wide-ranging set of activities that includes identifying options, assessing their technical feasibility, estimating the costs and potential quantities of various options, screening the options, and developing the specific information for the options required in subsequent stages of the planning process, such as hourly generation or demand impact profiles and outage rates. For DSM options, these activities also include assessing technical, economic, and market potential. For conventional supply-side technologies, these activities may include identifying specific sites. For renewable resources, these activities will include reviewing available data on resource quality and timing.

These assessments rely heavily on price forecasts. For some options, the assessments may also be dependent on demand forecasts. Potential demand impacts from DSM options depend on the starting levels of demand. The feasibility of generation options located on customer premises-both renewable and conventional-depends on levels of demand in specific customer sectors. Transmission and distribution options depend on area-specific levels of demand. The screening of options and the economic potential assessment of DSM options depend on forecasts of system marginal costs.

\footnotetext{
3 Other procedural and technical requirements are described by Hirst (1992).
} 


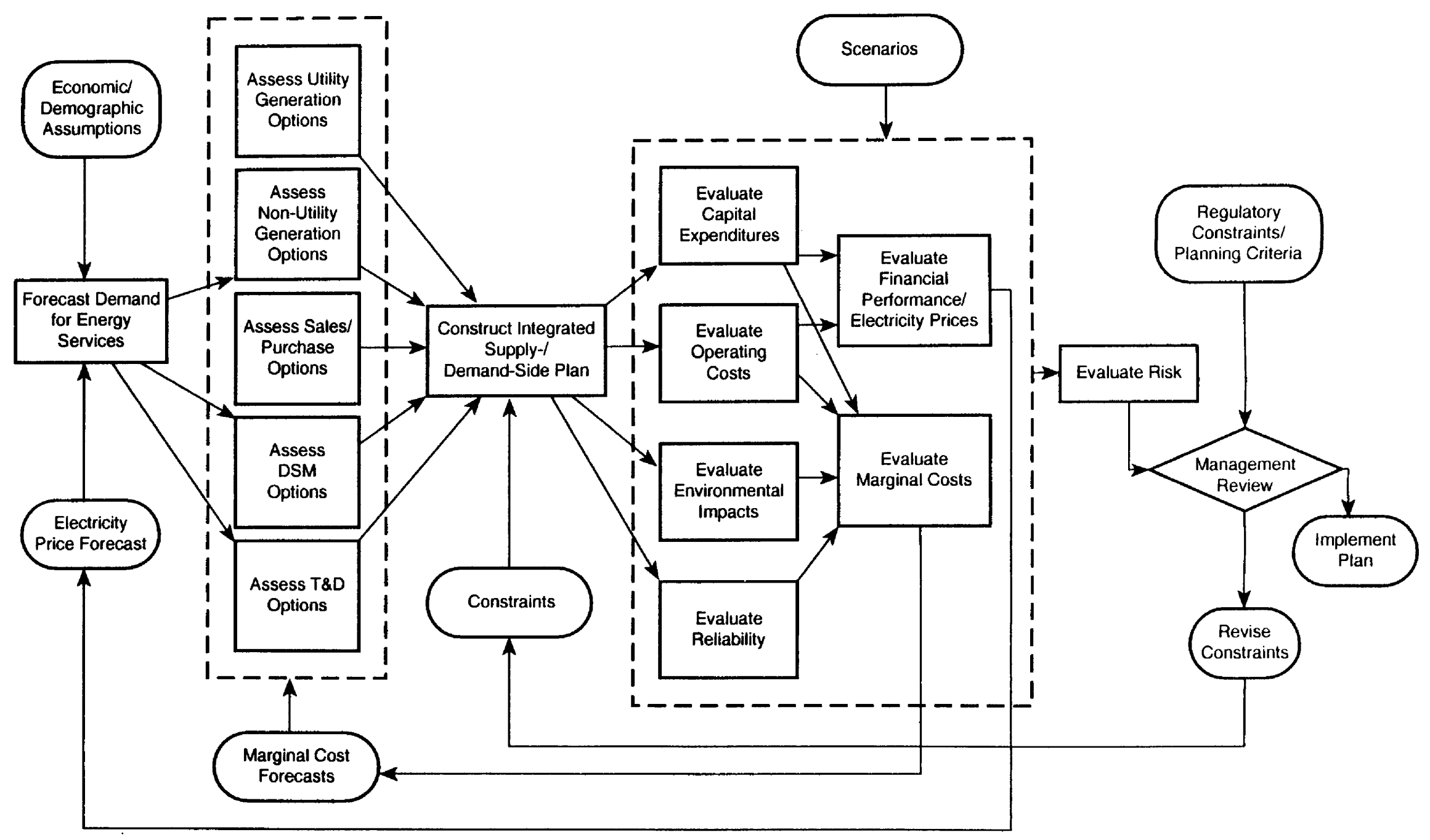


Constructing a plan entails selecting options and setting their implementation dates to balance supply and demand and to minimize costs, while satisfying various technical, environmental, financial, and regulatory constraints. There is a wide range of variation between utilities in their technical approaches to this activity and the types of resource planning or expansion planning models used.

Some utilities use a model that explicitly optimizes the demand- and supply-side resources in the plan to minimize some measure of total cost. Many other utilities construct their demand- and supply-side plans separately and call the combination of the two plans their "integrated" plan. The validity of this approach depends on whether there is any coordination, in a mathematical sense, between the demand- and supplyside processes. A one-pass sequential approach is commonly used. This approach consists of the following steps:

1. Construct the DSM plan by taking all DSM options that are cost effective for a given set of marginal costs.

2. Calculate the net demand after deducting DSM impacts.

3. Optimize the generation plan to minimize the cost of meeting the net demand.

This one-pass approach can, in many cases, yield a combined plan that is suboptimal relative to the plan that would have been constructed by a simultaneous optimization process. The same is true for a one-pass sequential process in which the generation plan is optimized first. However, an iterative process, in which the marginal costs resulting from the supply-side plan are fed back to the demand-side planning process and the sequential process is repeated until the marginal costs converge, is equivalent to a simultaneous optimization process. The marginal costs "coordinate" the separate supply-side and demand-side optimization processes.

An intermediate approach is one that evaluates demand- and supply-side options simultaneously and builds up an integrated plan iteratively according to prescribed cost-effectiveness tests. Two examples of this approach are the iterative cost-effectiveness methodology (ICEM) and the iterative test for resource evaluation (ITRE). The framework described in Section 5 follows this general approach. If the costeffectiveness tests are derived from optimal conditions, as in the case of ITRE and the framework in Section 5, and if the iterative process has been implemented to eliminate manual intervention, this approach can be regarded as optimization.

The staff of the California Energy Commission (CEC) reviewed alternative generation expansion planning methods and concluded that the ICEM approach tends to be biased against high-capital-cost, low-fuel-cost resources such as wind and geothermal. The CEC ran Elfin for each of the three investor-owned utilities in California and concluded that using ICEM with the standard criteria ranking by benefit cost ratio, and requiring a first-year test result of 1.0 , can bias the results against high-capital-cost, low-fuel-cost resources. It examined other decision criteria for use with ICEM. In the example of modeling the Southern California Edison system, the standard ICEM decision criteria resulted in selecting $200 \mathrm{MW}$ of renewable resources, while alternative decision criteria selected $2300 \mathrm{MW}$ of renewables and decreased the total cost by $\$ 212$ million.

The CEC did not find a simple fix to the problem, however. No set of alternative decision criteria has consistently yielded the least-cost expansion plan. The study concluded that the ICEM approach did not 
tend to identify the least-cost resource plan. The preferred solution was to use a different capacity expansion methodology, such as the ITRE approach being introduced by Elfin in early $1994 .^{4}$

Methods for integrating transmission and distribution (T\&D) planning with supply- and demand-side planning are not well established. There is no model that simultanecusly optimizes generation and transmission investments, much less DSM and distribution as well, with sufficient detail to be useful in a realistic utility setting. There have been only isolated instances of coordination of separate system planning and resource planning functions using marginal costs.

Utilities typically perform T\&D planning in sequence after supply- and demand-side planning are completed. Marginal T\&D capacity costs, on a service area average basis, are included in evaluating the cost-effectiveness of DSM options. This approach has been adequate when the DSM options were to be offered uniformly over the service area rather than targeted to specific local areas. But with greater interest in targeting DSM programs and using distributed generation options to defer transmission or distribution reinforcements, closer coordination between resource planning and system planning is necessary. A few utilities have recently attempted to integrate DSM or renewable resources and T\&D planning, as discussed in Section 4.

Evaluating a plan involves confirming the feasibility of the plan that has been constructed and deriving information that can help improve the plan further. Several different kinds of analysis are required here. These include:

- Reliability analysis. Reliability at three levels-generation, transmission, and distribution-must be confirmed. Although some utilities rely on deterministic reserve margin criteria specified by the pool or the North American Electric Reliability Council (NERC) region to which they belong, generation reliability is most commonly tested using a probabilistic generation reliability model to calculate indices such as loss-of-load probability, expected unserved energy, or marginal outage cost.

Transmission reliability is generally determined on a one- or two-contingency basis, that is, whether the system can operate within the emergency ratings of the elements (transmission lines or transformers), with one or two elements out of service. Probabilistic methods for transmission reliability are under development but are not yet widely used.

Distribution reliability is generally evaluated on the basis of deterministic planning criteria similar to that for transmission. When forecast demand exceeds the ratings of specific transformers or circuits, reliability is inadequate and reinforcements are required.

- Operating costs. Operating costs are evaluated using a production simulation model, which also estimates generation and emissions from each unit or plant.

- Environmental impacts. Environmental impacts include air emissions, thermal discharges, wastes, land use, and wildlife impacts. Thermal discharges and wastes are estimated on the basis of generation levels calculated by a production simulation model. Air emissions are frequently calculated directly by a production simulation model. The emission estimates must be checked

4 Belostotsky, Albert, Joel Klein, Pat McAuliffe, Angela Tanghetti, Evaluation of Alternative Capacity Expansion Planning Methodologies, Phase III-Final Report, California Energy Commission, June 29, 1993, pp. 6-10. 
against systemwide or unit-specific emissions limits or allowances. Land use and wildlife impacts must be evaluated on a site-specific basis, outside of a production simulation model.

- Capital expenditures. The capital requirements of the plan must be evaluated and compared to the capital available to the utility as part of evaluating the financial feasibility of the plan.

- Financial performance and electricity prices. Operating costs and capital expenditures are combined to estimate future revenue requirements, cash flows, financial statements, and electricity prices. The financial statements include income statements, balance sheets, and financial ratios. The relative financial health of the utility indicated by this information is the other part of evaluating the financial feasibility of the plan.

The electricity prices calculated at this point must be checked against the electricity prices assumed in forecasting demand to confirm their consistency.

- Marginal costs. Marginal costs include marginal energy costs and marginal capacity costs. Marginal energy costs are estimated using a production simulation model. Marginal capacity costs include generation, transmission, and distribution components. All three components can be calculated on the basis of deferred capital expenditures, although marginal generation capacity costs can alternatively be calculated on the basis of marginal customer outage costs using a generation reliability model. Marginal environmental costs may or may not be included.

To identify whether there are any significant problems in the assessments resulting from inconsistencies, the marginal costs calculated at this point should be checked against the marginal costs assumed in assessing the options.

Because assumptions underlying the analysis are uncertain, it is necessary to conduct scenario or sensitivity analyses with some, if not all, of the models used. The key issue is whether different plans or resources are preferable under different scenarios. As is often the case, the planner must weigh the advantages and disadvantages of resources in different scenarios against one another. Trade-off evaluation and decision analysis are two formal methodologies applicable here.

Reviewing the plan at various levels of management is an essential part of the planning process. Planning results must be understood and believed to be acted on. Management review considers the results of the analyses performed in evaluating the plan in light of regulatory constraints, corporate goals, and planning criteria. The review either establishes management's acceptance of the feasibility and performance of the plan or identifies directions for its modification. If the plan is accepted, implementation begins. If not, management's directives for changing the plan may be expressed as changes to the objectives or constraints that define the optimization problem to be solved.

Utility planning is necessarily an iterative process. Figure 3-1 has three iterative loops. Two of the loops involve checking for consistency between assumptions made early in the process and results obtained later in the process. Planners always face a chicken-and-egg problem: the first step requires the answer from the last step. The practical solution is to make an assumption that is close to the answer expected from the last step to get the first step started, then allow time to revise the analysis if inconsistencies are found later. The third loop follows management review.

There are two additional types of iteration: the revisions made necessary by (1) the receipt of new information into the planning process and by (2) a new understanding of the problem on the part of the people doing the analysis. The mechanical iteration that goes on within the process of solving for the integrated plan, such as within an automatic optimization model or within ICEM, is yet another type of 
iteration, but it is at a lower level of detail within the activity labeled "Construct Integrated SupplyDemand-Side Plan" in Figure 3-1.

The important point is that, although a clear logic must always link assumptions and conclusions, there may not necessarily be a straight path through the planning process from the first step to the last step. The formal planning cycle within a utility and the periodic filing requirements of the regulatory process merely provide snapshots of a constantly changing situation.

\subsection{Utility Planning Models}

Many different types of models are used in the IRP process shown in Figure 3-1. Table 3-1 lists the types of models and their functions. The functions in the right-hand column relate to the activities in Figure 3-1. Some types of models serve more than one function. Some functions require more than one type of model.

The introduction of a new model or modeling practice must take into account the market for utility planning models. Utility planning models come from a number of sources, including:

- Utility internal model development activity

- Model development sponsored by the Electric Power Research Institute (EPRI)

- Vendors

- Custom model development or model customization by a model vendor or consultant

- $\quad$ Public domain.

Utilities that are on the forefront of a new area in utility planning frequently develop their own models internally. Examples include early models to perform probabilistic generation reliability analysis and, more recently, the Delta model developed by Pacific Gas \& Electric for integrated DSM and T\&D planning. Many utilities develop their own models to correspond to their own planning or accounting conventions when the technical requirements are modest. This is frequently the case for project economic analysis or financial/rates models.

In the past, utilities often developed their own models even when the technical requirements were challenging, such as when developing production simulation models. Such efforts were justified by the argument that a utility's system is unique and could not be adequately modeled by any commercially available model. However, utilities have more recently been driven to seek lower cost sources of models as a result of competition in electricity markets and the need to reduce costs.

EPRI is an important source of models, particularly in new or developing areas. Even utilities that are not EPRI members use EPRI models through special licensing arrangements.

Vendors are the dominant source of some types of models, such as production simulation models.

Where the available models are inadequate from the utility's perspective, but internal resources are not sufficient to undertake model development, the utility may hire an outside consultant to develop a new model or customize an existing model. 


\begin{tabular}{|c|c|}
\hline Model Type & Functions \\
\hline Bulk power market & $\begin{array}{l}\text { Forecasts quantities and prices of firm and nonfirm energy available } \\
\text { within a region }\end{array}$ \\
\hline Capital expenditures & Forecasts capital requirements \\
\hline Composite reliability & $\begin{array}{l}\text { Calculates bulk power system reliability indices given a load forecast } \\
\text { and generation and transmission capability and availability parameters }\end{array}$ \\
\hline $\begin{array}{l}\text { DSM cost-effectiveness } \\
\text { analysis }\end{array}$ & Assesses the cost-effectiveness of individual DSM options or programs \\
\hline $\begin{array}{l}\text { DSM potential } \\
\text { assessment }\end{array}$ & $\begin{array}{l}\text { Assesses the technical, economic, and market potential of DSM options } \\
\text { in an area }\end{array}$ \\
\hline $\begin{array}{l}\text { Econometric demand } \\
\text { forecasting }\end{array}$ & $\begin{array}{l}\text { Forecasts demand on a yearly or seasonal basis given assumptions } \\
\text { about economic and demographic trends }\end{array}$ \\
\hline $\begin{array}{l}\text { End-use demand } \\
\text { forecasting }\end{array}$ & $\begin{array}{l}\text { Forecasts demand on a yearly, seasonal, or hourly basis given } \\
\text { assumptions about end-use profiles, appliance holdings, and economic } \\
\text { trends }\end{array}$ \\
\hline Energy sector model & $\begin{array}{l}\text { Forecasts supply and demand interactions between different energy } \\
\text { sectors of the economy }\end{array}$ \\
\hline Financial/rates & Forecasts revenue requirements, rates, and financial indices \\
\hline Generation reliability & $\begin{array}{l}\text { Calculates generation reliability indices given a load forecast and } \\
\text { generation capability and availability parameters }\end{array}$ \\
\hline Load flow & Evaluates the loading of transmission lines \\
\hline Location benefits & $\begin{array}{l}\text { Evaluates the avoided transmission and distribution costs attributable to } \\
\text { a resource at a specific location }\end{array}$ \\
\hline NUG forecasting & $\begin{array}{l}\text { Forecasts generation from and payments to the nonutility generation } \\
\text { (NUG) sector }\end{array}$ \\
\hline Production simulation & $\begin{array}{l}\text { Calculates generation, fuel use, production costs, and emissions given } \\
\text { load and fuel price forecasts and resource capability, availability, and } \\
\text { efficiency parameters }\end{array}$ \\
\hline $\begin{array}{l}\text { Project economic } \\
\text { analysis }\end{array}$ & Evaluates the costs and net benefits of individual generation projects \\
\hline Resource model & $\begin{array}{l}\text { Evaluates potential for generation from a specific technology or } \\
\text { category of technologies at a specific site or in a geographical area }\end{array}$ \\
\hline Resource planning & Optimizes the selection and timing of resource options \\
\hline Uncertainty analysis & Performs scenario, trade-off, and/or probabilistic analysis \\
\hline
\end{tabular}


The public domain is not a major source of utility planning models and is included here only for the sake of completeness. There are only a few public domain utility planning models available. In many cases, vendors are offering proprietary versions of the same model with additional features and software support.

A new model must compete against other models available from these various sources. Further, the model must offer benefits that outweigh the full costs to a utility of adopting a new model. The costs of adopting a new model are much more than the model license and support fees. Substantial effort may be required to obtain and format the data required by the model. Substantial staff and supervisory time may be required to perform, review, debug, and interpret the first runs of a new model. Additional effort may be required to integrate the model and its results into the utility's established planning practices.

In view of all this, our recommendations in the following sections focus on enhancing established models and practices rather than creating entire new modeling systems.

\subsection{Resource Attributes in the Planning Process}

Table 3-2 shows the types of models in which each of the attributes is modeled. These are the points at which the attributes enter the planning process. Each of the models listed for an attribute deals with one or more of the subattributes. But Table 3-2 does not necessarily imply any correspondence between models and subattributes. The types of models to focus on in this review were determined by identifying those in the table associated with the key attributes in Section 2.2. 
Table 3-2. Representation of Resource Attributes within Utility Planning Models

\begin{tabular}{|c|c|}
\hline Attribute & Model Type \\
\hline $\begin{array}{l}\text { CAPABILITY } \\
\text { Peak capability } \\
\text { Energy capability } \\
\text { Seasonal profile } \\
\text { Hourly profile }\end{array}$ & $\begin{array}{l}\text { Bulk power market } \\
\text { Composite reliability } \\
\text { Generation reliability } \\
\text { Load flow } \\
\text { Production simulation } \\
\text { Project economic analysis } \\
\text { Resource planning }\end{array}$ \\
\hline $\begin{array}{l}\text { AVAILABILITY } \\
\text { Intermittence } \\
\text { Forced outages } \\
\text { Maintenance requirements } \\
\text { Correlation with: } \\
\text { - Weather } \\
\text { - Hydrological conditions } \\
\text {. System demand }\end{array}$ & $\begin{array}{l}\text { Bulk power market } \\
\text { Composite reliability } \\
\text { Generation reliability } \\
\text { Production simulation } \\
\text { Project economic analysis } \\
\text { Resource planning }\end{array}$ \\
\hline $\begin{array}{l}\text { EFFICIENCY } \\
\text { Heat rate }\end{array}$ & $\begin{array}{l}\text { Bulk power market } \\
\text { Production simulation } \\
\text { Project economic analysis } \\
\text { Resource planning }\end{array}$ \\
\hline $\begin{array}{l}\text { DISPATCHABILITY } \\
\text { - Fully dispatchable } \\
\text { - Curtailable } \\
\text { - Base loaded } \\
\text { Constraints: } \\
\text { - Ramp rate } \\
\text { - Minimum output } \\
\text { - Minimum up time } \\
\text { - Minimum downtime }\end{array}$ & $\begin{array}{l}\text { Production simulation } \\
\text { Project economic analysis }\end{array}$ \\
\hline $\begin{array}{l}\text { LOCATION } \\
\text { Delivery point: substation/feeder }\end{array}$ & $\begin{array}{l}\text { Bulk power market } \\
\text { Composite reliability } \\
\text { DSM cost-effectiveness analysis } \\
\text { Load flow } \\
\text { Production simulation }\end{array}$ \\
\hline $\begin{array}{l}\text { MODULARITY } \\
\text { Incremental size } \\
\text { Pre-construction lead time } \\
\text { Construction lead time }\end{array}$ & $\begin{array}{l}\text { Expansion planning } \\
\text { Uncertainty analysis }\end{array}$ \\
\hline
\end{tabular}




\begin{tabular}{|c|c|}
\hline Attribute & Model Type \\
\hline $\begin{array}{l}\text { COSTS } \\
\text { Construction } \\
\text { O\&M } \\
\text { Fuel } \\
\text { Decommissioning } \\
\text { Correlation with other system costs }\end{array}$ & $\begin{array}{l}\text { Bulk power market } \\
\text { Capital expenditures } \\
\text { DSM cost-effectiveness analysis } \\
\text { DSM potential assessment } \\
\text { FinanciaVrates } \\
\text { NUG forecasting } \\
\text { Production simulation } \\
\text { Project economic analysis } \\
\text { Resource planning }\end{array}$ \\
\hline $\begin{array}{l}\text { INCENTIVES } \\
\text { Tax credits } \\
\text { Shareholder incentives } \\
\text { Emission allowance incentives }\end{array}$ & $\begin{array}{l}\text { Capital expenditures } \\
\text { DSM cost-effectiveness analysis } \\
\text { Financialrates } \\
\text { Project economic analysis }\end{array}$ \\
\hline $\begin{array}{l}\text { RISK } \\
\text { Start-up delay/cost overrun } \\
\text { Construction cost overrun } \\
\text { Fuel costs } \\
\text { O\&M costs } \\
\text { Reliability problems } \\
\text { Premature retirement/diversity }\end{array}$ & $\begin{array}{l}\text { FinanciaVrates } \\
\text { Generation reliability } \\
\text { Project economic analysis } \\
\text { Uncertainty analysis }\end{array}$ \\
\hline $\begin{array}{l}\text { EXTERNAL COSTS } \\
\text { Air/water emissions } \\
\text { Land use } \\
\text { Waste disposal } \\
\text { Public safety }\end{array}$ & $\begin{array}{l}\text { DSM cost-effectiveness analysis } \\
\text { Project economic analysis } \\
\text { Production simulation }\end{array}$ \\
\hline
\end{tabular}




\subsection{Modeling of Resource Attributes}

Five attributes were identified in Section 2.2 as particularly important in evaluating renewable resources. These attributes are

$\begin{array}{ll}- & \text { Capability } \\ \text { - } & \text { Availability } \\ \text { - } & \text { Modularity } \\ \text { - } & \text { Docation } \\ & \text { Diversity. }\end{array}$

This section reviews the state of the art in modeling these five attributes. Capability and availability are discussed in the same section since many issues relate to both attributes. The five attributes need to be accounted for in two types of analyses: systemwide and incremental. We address the modeling of renewable resources in both types of analyses.

The aggregate effect of all of the renewable resources in the plan on the output and operating costs of other generation needs to be accounted for in systemwide analyses, whereas the incremental effect of a renewable resource project on system reliability and costs needs to be accounted for in incremental analyses of individual projects. Incremental analysis provides the basis for accepting or rejecting individual options in the resource plan; systemwide analysis is a key component of revenue requirements and financial forecasting and provides the baseline for incremental analysis.

Incremental analysis can sometimes be done with the same production simulation, reliability, and financial models that are used for systemwide analysis. The incremental effect of an individual resource is calculated as the difference between the results from detailed model runs with and without the candidate resource. However, some renewable options are so small relative to the rest of the system that these differences are discernable only in the least significant digits. Because of numerical approximations and the behavior of unit commitment algorithms in production simulation, there may be no significant differences at all.

Therefore, for small projects, a marginal approach may be preferable for incremental analysis. A marginal approach relies on system marginal costs calculated using detailed models at a level of temporal detail corresponding to the resource option data available. This approach will be described further in this section.

Whether a marginal approach or "with/without" runs of a detailed model are used for incremental analysis, the incremental analysis will depend on systemwide analysis. Therefore, it is important to model accurately the aggregate impact of renewables to the extent that the share of renewables in the resource mix is sufficient to affect system marginal costs.

The fundamental issue underlying the relevance and importance of each attribute in IRP is cost. The objective of IRP is to select a combination of resource options that minimizes total costs. Our discussion of each attribute considers the potential impact that the attribute may have on total costs and how the attribute should be modeled to capture this cost impact.

For each attribute, we discuss the concepts underlying the attribute, methods for quantifying, ways the attribute is handled in current models, and utility practices in using the capabilities of the models. In examining the ways attributes are handled in current models, we focused on the selected 11 models described in Section 1 and Appendix A. 


\subsection{Capability and Availability}

\subsubsection{Concept}

Two generating resource attributes—capability and availability—represent important characteristics that must be appropriately modeled to reasonably simulate both the operation of a candidate resource and its effect on the operation of other system resources. The capability of a generating resource in a given time period is its maximum capacity and energy output under normal conditions. The term availability refers to departures from normal conditions such as forced outages, maintenance, and unavailability of the underlying fuel or energy source.

Some renewable resources operate as conventional resources. For example, a MSW plant operates much like a fossil-fired plant. Its dispatchability is determined by fuel supply and contractual constraints. However, wind and solar resources without storage or backup generation are very different from conventional utility generating resources in several respects, particularly in regard to their

- Time dependence

- Short-term fluctuation of generation

- Multiplicity of generating units.

Time Dependence. A utility cannot call on some renewable resources such as wind and solar to generate electricity the way it can call on most of its conventional resources. Generally, a utility takes energy whenever it is available, given that the resources' variable operating costs are negligible. However, if the wind is not blowing or the sun is not shining, a wind or solar project without dedicated storage will not generate electricity, even though the generating equipment may be in perfect operating condition. Thus, the distinction between the resource's capability and its availability is somewhat blurred. Therefore, this discussion merges the two resource attributes in the context of renewables.

The hour-to-hour delivery of power from wind and solar resources is difficult to forecast, particularly on a long-term basis. Short-term (daily) forecasts may be somewhat predictable, but the precision of such forecasts will depend on the utility's degree of certainty about short-term weather conditions and the geographic concentration of a utility's renewable resources. The more geographically concentrated a utility's renewable resources are, the more dependent the utility's renewable generation will be on localized weather conditions, which are usually more difficult to predict than for larger regions.

Although the timing of power delivery from solar and wind resources may be difficult to predict, this timing may be correlated with the utility system's peak demand in some circumstances. In some parts of the country, wind speeds commonly pick up in the afternoon, the time of day when utilities often experience daily peak demands in the summer. Insolation also is likely to be near its high at the time of daily peak demand, at least in the summer. Careful identification of the sites within a utility's territory where peak wind speed or insolation coincide with peak demands is a critical first step for the appropriate evaluation of renewable resource potential. On the other hand, some utilities may find that their renewable generation opportunities are generally uncorrelated with their peak load periods. Therefore, careful consideration is required when modeling renewables in order to accurately reflect their contribution to the utility system.

Table 4-1 compares the time dependence of several categories of renewable resources. An " $\mathrm{X}$ " under a column indicates that the characteristic can be found in the resource in the corresponding row. The columns represent the time scale on which variations in output can occur outside of utility control, 


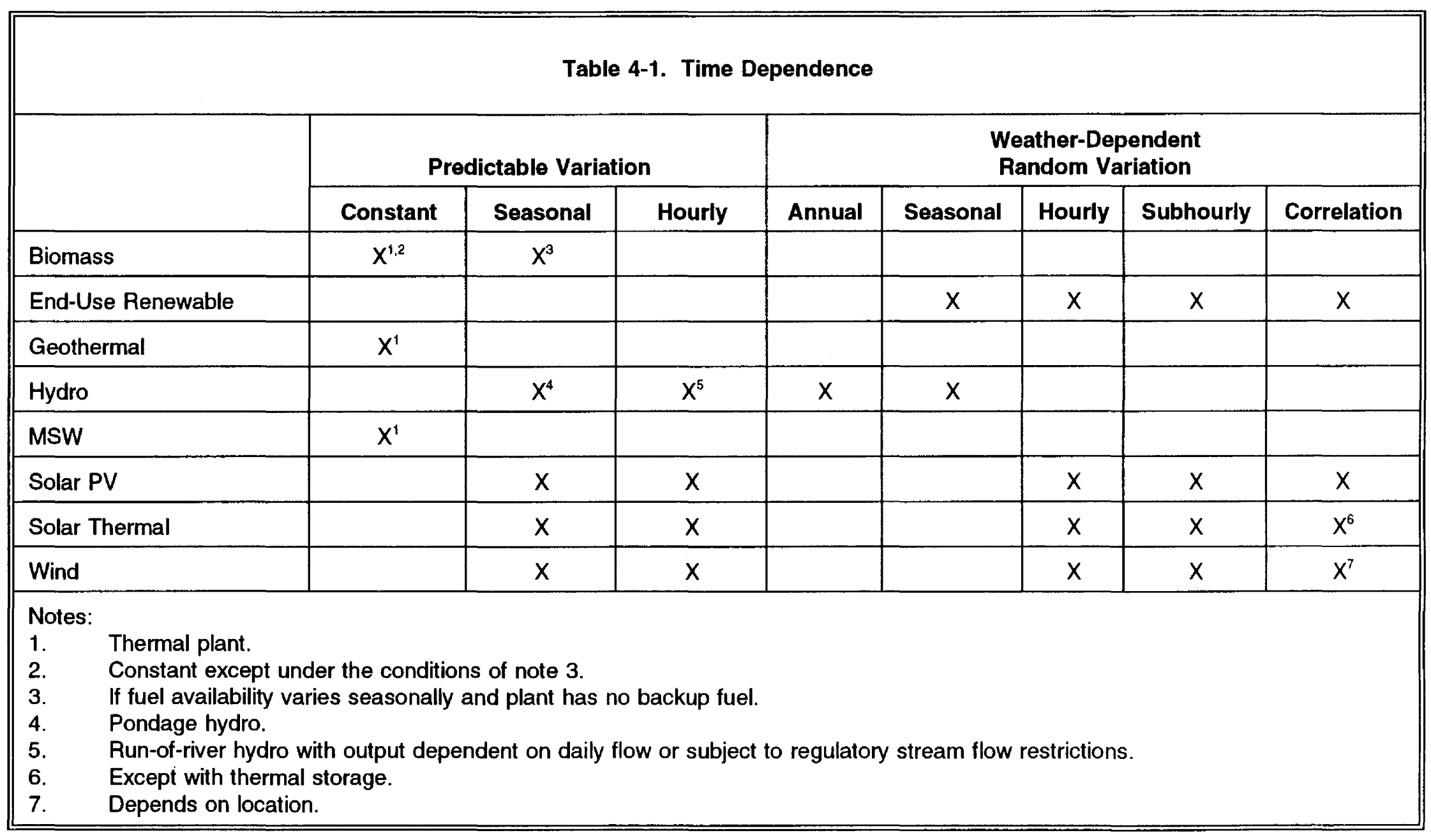


including both predictable and weather-related random variations. The column labeled "subhourly" relates to short-term fluctuations, described in the next subsection, whereas the column labeled "correlation" indicates whether random variations can potentially be correlated with variations in demand.

Short-Term Fluctuation. Renewable resources may exhibit considerable fluctuations in power delivery that must be balanced with the customer loads and accommodated through reliance on flexible, dispatchable, load-following generating units (such as intermediate-duty coal-fired facilities, combustion turbines, or diesel generators). ${ }^{5}$ These fluctuations can occur in very short time periods. If the wind velocity at a site is erratic or the sun keeps moving in and out of patchy clouds, the power delivery from renewables at the site will fluctuate from one minute to the next. Obviously, the weather conditions at a specific site and the degree of geographic concentration of the renewables at the site will be major factors in the intermittence of power delivery. Short-term fluctuations may have different impacts on the generation system than on the T\&D systems.

To the extent that utilities geographically diversify their renewable resources-that is, locate them far enough apart that erratic local weather conditions are averaged out-they may be able to reduce the fluctuations on the generation system. Otherwise, intermittent generation can complicate the operation of a utility system.

From a system dispatcher's perspective, there is a difference between a resource that will operate consistently at a certain capacity during an hour and one that may deliver the same average capacity over the hour but may fluctuate by $10 \%$ or $20 \%$ above or below that value minute by minute. The fluctuating resource will require the commitment of more capacity for load following and spinning reserve requirements. Spinning reserve refers to the amount of unloaded capacity available to a system dispatcher that is currently synchronized with the power system. Since it can take some time to bring certain units on line, units already on line but not operating at their full capacity represent a valuable resource that a dispatcher can draw on if additional power is needed quickly. "Ramping up" these units can be done much faster than starting up similar units that are off line. An operating unit's contribution to spinning reserve is merely the difference between its maximum capacity and the operating point at which it is currently dispatched. A utility's spinning reserve requirement is a targeted amount of capacity (or percent of system load) that must be met or exceeded by the sum of all of the operating units' spinning reserves. If the system's spinning reserve drops below this requirement, additional units must be brought on line to shore up the reserves.

However, the impact of an intermittent resource on system operations will depend on two issues: (1) the size of fluctuations in resource output relative to the customer load fluctuations that are already accommodated and (2) the degree of correlation between the resource's fluctuations and the load fluctuations. Regarding the first issue, the total amount of renewable resources subject to short-term fluctuation is likely to be small within the planning horizon of a utility. The renewable resource with the largest capacity and energy share is generally hydro, which is not subject to short-term fluctuations.

On the second issue, it is likely that these minute-to-minute fluctuations will be largely uncorrelated. Although renewable generation and system loads can be highly correlated in some systems on an hourly or daily basis, minute-to-minute fluctuations are different. Although loads certainly are broadly affected by hourly and daily weather conditions, minute-to-minute load fluctuations are driven more by random behavior patterns than by localized, temporary weather fluctuations. Overall, the impact of short-term fluctuation on the generation system is negligible if the range of fluctuations is small enough relative to

5 Bose and Anderson (1984). 
the rest of the system so that the rest of the system can absorb the fluctuations. In such cases, dedicated storage or backup generation offers little value.

However, short-term fluctuation may have a much bigger impact on the T\&D systems because the range of fluctuations is not so small relative to the loads on the transmission or distribution circuit. Storage capacity to accommodate short-term fluctuation or time-dependent generation that does not match load may be more beneficial on the scale of the T\&D systems.

Multiplicity of Units. Wind and solar resources tend to be built as aggregated projects of many small, independent generating sources. This has reliability ramifications. One large unit has a higher variance of available capacity than several smaller units of the same aggregated capacity, given the same forced outage rate and assuming that outages of individual units are independent of others. One might conclude that renewable units inherently provide reliability benefits because of their multiple-unit nature (notwithstanding the obvious drawback of being nondispatchable). However, the practical value of this benefit depends on the aggregate size of the renewable resources relative to the rest of the system. If the aggregate size of the renewable resources is much smaller than the rest of the system, then the difference in reliability impact between a single unit and several smaller units is negligible.

Further, the conclusion that several smaller units are more reliable is based on the assumption that each of the smaller units has independent availability. With renewables, this may not be the case. As far as physical availability (i.e., the equipment is in operating condition), it is likely that the routine equipment failure of individual units has little or no dependence on that of the other units. ${ }^{6}$ However, the energy availability of a collection of renewable units at the same site is likely to be dependent. The weather conditions at that site will be the driving factor in determining whether or not any units that are physically available will actually produce any power.

Given this interdependence, it is difficult to say whether the multiple-unit nature of a renewable project provides any additional reliability benefits. It is likely that renewable projects must be geographically diversified across a utility's territory to achieve any substantial availability independence. Even then, the distances between facilities, or more specifically the differences in the area weather patterns, must be great enough to allow for varying generating conditions. Thus, the fact that a renewable project usually involves many small units probably does not in and of itself provide reliability benefits. In the context of utility modeling practices, this means that it is probably appropriate to model a cluster of renewable units at one site as one resource.

\subsubsection{Modeling Techniques}

There are two general types of production simulation or dispatch models, chronological models and load duration curve (LDC) models. Chronological models simulate the operation of the generation system for a sequence of points in time, often hourly, but sometimes on 2-hour, 15-minute, or other intervals. Some hourly chronological models simulate 8760 hours per year, others only 168 hours per week for selected representative weeks or 24 hours per day for representative days.

LDC models start by converting an hourly load profile into a LDC, which represents a probability distribution of load within the simulation period. It then combines the LDC with probability distributions representing the availability of each of the generating units to create a sequence of equivalent load duration curves representing the probability distribution of the demand on each unit. This approach provides some

${ }^{6}$ Obviously, a widespread calamity such as a hurricane or flood could render an entire renewable facility inoperable, but a single conventional resource could be equally vulnerable to such circumstances. 
computational efficiencies but sacrifices the ability to deal with ramping rate constraints and other chronological issues because the chronological pattern of load levels is lost. However, some chronological issues can be addressed by dividing the simulation period into subperiods and performing LDC calculations separately for each subperiod.

The characteristics of renewable resources that are described above have presented utility planners with modeling challenges that may or may not be appropriately addressed in current modeling practices with either type of model. With these renewable resource characteristics in mind, we examined current modeling practices and formulated conclusions discussed in greater detail below.

Utilities usually model renewables either as generating units or as load modifiers. These representations are described in detail below. Either approach can be used to adequately assess the operational contribution of renewables to a utility system. However, biases can be introduced if the modeler is not careful.

Generating Unit Modeling. As a generating unit, a renewable resource may be specified as being either dispatchable or nondispatchable. Dispatchability may be appropriate for some renewables such as MSW or time-dependent resources with storage, but it is not an accurate characterization of a wind or solar resource. Modeling a nondispatchable resource as dispatchable would allow generation to be dispatched unrealistically into the hours of highest economic value and could understate any minimum load problems that might exist.

If time-of-day power delivery information is not available, modeling a time-dependent resource as a generating unit with constant capability and an appropriate forced outage rate may yield a reasonable approximation. The benefit of modeling the resource as a generating unit is that many utility planning models have probabilistic algorithms for addressing generating unit unavailability attributable to random equipment failures. This feature could be used to reflect the uncertainty associated with renewable power delivery. In some models, unit unavailability is specified by a forced outage rate - the percentage of time that a unit is expected to be unavailable. Other models (notably those of a chronological nature) allow a user to model a unit's availability by specifying probability distributions for the time between outages and the time it may take to restore the unit to service. In renewable resource modeling, any of these availability features could be used to represent the renewable generation that would be curtailed because of equipment failure (usually a minor factor) or lack of wind or sunshine (the major factor that limits wind and solar resource generation).

Some models allow the user to modify a generating unit's capability on an hourly basis, thereby capturing the hour-by-hour delivery characteristics that otherwise can only be captured by load modifier modeling.

Load Modifier Modeling. Utility planners often model time-dependent resources as load modifiers-hourly modifications to the system's loads. Most planning models provide a means of defining such hour-by-hour profiles that are subtracted from the loads in a manner similar to a system power purchase. However, most of the models that were reviewed do not seem to provide a convenient way of representing the uncertainty associated with renewable power delivery when modeling such resources as load modifiers. Nonetheless, such profiles allow planners to capture expected changes in resources on an hour-to-hour basis. Typically, utility planners develop an hourly profile that is representative of average conditions and use that profile in a single simulation. Such a profile may be based on average weather conditions at a site that is being contemplated for renewable resources. Figure 4-1 displays an example of a renewable resource power delivery profile and its impact on net system loads. 


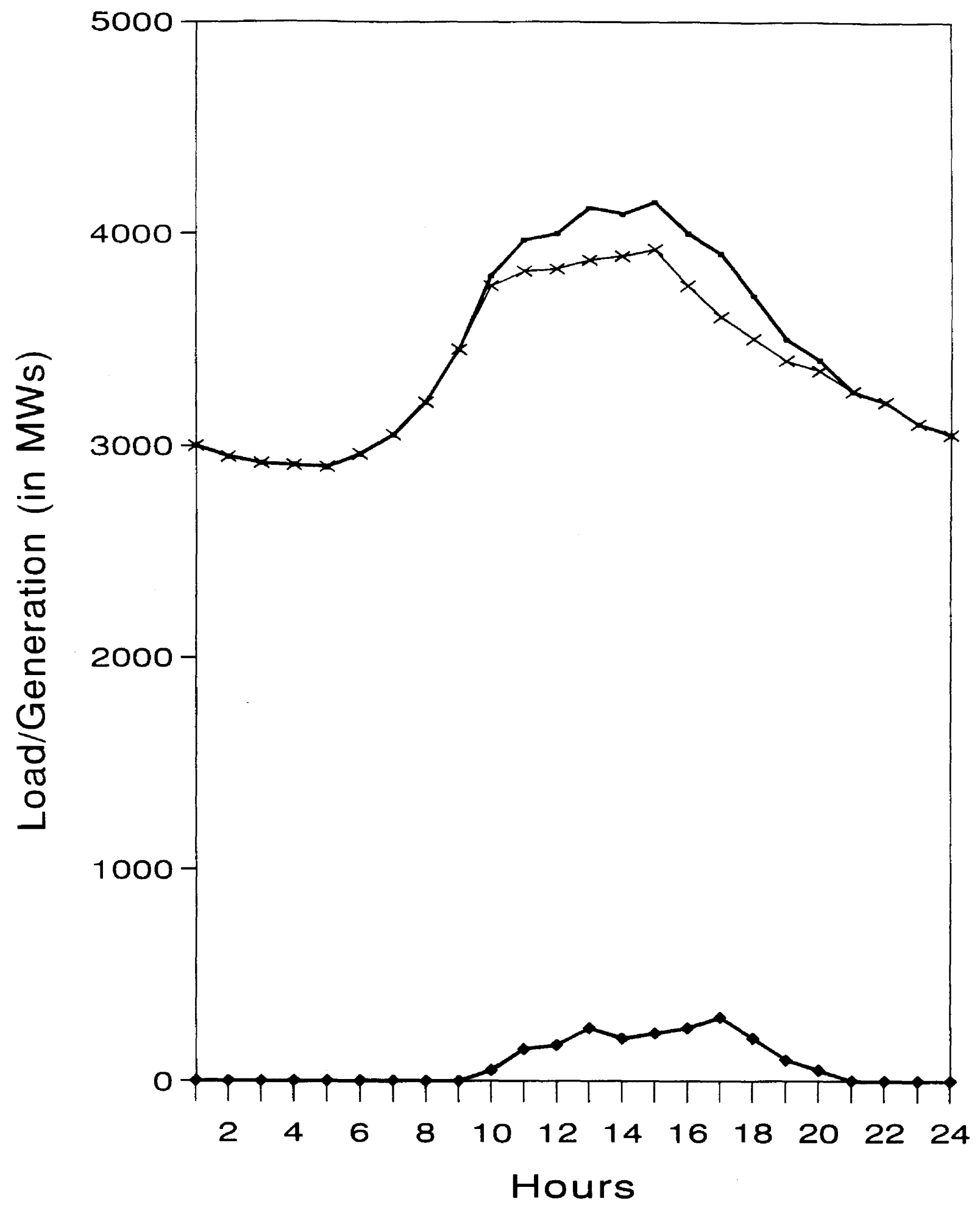

- Original Loads

- Renewable Resource Generation

* Modified Loads

Figure 4-1. Renewable resource power delivery profile 
At least one model, EGEAS, provides a means of modeling load modifiers with forced outage rates to reflect the uncertainty associated with availability. The procedure is known as orthogonalization. ${ }^{7}$ Unlike the standard process of first subtracting load modifiers from the load profile and then dispatching generating units, EGEAS sets these special load modifiers aside and dispatches them in a manner similar to generating units. EGEAS is a load duration curve model and uses a convolution technique for incorporating unit operational uncertainties into the dispatch process.

NREL has analyzed actual utility systems using Elfin. NREL found that different approaches for modeling renewable resources result in significantly different costs. Modeling renewable resources as load modifiers in Elfin gives maximum credit to renewable resources. If the renewable resources are modeled as generating units, there is the possibility that they will be curtailed and there tend to be more start-ups and shutdowns for renewable resources with moderate or low capacity factors. Also, forced outage rates and maintenance outage rates on generating units may reduce the capacity and energy credits of renewable resources. ${ }^{8}$

Another approach is modeling resources as energy-limited units. In this approach, the maximum and minimum capacities at which the resource can be operated and its maximum energy generation in the simulation period must be specified. The model then determines the optimal profile of generation from the resource within the specified constraints. However, this approach is not appropriate for resources whose dispatch profile is not subject to control of the utility.

\subsubsection{Issues}

Multiplicity of Units. Utilities usually do not try to model individual renewable power sources at a specific site as small, discrete units. Instead, they combine the separate sources combined into one single source. This greatly simplifies the task of modeling a complete renewable facility and probably does not introduce any significant modeling distortions.

Weather- versus Equipment-Related Unavailability. A large number of small units subject only to independent equipment-related outages can be modeled as a single unit having a capability equal to the expected total output of the units and an outage rate of zero. If these units are all subject to a common weather-related uncertainty, they can be represented as a single unit having a capability equal to the total output of the units under reasonable high-output conditions and a forced outage rate that yields the expected output. Then the weather-related unavailability of this project can be convolved with the outages of other units.

As an example of the case without weather-related uncertainty, consider a facility with $100 \mathrm{MW}$ of installed capacity and an expected capacity factor of 30\%. This plant could be modeled as a 30-MW facility. This will yield different results for both production simulation and generation reliability analysis than modeling the facility as a $100-\mathrm{MW}$ resource with a $70 \%$ forced outage rate.

Uncertainty in the Time-Dependent Profile. During execution, most models process load modifiers by first making the adjustments depicted in Figure 4-1, then dispatching the generating units to meet the remaining loads. In most probabilistic models, only the generating units have availability probabilities associated with them, such as forced outage rates or time-between-failure statistics. There is implicitly $100 \%$ certainty about the impact of resources modeled as load modifiers.

7 Caramanis et al. (1982); Caramanis (1983).

8 Milligan and Miller (1993). 
Given such modeling conventions, a user may want to capture the uncertainty of renewable power delivery by running multiple scenarios based on different assumptions about the hourly capability and availability of a resource. For example, a planner might develop profiles for low-energy, medium-energy, and highenergy scenarios for a renewable resource. As another example, partial correlation between renewable resource generation and peak loads could be modeled by developing more than one hourly profile of generation. In either case, each of the profiles will have a probability of occurrence associated with it. A utility planner could then make several runs to simulate the utility system under the various assumed profiles for the renewable resource. The results (e.g., total system costs or reliability indices) could be either examined as separate scenarios to identify the range of possible outcomes or combined into expected results by weighting them with their associated probabilities. Figure 4-2 presents a schematic display of this multiple-scenario process.

Another approach is Monte Carlo analysis, in which the output of one or more renewable resource installations is determined for a large number of conditions selected in a pseudo-random manner from underlying probability distributions. Whatever correlation exists between the installations can be accounted for by appropriate structuring of the underlying distributions. ${ }^{9}$

There are two approaches for representing weather uncertainty. One uses the forced outage rate. The other incorporates different weather conditions into the typical days included in a load modifier. An 8760-hour load modifier constructed of multiple typical days that represent a variety of weather conditions and also capture whatever correlation exists between output and system load can yield results equivalent to Monte Carlo analysis. The forced outage rate approach requires partial outage rates to model something other than all-or-nothing availability.

Short-Term Fluctuation. Because the smallest time increment considered in most utility planning models is a single hour, the complicating effects of short-term fluctuations may not be captured. However, as was noted in the previous discussion on intermittence, the extent to which fluctuations cause problems for the system dispatcher depends on the magnitude of the fluctuations relative to the short-term load fluctuations and their degree of correlation. Consequently, fluctuations on a subhourly time scale may not be very disruptive, and ignoring them may be justifiable in modeling the generation system for long-term resource planning. A means of assessing whether or not this is the case for any specific resource is discussed below.

Assume that the minute-to-minute customer load fluctuations that a utility might experience in a particular hour were normally distributed with a standard deviation of $10 \mathrm{MW}$. In other words, there would be a $68 \%$ probability that the load could fluctuate up or down from its current value by as much as $10 \mathrm{MW}$ within a 1-minute period. ${ }^{10}$ If the dispatcher used two standard deviations as a reference for committing load-following capacity, this would correspond to a targeted capacity of $20 \mathrm{MW}$, which would have a $95 \%$ probability of being sufficient (i.e., there would be less than a 5\% chance that the fluctuations would exceed $20 \mathrm{MW}$ ). Now assume that a renewable project was added to the system that had an intermittent generation characteristic in which generation might fluctuate in a normally distributed fashion with a standard deviation of $2 \mathrm{MW}$. Of critical concern is the extent to which the addition of this resource will require the commitment of more than $20 \mathrm{MW}$ of load-following capacity. Assuming that the dispatcher wanted to maintain the two-standard-deviation requirement, the new level of capacity would be determined

9

Yamayee (1984).

10 This is a property of a normal distribution - namely, that approximately $68 \%$ of the probability density function lies within one standard deviation of the mean and that more than $95 \%$ lies within two standard deviations of the mean. 


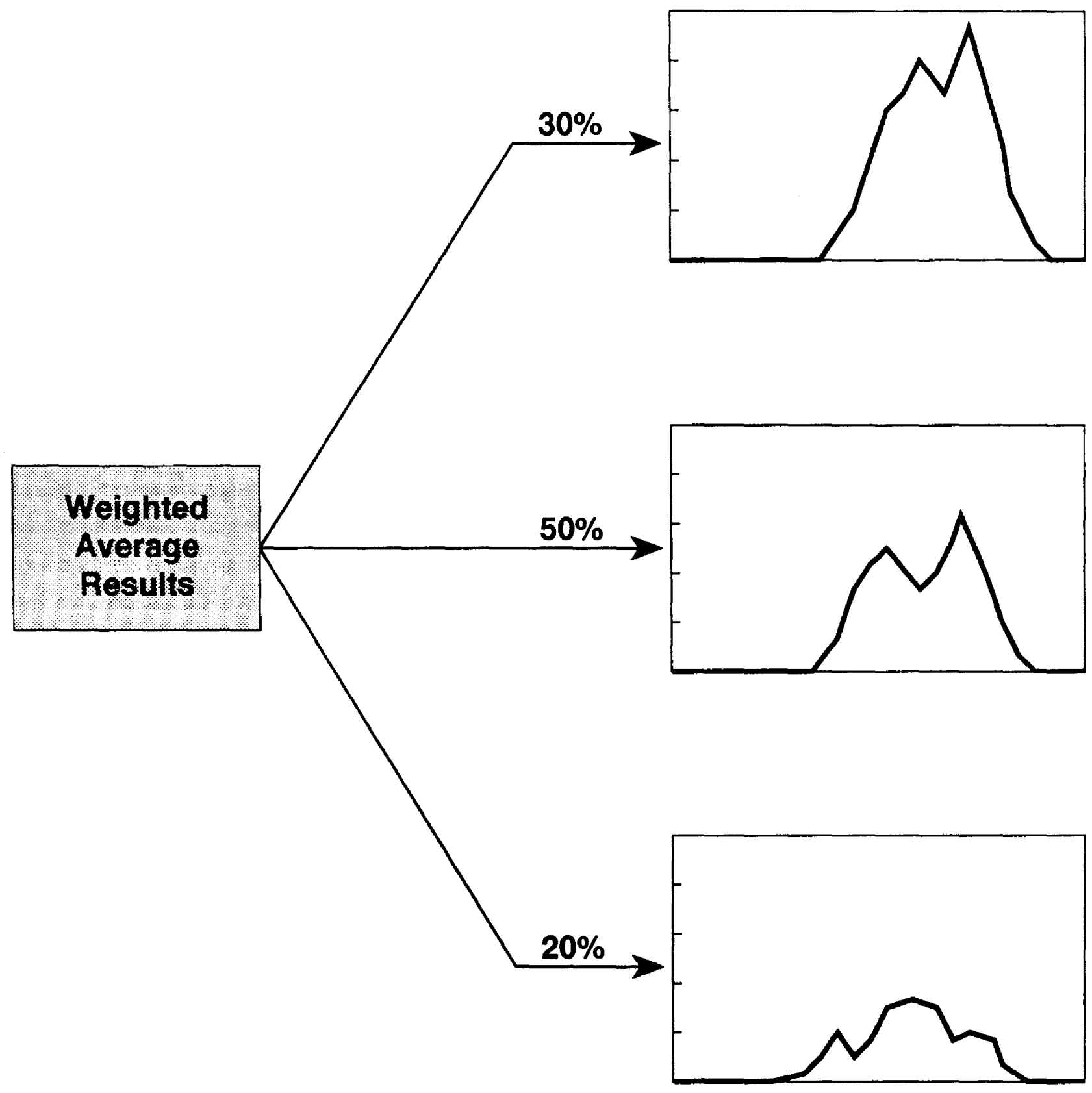

Figure 4-2. Multiple-scenario power delivery profiles 
by calculating the standard deviation of the new system's fluctuations (i.e., the combined distributions of both the existing load fluctuations and the renewable resource fluctuations):

$$
\text { Std } \operatorname{Dev}_{L+R}=\sqrt{\operatorname{Std} \operatorname{Dev}_{L}^{2}+\operatorname{Std} \operatorname{Dev}_{R}^{2}+2 \cdot \operatorname{Cov}(L, R)}
$$

where:

\begin{tabular}{|c|c|c|}
\hline Std $\operatorname{Dev}_{\mathrm{L}+\mathrm{R}}$ & $=$ & standard deviation of the combined Ioad and renewable fluctuations \\
\hline Std $\operatorname{Dev}_{L}$ & $=$ & standard deviation of the load fluctuations \\
\hline Std $\operatorname{Dev}_{R}$ & $=$ & standard deviation of the renewable fluctuations \\
\hline $\operatorname{Cov}(L, R)$ & $=$ & covariance of the load and renewable fluctuations. \\
\hline
\end{tabular}

It was argued earlier that the load and renewable fluctuations are likely to be independent (i.e., they may not be correlated in any way). Under this assumption, the covariance term in equation 1 would be zero. Thus, the standard deviation of the combined distributions would be $10.2 \mathrm{MW} .{ }^{11}$ Abiding by the twostandard deviation rule, the dispatcher would have to commit $20.4 \mathrm{MW}$ of load-following capacity instead of $20 \mathrm{MW}$. Thus, the addition of a renewable resource with a two-standard-deviation probability of 4-MW power fluctuations would not require an additional commitment of $4 \mathrm{MW}$ of load-following capacity but only $0.4 \mathrm{MW}$.

If additional renewable projects were added to the system and these projects were geographically diversified, it is likely that their short-term fluctuations would be uncorrelated. Thus, the addition of more renewable projects to the system could stabilize the renewable "portfolio" and potentially result in diminished capacity commitment requirements for accommodating renewable generation fluctuations. It is likely then that the costs associated with accommodating intermittent renewable generation may not be very high. If current planning models do not capture this cost, they probably are not missing anything significant.

Penetration Effects. The impacts of a particular type of renewable resource depends on the penetration of that type of resource into the utility's overall resource mix. The impacts may change qualitatively as the penetration increases. At low penetrations, potential negative impacts on the system are generally negligible. But with high penetrations, negative impacts may become more significant. A number of studies of the impacts at different penetrations have been done and are reviewed by Wan and Parsons (1993).

Commitment Modeling. Many types of generating units have limitations on how quickly or how frequently they can be brought on line or taken off line. Consequently, the utility dispatcher's job is more difficult than simply turning different generating resources on or off as customer loads change. Commitment scheduling is the task undertaken by the dispatcher to identify which generating units should be brought on line at the start of a day or week in order to ensure that the system can respond in a reliable and efficient manner to the peak loads and generation outages that may occur. Some background in commitment decisions is needed to understand how renewable technologies may affect these decisions.

$11 \quad 10.2=\sqrt{104}=\sqrt{10^{2}+2^{2}}$ 
Unit commitment decisions are based primarily on the following issues:

- $\quad$ Loss-of-unit contingency considerations
- $\quad$ Unit-specific operational constraints
- The need for spinning reserves versus quick start units.

If a unit suffers an operational problem and drops off line, the dispatcher must accommodate the loss of that capacity immediately. Likewise, if a transmission line fails, generating patterns across a utility's territory may have to change quickly. For these reasons, utility dispatchers usually commit more units than they actually need. Committing a unit refers to bringing it on line to generate electricity.

Most generating units have a minimum capacity below which they cannot be operated; thus, when a unit is committed, it is dispatched at least to its minimum capacity. As mentioned previously in the discussion about spinning reserve, the portion of a unit's total capacity that is above and beyond the currently dispatched level represents capacity that can be utilized fairly quickly if necessary. Whereas it may take hours to start up some units, units that are already on line often can be ramped up to higher operating capacities in a matter of minutes. The speed at which this can be accomplished is referred to as the ramp rate, in megawatts per minute. In addition to the ramping flexibility of committed units, a utility system usually has "quick start" units, such as hydro units, combustion turbines, or diesel generators, that can start generating electricity in a matter of seconds.

The committed units and quick start units serve as the major supply of short-term capacity that can be used to follow the customer loads or respond to system emergencies (e.g., sudden loss of a generating unit or transmission line). Some units have operating constraints that make it difficult to take them off line for short periods of time. In other words, if they are shut down, they must stay off line for a minimum period before they can be restarted. Therefore, utilities may be forced to keep such units on line through low-load periods (e.g., nights and weekends) even though they are not really needed. This generally happens when a unit is expected to be needed during the next day but will require too much time before it can be restarted if it is shut down.

Many planning models attempt to simulate a utility dispatcher's commitment decisions based on the operational constraints described above. Generally speaking, the models focus on specific capacity targets for initial commitment decisions for each hour or for groups of hours and focus on ongoing requirements for spinning reserve decisions. In many models, individual generating units can be designated as eligible to contribute these capacity targets or not.

For modeling a renewable resource, this poses some complications. Given the uncertainty associated with daily renewable power delivery, one needs to ask what amount of credit toward spinning reserves a renewable resource provides. In reality, during days when the short-term weather outlook is favorable, a dispatcher may give a renewable project a reasonable amount of capacity credit in the commitment scheduling process. On other days, when unfavorable weather looks likely, he or she may not count on any capacity from the project. However, the more variable the output of a renewable resource, especially during the system peak hour, the less likely the system dispatcher is to view the resource's capacity as sufficiently dependable to include in commitment decisions-even on what appear to be favorable days for the resource. For example, if the short-term weather forecasts are not sufficiently dependable, the dispatcher may err on the conservative side and decide against giving the resource full credit for its expected output. A model's ability to evaluate the effect of a renewable resource on unit commitment depends in large part on whether it adequately captures the effect of the resource on spinning reserve requirements. 
Models differ in the degree of flexibility they offer for reflecting a renewable resource's contribution to the commitment target and spinning reserves. Some models allow any value between $0 \%$ and $100 \%$; others only allow the user to specify the resource as contributing either $100 \%$ firm capacity or no firm capacity at all. Designating the renewable resource as $100 \%$ firm may be appropriate if it has been modeled with a maximum capacity that is comparable to the project's expected value of output during the system peak hour. However, if the dispatch policy is conservative, even the expected output may overstate the capacity commitment benefits of the renewable project. If the project is modeled as a generating unit with a capacity equal to total installed capacity, this could significantly overstate the resource's commitment scheduling benefits because the average output of the project may be well below the installed capacity. Even if the user has designated a large forced outage rate to reflect the daily availability realities of the project, this may not be included in a model's commitment calculations.

If the user models a renewable project as a load modifier, the system loads will be reduced during the specific hours that generation is expected from the project. Some models use the net system loads (i.e., after load modifiers have been subtracted from them) as the basis for establishing commitment targets. For example, capacity targets might be specified as a percentage of the net peak load or as a level that would cover the net system loads for some percentage of the day. If this is the case, the model would consider only a portion of the renewable generation impacts as firm contributions to the commitment targets. Not all of the capacity would be given credit-only a portion that would be comparable to the load target percentage specified by the user.

A simplistic example illustrating this issue is provided by a hypothetical utility with a 1000 -MW peak and a commitment target of $90 \%$ of the net peak. If there were no load modifiers modeled, this would mean that $900 \mathrm{MW}$ of slow-start capacity would need to be committed, with each committed unit operating at its minimum capacity rating before any units could be dispatched at higher operating levels. Assume that the utility had a renewable resource that had a maximum output of $100 \mathrm{MW}$ that tended to be very closely correlated with the system peak. Assume that the utility also had conventional resources that included one 500-MW generating unit and half a dozen or so 100-MW generating units. Table 4-2 compares the impacts on commitment decisions if the renewable resource were modeled as a generating unit or as a load modifier.

When the renewable resource is modeled as a generating unit, the net peak is $1000 \mathrm{MW}$ and the commitment target is established at $900 \mathrm{MW}$ (90\% of the net peak). The commitment target is satisfied by the commitment of five generating units: the $100-\mathrm{MW}$ renewable unit, the 500-MW conventional unit, and three $100-\mathrm{MW}$ conventional units. In the load modifier case, the net peak is reduced by the 100-MW renewable resource; however, this only results in a reduction of the commitment target by $90 \mathrm{MW}$ (from $900 \mathrm{MW}$ to $810 \mathrm{MW}$ ). Effectively, the renewable resource's contribution to the commitment target is reduced from $100 \mathrm{MW}$ to $90 \mathrm{MW}$. This results in the ultimate commitment of more conventional units than in the previous case because an additional 100-MW conventional generating unit is required to reach the commitment target. The commitment of the additional resource will translate into higher simulated system costs.

This is not to say that modeling renewable resources as load modifiers is incorrect. However, a utility planner must be aware of the algorithms employed in his or her planning model and determine whether or not data adjustments may be necessary to overcome inadvertent biases. In the case of commitment algorithms, modeling renewables as generating units or load modifiers may not make much of a difference in simulation results unless the renewables become a sizable portion of a utility's generation mix. 


\begin{tabular}{||l|c|c||}
\hline \multicolumn{2}{|c|}{ Table 4-2. $\begin{array}{c}\text { Comparison of the Impact on Commitment Decisions of Modeling } \\
\text { Renewable Resources as Generating Units or Load Modifiers }\end{array}$} \\
\hline & Generating Unit & Load Modifier \\
\hline Total peak & $1000 \mathrm{MW}$ & $1000 \mathrm{MW}$ \\
\hline Load modifier & $0 \mathrm{MW}$ & $100 \mathrm{MW}$ \\
\hline Net peak & $1000 \mathrm{MW}$ & $900 \mathrm{MW}$ \\
\hline Commitment target $(90 \%)$ & $900 \mathrm{MW}$ & $810 \mathrm{MW}$ \\
\hline Units needed to meet target & $\begin{array}{c}100-\mathrm{MW} \text { renewable unit } \\
500-\mathrm{MW} \text { conventional unit } \\
\text { Three 100-MW conventional } \\
\text { units }\end{array}$ & $\begin{array}{c}\text { 100-MW renewable unit } \\
500-M W \\
\text { Four 100-MW conventional } \\
\text { units }\end{array}$ \\
\hline
\end{tabular}

'Note: The renewable unit is already "committed" because it was subtracted from the loads; however, it does not get included in the capacity calculations for meeting the $810-\mathrm{MW}$ commitment target.

\subsubsection{Summary}

There are several modeling considerations that utility planners should keep in mind when modeling the capability and availability attributes of renewable resources. First is the availability of site-specific data that provide time-of-day generating information. If such data are available, it may be beneficial to model the resource as a load modifier if the planning model allows for hourly definition of such modifiers (as most models do). The load modifier can be constructed to represent the uncertainty associated with the timing and quantity of the resource's generation. Merely taking an hour-by-hour average to collapse several years of data into a generation profile for a planning model will result in a profile that is likely to understate both the resource's maximum capability and the variability of its output. Instead, a planner may want to examine different years of data and develop several different profiles to use as scenarios within a multiple-scenario process.

A planner should examine the degree to which the capability and availability of a renewable resource may be correlated with the system peak load. If the resource is not correlated with the peak, modeling it as a generating unit in a probabilistic model is likely to overstate its value to the system. If the resource is only partially correlated with the peak, a planner may use a multiple-scenario process to capture the uncertainty of the correlation. This would probably entail the use of the load modifier modeling technique. In the simplest case, two scenarios could be developed and assigned probabilities: one in which the resource produced its maximum output during the system peak, and the other in which the maximum output was achieved in some other nonpeak hour.

If a planner is examining several different renewable projects, some thought should be given to the degree of correlation between the projects. Those resources that are located in close proximity (and are of the same renewable category, such as wind) are likely to be more correlated than a geographically diverse set of resources. Even if resources are far apart, the weather patterns of the different regions may be correlated, thereby resulting in similar patterns of generation between the projects. In most planning models, the availability of a generating unit is assumed to be independent of the availability of other units. 
Therefore, if the generation from different renewable projects is expected to be correlated, the projects probably should not be modeled as generating units.

With regard to the simulation of renewable resource capability and availability, it is difficult to generalize about any biases either for or against renewables that may be present in a particular planning model or that may be inherent in generating unit or load modifier modeling techniques. The data constructs of a specific utility in a specific model would have to be examined and tested to determine whether or not a renewable project was being appropriately represented. Therefore, this discussion has focused more on general issues that cut across most planning models. Planners should examine these issues closely to ensure that they are appropriately modeling renewable resources.

\subsection{Location}

\subsubsection{Concept}

In four general ways, the location of a resource option can affect the utility's rest-of-system costs and the costs borne by customers: ${ }^{12}$

1. Integration cost. Unless the option is located at a site that is already served by adequate T\&D to handle the output from the option, additional capital investment will be required to integrate the option with the system.

2. Losses. If the option is distant from customer loads, then a portion of the output from the option will be consumed by T\&D losses. If the option is close to customer loads, then a much smaller portion of the output will be consumed by losses. In fact, if the option displaces more distant generation, then the losses associated with the displaced generation also will be avoided.

3. Avoided reinforcement costs. Resources sited in particular areas can serve local loads and potentially defer investments in T\&D reinforcements that would otherwise be required.

4. Reliability. Whether or not an option defers T\&D reinforcements, it can affect the reliability of service to the local area. Reliability may be affected either by changing the probability that circuit flows will exceed ratings or by providing a backup supply to maintain the continuity of service in contingencies that would otherwise result in curtailments.

Table 4-3 shows the levels at which various renewable resources are typically connected and whether they are typically located remote from or close to loads. Of course, resources are occasionally connected at levels other than those indicated in this table. End-use renewable applications may not be connected directly to the utility system but displace loads at the primary or secondary distribution level.

In traditional utility planning, the three functional levels-generation, transmission, and distribution-are planned separately. The distribution system is planned to meet local customer needs. The generation system is planned to meet total systemwide customer demand at the lowest cost. The transmission system is planned to connect generation to the distribution system and has some degree of redundancy for network reliability and flexibility.

12 This review addresses only grid applications of renewable resources. There is an additional wide range of nongrid applications. 


\begin{tabular}{|c|c|c|c|c|c|}
\hline & \multirow{2}{*}{$\begin{array}{c}\text { Remote } \\
\text { from } \\
\text { versus } \\
\text { Close to } \\
\text { Loads }\end{array}$} & \multicolumn{4}{|c|}{ Interconnection Level } \\
\hline & & $\begin{array}{c}\text { Bulk } \\
\text { Transmission } \\
\text { (Generation) }\end{array}$ & $\begin{array}{c}\text { Area } \\
\text { Transmission } \\
\text { (Substation) }\end{array}$ & $\begin{array}{c}\text { Primary } \\
\text { Distribution } \\
\text { (Feeder) }\end{array}$ & $\begin{array}{c}\text { Secondary } \\
\text { Distribution } \\
\text { (Small Customer) }\end{array}$ \\
\hline Biomass & Either & $x$ & $x$ & & \\
\hline $\begin{array}{l}\text { End-Use } \\
\text { Renewable }\end{array}$ & Close & & & $x$ & $x$ \\
\hline Geothermal & Remote & $x$ & $x$ & & \\
\hline Hydro & Remote & $x$ & $x$ & $x$ & \\
\hline MSW & Close & $x$ & $x$ & & \\
\hline Solar PV & Either & & $x$ & $x$ & $x$ \\
\hline $\begin{array}{l}\text { Solar } \\
\text { Thermal }\end{array}$ & Remote & $x$ & $x$ & & \\
\hline Wind & Remote & & $x$ & $x$ & $x$ \\
\hline
\end{tabular}

Transmission is considered in generation planning primarily in two ways:

1. In screening level analyses of generation options, preference is sometimes given to options that can be sited close to load centers or easily connected to the existing network.

2. In detailed analyses for decision making, the costs of connecting an option to the existing network are included as a component of the total cost of the option.

But the relationship between the planning processes at the three functional levels is, at best, "arms length."

In recent years, the location of resource options has been getting increased attention with the emergence of the concept of the distributed utility (DU), also known as dispersed system or distributed resource planning. ${ }^{13}$ The fundamental idea of DU is that some types of resource options-for example, photovoltaics, diesel generators (gen sets), and DSM-are particularly suited to distributed or dispersed deployment (at numerous locations close to customers) and provide unique benefits relative to central station options.

This section addresses issues related to location for both central station and distributed options.

\subsubsection{Modeling Techniques}

Central Station Options. In evaluating central station options, the following types of studies are done to evaluate transmission system requirements and impacts:

13 Lamarre (1993); Quantitative Solutions (1993). 
1. Power flow - to determine the impact of an option on line and transformer loadings, voltage levels, reactive power requirements, losses, and required system reinforcements. Power flow studies are performed for multiple scenarios representing various levels of system load and contingencies, or combinations of generating units and transmission circuit elements out of service. If overloads or voltage limit violations are found for particular scenarios, then reinforcements are required to avoid those conditions.

2. Fault analysis - to determine whether an option impairs the ability of the system to handle a fault on the transmission system.

3. Dynamic stability - to determine whether an option has a significant impact on the ability of the system to withstand disturbances on the system. Dynamic stability refers to maintaining within acceptable bounds the excursions of power flows, voltages, and frequency that result from a disturbance and the ability of a system to settle down to a new steady state.

If required reinforcements are identified in the power flow studies, then cost estimates for these reinforcements are developed. If dynamic stability problems are identified, then changes in operating policies to avoid those problems, such as limits on simultaneous transfer over a set of circuits or improvements to the system to mitigate such problems, are identified and their costs are estimated.

Distribution system impacts are not relevant in evaluating central station options.

Approximate Analysis for Medium and Small Options. The analysis described above for central station options requires substantial computational effort and personnel time to set up and evaluate the computer simulations. Approximate methods have been developed for medium and small generation options. These methods use automatic sensitivity analysis of an optimal power flow model to identify the effects of resource additions at various locations on losses and on the need for reinforcements. They assume that the stability impacts of these options are negligible.

An example of this approach is the LOCATION model developed by the Pacific Gas and Electric Company (PG\&E) as part of the MABS effort. ${ }^{14}$ It derives incremental loss factors and marginal transmission capacity costs at various locations on the system. These values are input to the MABS model to do a marginal analysis of resource options.

Distributed Utility Options. DU options include both generation technologies that can be located close to customers and DSM options. DU planning includes T\&D with generation and DSM options in the overall integrated optimization framework. Three possible locations for DU options and the benefits they yield are: ${ }^{15}$

- At the substation

- Relieve transformer loading and defer investments in new transformer capacity

- Improve reliability by reducing the probability of transformer overloads and by allowing continuity of service to customers connected to the substation.

14 Shirmohammadi and Thomas (1990).

15 El-Gassier et al. (1991); Energy and Environmental Economics and Pacific Gas and Electric Company (1992); Ma and Isaksen (1979). 
- On the feeder

- Defer conductor and line equipment replacements by reducing line loading

- Improve voltage profile along the feeder

- Improve reliability by reducing the probability of circuit overloads and by allowing continuity of service to customers along the feeder as an "island" when supply to the feeder is interrupted or by providing voltage support to enable a larger portion of the load on a faulted feeder to be served by back-feeding from another feeder

- Reduce line losses.

- On the customer's premises

- Provide backup generation for customer service reliability.

These benefits are cumulative. For example, a DU option located on a feeder would provide benefits at the central generation, transmission, substation, and feeder levels. At customer sites, it is possible to realize benefits at all levels.

Approaches for evaluating each of these benefits have been developed in recent years and are described below.

PG\&E developed an approach for evaluating the benefits from deferring investments in new transformer capacity and conductor and line equipment replacements. This approach was demonstrated in a pilot project to target DSM in a local area to defer T\&D reinforcements, known as the Delta project. ${ }^{16}$ The approach develops an integrated T\&D and DSM plan that minimizes the cost of serving a local subarea.

It is applicable to renewable resources and other DU options as well as DSM.

The key steps in this approach, shown in Figure 4-3, are the following:

Step 1. Develop a base case T\&D investment plan for the local subarea. This plan establishes the reference point for determining marginal $T \& D$ costs.

Step 2. Calculate marginal T\&D costs. Alternative approaches are discussed in the next subsection.

Step 3. Determine the impact on feeder and substation load profiles of the candidate DU options.

Step 4. Perform cost-effectiveness evaluation of the DU options. This requires the marginal T\&D costs and load profile impacts, as well as the option costs and marginal generation energy and capacity costs.

Step 5. Select DU options and T\&D deferrals.

Step 6. Iterate. Recalculate the marginal costs. Redo steps 4 and 5 if the change in marginal costs may be sufficient to change the cost-effectiveness of the DU options relative to each other and relative to going ahead with the $T \& D$ projects.

16 Energy and Environmental Economics and Pacific Gas and Electric Company (1992). 


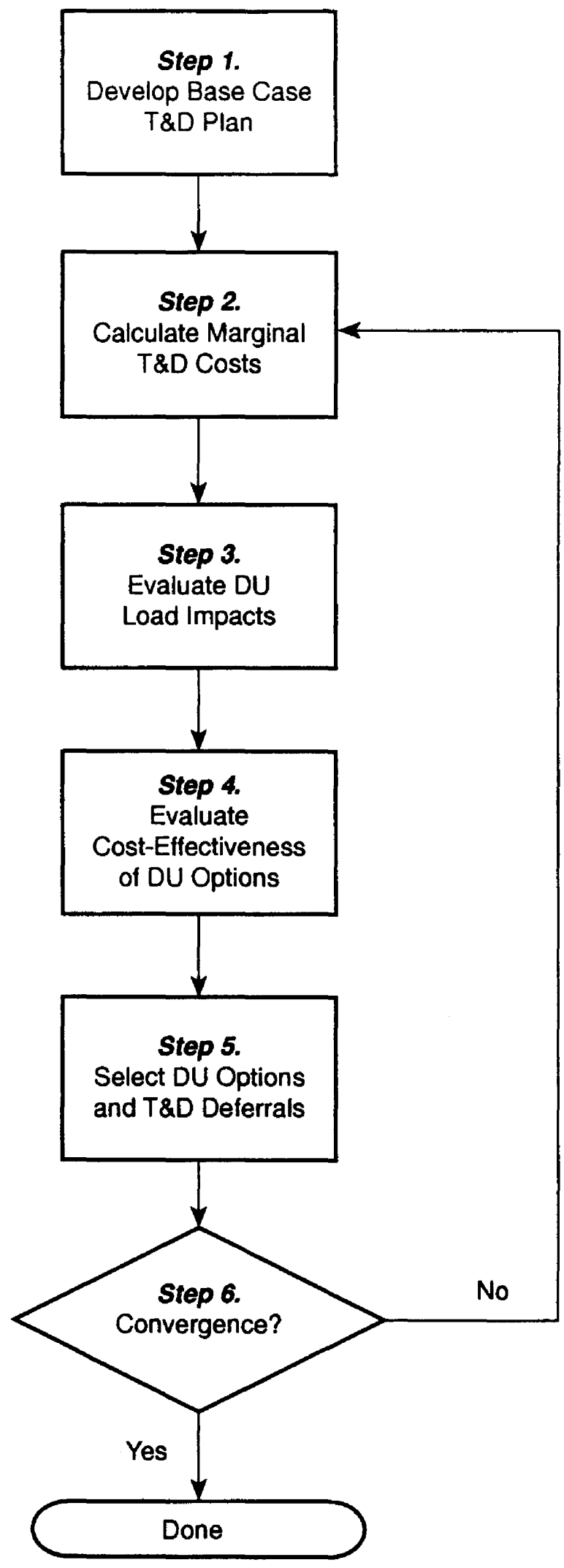

Figure 4-3. The distributed utility planning process 
The benefits of improving a feeder voltage profile can be evaluated using this approach by determining the extent to which investments required for an acceptable voltage profile are deferred by a DU option.

Value-based resource analysis (VBRA) provides a method to evaluate the reliability benefits of a DU option. In VBRA, alternative configurations of an electrical system are compared on the basis of total costs, which are defined as the sum of capital costs, operating costs, and unserved energy costs. ${ }^{17}$ Unserved energy costs represent the economic costs to customers of the outages that would occur given the reliability of a particular configuration.

Unserved energy cost is typically calculated as the product of expected unserved energy and a customer outage cost. The expected unserved energy is calculated by a failure mode and affect reliability analysis. ${ }^{18}$ At the distribution level, the calculations can be done by hand. The customer outage cost represents the cost per kilowatt hour of energy not served as a result of an interruption. The customer outage cost is often determined from customer surveys. A project that improves reliability will reduce expected unserved energy and unserved energy costs.

In a pilot project to demonstrate the local benefits of a photovoltaic installation, known as the Kerman Project, PG\&E found that the photovoltaic plant, located between the Kerman and Biola substations, could offer continuity of service to a portion of the customers who would otherwise be interrupted if either substation experienced an outage. ${ }^{19}$

\subsubsection{Issues}

Hourly Profiles. Whether a particular DU option can defer a transmission or distribution reinforcement depends on the impact that option has on the hourly profile of demand on the circuit elements to be reinforced. The impact on peak demand is not necessarily the maximum demand impact of the option, unless the maximum impact of the option is coincident with the peak demand on the circuit. Even if the peaks of the two variables are coincident, consideration of the original feeder peak hour only is inadequate if the hour of the net peak demand shifts as a result of the DU option. Therefore, it is in general essential to consider the full hourly profiles of original demand and DU option capability.

Marginal Costs Differentiated by Time and Location. The economic value of a DU option depends on where the option is installed and on the hourly profile of its capability. The system marginal costs used in evaluating benefits must account for variations in marginal costs between different locations and variations over time. This issue is most important for marginal T\&D costs. System average marginal $\mathrm{T} \& \mathrm{D}$ costs are inappropriate because they do not reflect geographical variations, they do not reflect differences in demand reductions between peak hours and other hours, and they do not reflect year-to-year variations that determine the timing of reinforcements.

Determination of Marginal T\&D Costs. There are a number of different ways to determine marginal T\&D costs. Three alternative approaches are
17 RCG/Hagler Bailly (1994).
18
Billinton et al. (1993).
19
El-Gassier et al. (1991). 
1. Incremental present value

2. Power-flow sensitivity

3. Value-based.

The incremental present-value approach is used as the basis for marginal T\&D costs in the Delta model. It first constructs a hypothetical load reduction, then constructs a modified $T \& D$ investment plan corresponding to the additional load reduction. The difference between the present value of investment costs for the two plans is estimated. This difference is then divided by the load reduction to get the marginal T\&D cost. ${ }^{20}$

The power-flow sensitivity approach is used by the LOCATION model to calculate marginal transmission costs, as mentioned above. This approach starts with the generic cost for reinforcing various types of facilities. The marginal transmission cost attributable to a change in generation or demand at a particular location is calculated by multiplying the costs of reinforcing the facilities required to serve that location by factors representing how close these facilities are to being overloaded. These factors are calculated on the basis of sensitivity analysis with an optimal power flow model. ${ }^{21}$

The value-based approach starts with the principle that in an optimal capacity plan the marginal cost of an increment of capacity is equal to the marginal benefit. The marginal benefit of an increment of transmission or distribution capacity is related to the operating cost savings and reliability impacts it provides. $^{22}$ Operating cost savings include reduced losses and fuel cost savings resulting from eliminating transmission bottlenecks. The reliability impacts are reduced interruptions of service to customers. The economic value of the reliability benefits from an increment of capacity is calculated by determining the reduction in unserved energy and multiplying this reduction by an outage cost representing the cost to customers of unserved energy.

Both the incremental present value and value-based approaches require a base-case T\&D plan for each subarea under consideration. The incremental present value approach requires this plan as a basis for determining the cost reduction resulting from deferring the plan in response to a reduction in demand. The value-based approach requires this plan as a basis for determining the reliability of service to customers and the effect on reliability of incremental capacity.

The incremental present value and value-based approaches will yield equivalent results if the utility plans T\&D additions to minimize the sum of capital, operating, and unserved energy costs. However, this approach to $T \& D$ planning is not widespread. Traditional $T \& D$ planning criteria may result in either higher or lower overall levels of capital expenditures in T\&D reinforcements. If a utility's planning approach yields higher $T \& D$ investments than a value-based approach, then the marginal benefits of capacity will be lower than the marginal costs. Value-based approaches to T\&D planning are likely to be used more widely in the future as utilities seek to control T\&D investments more closely.

Reliability Benefits. The reliability impact of distributed generation options depends on how they are operated under emergency conditions. As mentioned above, distributed generation can conceptually improve reliability by allowing continuity of service to customers along the feeder as an "island" when supply to the feeder is interrupted. However, typical utility practice is to separate distributed generation

20 Energy and Environmental Economics and Pacific Gas and Electric Company (1992).

21 Shirmohammadi and Thomas (1990).

22 RCG/Hagler Bailly (1994). 
from the system in any abnormality. One reason for this practice is to reduce the risk of electrocution to emergency crews dispatched to clear faults. A consequence, however, is that certain potential reliability benefits of renewable options are not realized.

Level of Effort. A drawback of considering location is the increased level of effort and data requirements. Detailed T\&D investment plans are required. Analysis must be repeated for different locations. Additional complexity is introduced into the IRP process, as well. T\&D planning involves several complex models that are not part of an IRP process without T\&D. These include load flow, transient stability, and fault analysis models. Some practitioners recommend that analysis should focus on a 3-5 year planning horizon and on first-order impacts to manage the overall level of effort and complexity. ${ }^{23}$

\subsubsection{Summary}

Location has long been recognized as an important attribute of major central station generation options. Techniques for fully incorporating location in the evaluation of central station options have been thoroughly developed and are well entrenched in planning processes.

However, because these methods require running large computer programs for each individual option, they are not suited to the evaluation of numerous options at numerous locations, as is required for DU planning. DU planning has been accomplished in relatively small local areas on a pilot testing basis, but has not yet been applied on a systemwide basis at the distribution level. Systemwide evaluation of the location attribute has been done only at the transmission level using an approximate approach in the LOCATION model.

A critical need for systemwide DU planning is the ability to automatically generate optimal T\&D plans for each local subarea. For a large utility like PG\&E, with more than 200 distribution planning areas, this is a substantial requirement.

Location benefits can be a substantial fraction of the total benefits of an option. For example, PG\&E's Kerman study shows that the location benefits, including transmission capacity, substation and distribution system value, reactive power value, and reliability benefits are more than one-third of the total benefits provided by a photovoltaic station at the Kerman Substation. ${ }^{24}$

\subsection{Modularity}

\subsubsection{Concept}

Modularity is an advantage that some renewable resources have over many conventional resources. Modularity is defined by the incremental size of resources and the lead time required for adding them. Some of the benefits of modularity show up only in uncertainty analyses, while others show up in singlescenario analyses as well. Modularity concepts are discussed in this section, as well as the modeling of modularity in planning studies.

\footnotetext{
23 Barakat \& Chamberlin, Inc. (1993).

24

El-Gassier et al. (1991).
} 
Incremental Size of Renewable Resources. Some renewable resources, such as wind or photovoltaics, can be built in small increments. They may be constructed from individual units of a few kilowatts each. On a utility scale, when the analysis is often concerned with units of at least $50 \mathrm{MW}$, it takes many individual units of renewable resources to achieve the size of units normally considered in modeling studies using the models examined here. For example, Northern States Power recently received bids for $25 \mathrm{MW}$ of renewable resources that consisted of 50 to 100 individual wind turbines.

The small incremental size of renewable resources allows utilities to more closely match capacity to load with renewable resources than with "lumpy" resources. Utilities can avoid the temporary overcapacity that typically results from adding a large, new conventional resource. Utilities can add only enough modular renewable resources each year to exactly match load growth requirements; this should help reduce a utility's costs and make the cost of renewable resources more competitive with conventional resources.

Not all utility modeling takes advantage of the modularity of renewable resources. Generation expansion models are often designed to handle power plants that are added in discrete increments of capacity, even though this approach is computationally more difficult than dealing with plants with variable capacity sizes. Studies typically consider, for example, units of 50,80 , or $120 \mathrm{MW}$, and not a plant of any size from 30 to $140 \mathrm{MW}$. Using models that add plants with variable sizes may be useful for analyzing modular renewable resources. This variable size approach would allow the utility to analyze the benefits of adding only the capacity required to match its planning criteria.

The modularity of renewable resources means that a large number of units may still add up to a small aggregate amount. Modeling small units may be a concern, however, because the units may be too small to see in the modeling. A production costing model analysis of a utility with several thousand megawatts of capacity may not provide sufficient resolution for an incremental analysis of a renewable resource of only a few kilowatts or even up to a few megawatts. In some cases, the number of significant digits in the model may not be enough to analyze the renewable unit. It may be necessary to analyze small renewable projects on a marginal basis or with approaches like those used for analyzing DSM, rather than trying to include them in generation planning models. Some of the integrated resource planning models that could model a renewable alternative as either similar to a DSM option or as a generation option may be preferable to models that have only a generation planning option.

Short Lead Times. Another aspect of modularity is that it generally requires only short lead times for permitting and constructing renewable facilities. Short lead times are valuable to utilities because of the uncertainty in future demand levels and fuel prices. Short lead times mean that utilities can delay making decisions on adding resources until additional information about uncertain factors is known.

Short lead times also are important to utilities and shareholders as a means of reducing the potential for regulatory disallowances. Modular resources minimize the risk of disallowances from excess capacity because short lead times reduce the likelihood of constructing plants that result in excess capacity. Short lead times also reduce the amount of capital that is at risk if a plant is cancelled. With short-lead-time plants, a greater proportion of expenditures are concentrated close to the completion date and are, therefore, eliminated if a plant is cancelled.

Short lead times have the further advantage of reducing construction financing costs relative to direct construction costs. Construction financing costs under traditional utility rate making are accumulated in an account called allowance for funds used during construction (AFUDC), which is added to the direct costs to determine the total capital cost of the project to be recovered through rates after the project comes on line. Financing costs compound over the construction period. The longer the construction period, the greater the compounding of financing costs. Conversely, a shorter construction period results in a lower relative share of financing costs. 
Renewable resources often have shorter lead times for permitting and construction than conventional generating units. A coal-fired generating unit may require 3 years to permit and license; a renewable facility may require 1 to 2 years. According to EPRI's Technical Assessment Guide (TAG), it may take 1 year to construct a photovoltaic or wind facility, whereas conventional facilities could take 1 year (combustion turbines), 2 years (combined cycle facilities), or 3 or more years (pulverized coal). Lead times for permitting and construction of an advanced light-water reactor unit are 4 and 5 years in $\mathrm{TAG}^{25}$

The modularity and flexibility of renewable resources are important because many factors affecting capacity requirements are uncertain. Growth in demand, in particular, is uncertain. Many utilities in the 1970s and 1980s discovered this when they started construction of coal and nuclear power plants in response to high growth rates and then had excess capacity when growth slowed. Because of continuing uncertainty in load growth and regulatory disallowances due to excess capacity, many utilities now eschew long-lead-time options.

Planners in the Pacific Northwest also concluded that the standard modeling approach did not show the benefits of short-lead-time options. They concluded:

Traditional planning models typically are designed to schedule or evaluate a set of future resources under one specific load condition or forecast. Loads are treated deterministically, and resource plans are formulated as if a utility has perfect knowledge of future loads where demand and supply are in close balance over the planning horizon. This type of study structure reflects none of the benefits inherent in short lead time resources. A study that assumes perfect information on load will show no economic difference between two resources that have the same total cost, regardless of any differences in lead time. ${ }^{26}$

\subsubsection{Modeling Techniques}

Multiple Scenarios. The benefits of modularity are exhibited most when there turn out to be differences or changes from the forecast. Utilities and utility models often do not include analyzing changes in various factors once a decision has been made. Utilities often look at high, medium, and low demand growth, but not at growth rates that change over time. It is this last case where the value of renewable resources is more apparent. This case includes both the situation when demand growth is low or medium in the first few years and then suddenly accelerates and when high or medium initial growth is followed by low growth. Even the models such as MIDAS and IRP-Manager that include a decision analysis framework often do not account for the benefit of short lead times. Branches for high growth and low growth are included, but the branch has high or low growth for the whole forecast period and not high growth changing to low growth or vice versa. Many utility models also do not provide a way to combine the results of different sensitivity cases. Most utilities and models examine only the current set of assumptions other than providing the option of waiting 1,2 , or 3 years to determine the impact of uncertain factors. The models do not provide an indication of the value of "perfect information," to use the decision analysis term.

Electric Power Research Institute (1989). 
Flexible Start-up Date. Another approach was used in the Multi-Attribute Bidding System (MABS). MABS performs an incremental evaluation of specific resource options and incorporates a feature to evaluate the benefits of start-date flexibility. A resource with a short lead time can provide greater startdate flexibility than one with a long lead time. MABS calculates the net benefits of a project for each of three different demand scenarios. If the project offers start-date flexibility, then maximum acceleration and deferral are assumed in the high and low demand scenarios, respectively.

In the high-demand scenario, MABS assumes that the project is accelerated to the maximum extent possible given its lead time. The net benefits in the high-demand scenario are higher than they would be without the acceleration because of benefits obtained in the years between the accelerated start date and the base-case start date. Similarly, in the low-demand scenario, the net benefits are higher, or the absolute value of negative net benefits is smaller, because net losses in the years between the base-case start date and the deferred start date are avoided. MABS explicitly displays the gain that results from acceleration in the high scenario and the reduction in loss that results from deferral in the low scenario.

Probabilistic Simulation. Recognizing the importance of explicitly capturing the benefits associated with increased flexibility in a resource portfolio, planners in the Pacific Northwest developed the Integrated System for Analysis of Acquisitions (ISAAC) model, which incorporates more analysis of uncertainty than many models. ${ }^{27}$ ISAAC performs Monte Carlo simulations of uncertain factors such as load growth, fuel prices, hydro resources, resource costs and completion times, and out-of-region markets and supplies. For example, probability distributions are created for each of these variables. For each year in the future, a random draw is taken based on the probability distribution. In addition, trend growth rates may be modified because of random shocks, resulting in more volatility in the variable. The model makes decisions to add resources in future years based on the existing load levels and the expected load growth, but actual load may turn out to be significantly different. The changes in growth rates during the permitting and construction periods for specific resources can show the benefits of options like renewable resources that have shorter lead times.

A probabilistic approach is also used in the Over/Under model. ${ }^{28}$ The Over/Under model simulates the evolution of the resource plan through a decision tree and determines the optimal reserve margin to minimize total costs. Options with short lead times allow the minimum cost to be achieved at a lower reserve margin.

Expansion Planning Methods. The analysis of modular resources involves considering the approach used by planners to determine the addition of resources. There are several approaches used in utility modeling for adding new resources, including:

- Manual insertion of new resources

- Adjustment of timing of a fixed set of resources

- Single-scenario optimization

- Decision-tree optimization.

The simplest approach for system expansion planning is the manual approach. The utility planners insert new resources at specific times and in specific sizes. The model is then run with the specified expansion plan. To consider alternatives, the planners can specify alternative expansion plans or assumptions and rerun the complete model. The results under different alternatives are then compared and the least-cost 
alternative identified is generally selected as the plan to be constructed. This is the approach that must be used with pure production costing models such as PROMOD and the original version of Elfin.

One constraint with the manual method is that there may be fewer alternatives that can be considered than with automatic models. The physical ability to run sufficient alternatives may be a limiting factor.

In the second expansion planning method, a fixed order of generating alternatives is supplied to the model, and the model adjusts the in-service date of these alternatives to match capacity requirements. For example, the model may be told to add a coal unit first, then a combustion turbine, and then a confined cycle. The model selects the base-case in-service date for each unit; as the load forecast is changed, the units are installed in the same order as for the base case, but the model changes the in-service date of the units.

The third alternative is single-scenario optimization. The model is supplied with a list of alternatives and selects the least-cost set of alternatives for a given set of input assumptions on, for example, growth, fuel costs, and capital costs. In essence, the models and their optimization routines assume that the future is determined by the assumptions used in the single scenario. This is the approach used by generation expansion models such as EGEAS and the ICEM version of Elfin and IRP-Manager. Dynamic programming packages in EGEAS and PROSCREEN also optimize the plant selection under the assumptions of a single scenario.

We refer to this as single-scenario optimization because only one set of assumptions is used in each run. The cost of an option must be considered in the context of the scenario studied. Because the calculated cost is based on the assumptions made and because there is considerable uncertainty in those assumptions, many utilities perform, and many utility commissions require, sensitivity studies using different assumptions. High, medium, and low scenarios for load growth and fuel prices are usually the minimum set of alternatives run. Scenarios with changing growth rates also are desirable. Some integrated resource plans report the results of nearly 100 sensitivity studies.

The fourth approach to modeling capacity expansion is decision-tree optimization. The approach explicitly considers multiple alternatives for factors such as load growth and fuel costs, although some models only calculate results for a given expansion plan rather than optimize the plan. Rather than a single cost estimate for an expansion plan, therefore, the model returns an expected cost that reflects the probability of occurrence of various scenarios.

\subsubsection{Issues}

It is potentially important to separate the lead time required to construct resources into the permitting phase and the construction phase, each of which is initiated by a utility decision. The first decision is to start pre-construction activities on a unit, including permitting, licensing, and engineering design. If the permitting phase for a resource option is successfully completed, the option can go into an inventory of potential projects. Resources can be held in inventory for several years, but they may also "fail" while they are in inventory. The second decision is to start construction of a resource from the inventory of available projects. A strategy of adding resources in two separate phases would significantly reduce the risk of adding resources, because the failure of projects is often associated with the permitting phase and not the construction phase. Pursuing the pre-construction activities prior to need would enable the risk inherent in this step to be addressed. Then the risk of construction is reduced because the lead time for the construction decision alone is much shorter. 
Adding resources in two steps is a potential benefit to renewable resources because of the combination of the short lead time and small capacity increments relative to conventional resources. If a renewable site is permitted and licensed, additional increments of capacity could be constructed each year on an asneeded basis. Permitting a whole wind farm or solar field would separate the pre-construction lead time from the construction lead time. Once permitting, licensing, and engineering design are complete for the entire field, the utility would have only a very short forecast period to determine the need for additional resources and to construct them.

This approach would provide a utility with much more flexibility than building large, central station power plants. The utility could wait until it is confident that it needs more capacity, and then build only as much capacity as it needs. Excess capacity should be minimized with this approach-both the large excess capacity resulting from changes in demand growth during construction of projects with long construction periods and the "lumpiness" associated with adding large increments of capacity.

However, separating lead times is not a widespread practice. The Pacific Northwest is one of the few areas that is beginning to pursue the idea of permitting options and placing them in inventory for construction when needed. Planners there note that the cost of design, siting, and licensing is typically small compared to the total costs of constructing a resource. ${ }^{29}$ New England Electric System (NEES) also recently applied this concept in developing NEESPLAN $4 .^{30}$

Also, most utility planning models do not separate permitting and construction. Modeling new resources usually includes only one construction lead time rather than separate decision points and lead times for permitting and construction of resource options.

\subsubsection{Summary}

Most system planning models and utility implementation of these models do not fully account for the benefit of short-lead-time resources. The future is modeled in an essentially deterministic manner. The benefits of being able to wait longer before deciding to proceed with a specific resource are not exhibited in this type of modeling. The ISAAC model is the principal exception among the models reviewed. Most utility planning models and utility planning approaches, therefore, fail to capture the benefits of modularity.

One possible way in which utilities could address this issue would be to add scenarios that change the assumed growth rates partway through the planning horizon. Instead of only high and low scenarios, the analysis would include scenarios with unanticipated changes in growth rates during the forecast horizon. The demand forecast, for example, would start off at the base growth rate, but then slow. The costs of long-lead-time resource alternatives selected before the slowing of growth would be compared with the cost of alternatives with shorter lead times that have more flexibility for changing after the slowing in growth is apparent. Decision-tree studies would also need to include branches with changes in demand growth rates, not just high and low rates for the entire forecast horizon, and a range of fuel price scenarios.

29 Northwest Power Planning Council (1991), Volume II-Part II, p. 49

30 New England Electric System (1993). 
lead time plants. From the year of this decision point, however, there would again be branches for different growth rates in demand. This would allow for different rates of growth over the entire forecast horizon, similar to the changes in growth scenarios suggested above. The insertion of an additional decision point with uncertain demand growth beyond that point would allow the planners to compare short-lead-time plants with long-lead-time plants, while crediting the long-lead-time plants with the benefit of being able to be cancelled.

Some expansion planning models are designed to handle only a finite set of candidate resources with prespecified capacity increments, while others allow the capacity added for a particular technology to be any value within a range. Using models that add plants with continuous rather than discrete sizes may be useful for analyzing modular renewable resources. This would allow the utility to add only the capacity required to match its planning criteria and would indicate the benefit of modular resources.

Utilities do not typically place potential resources in inventory for addition when required. They do not obtain permits for a wind farm or a group of CTs, for example, and then add units as demand grows. Some utilities in the Pacific Northwest are beginning to take this approach, but it is the exception rather than the rule. Advance permitting and inventorying and incrementally adding units to match load would encourage the development of renewable resources.

\subsection{Risk Diversity}

\subsubsection{Concept}

Resource diversity, achieved using new types of generation resources, can provide value to a utility by reducing its exposure to risks from political, regulatory, and fuel price changes that may accompany overreliance on any one fuel type or technology. Diversity is an attribute of a portfolio of resources rather than of a specific resource. But a specific resource can contribute to the diversity of a portfolio if it is sufficiently different from other resources in the portfolio.

Renewable resources, in particular, can provide diversity benefits. Non-fuel-based resources can reduce a utility's reliance on and sensitivity to fossil fuel cost changes. Because the costs of these resources are independent of fuel costs for conventional resources, adding renewable resources can result in a system that is less sensitive to the uncertainty in specific fuel costs.

The concept of diversity incorporates the consideration of the riskiness of the alternatives and the fact that the future is uncertain. The focus is generally on fuel prices. Diversity often compares portfolios of resources that use similar fuel types to portfolios of resources with fuel costs that are at least somewhat independent of the principal fuel type. For example, a utility system that is highly reliant on natural gasfired generators would not receive any diversity benefits from additional gas-fired generation, whereas adding wind power would reduce the risks to the utility system arising from increases in gas prices.

Although the focus of diversity typically is on fuel risk, a portfolio may also be technologically diverse if it contains a mix of technologies. Technology diversity encompasses any non-fuel risk that could be correlated between generating units.

Environmental benefits are sometimes cited as an advantage of diversifying the resource portfolio. We are defining the term diversification more narrowly here to focus on financial risks, although these may include costs related to further environmental regulations, such as $\mathrm{CO}_{2}$ limits. Environmental benefits could be considered through the inclusion of monetized environmental externalities as a complement to the financial risk issues captured by portfolio diversity analysis. 
The key concept underlying diversification in electric resource planning is independence of the cost or availability of one resource from events affecting the cost or availability of other resources. This definition implies that there are two dimensions of independence:

1. Cost. A resource contributes to cost diversity if the cost of power from that resource is independent of the cost of other resources that represent a large portion of the utility's costs.

2. Availability. A resource contributes to availability diversity if its availability is independent of conditions that could limit the output of large blocks of other resources.

Two examples illustrate the concepts of fuel and technology diversity. Fuel diversity would be provided by the addition of a biomass project in a utility system that is made up primarily of gas-fired generation. The biomass project provides cost diversity because its cost of power is not subject to the same fluctuations in natural gas prices that affect the cost of the gas-fired generation. Fuel supply to the biomass project is not subject to the same curtailments affecting natural gas, so the biomass project also provides availability diversity to the system. Diversity also mitigates risk by allowing the dispatch of various units and the generation from different fuels to be adjusted to minimize costs in different fuel-price regimes.

Technology diversity would be provided by the addition of any technology other than nuclear to a system that consists of a high proportion of nuclear generation. The non-nuclear technology provides cost diversity because it would not be subject to, for example, increased maintenance requirements that would affect the nuclear units as a class. The non-nuclear technology would also provide availability diversity because it would still be able to operate if generation from nuclear units were restricted by regulatory action.

There is no minimum resource size for realizing diversity benefits in the same way that there is no minimum size for realizing benefits from a DSM option. Even if an option replaces only $1 \mathrm{kWh}$ of oilfired generation in a high-oil-price scenario with generation at a stable price, it will provide measurable, although small, benefits to ratepayers.

The concept of diversity in resource planning is parallel to diversity in a financial portfolio. The risks in, say, common stocks of individual companies are divided into two components-systematic risks and diversifiable risks. Systematic risks are those that affect the return of all of the stocks together, resulting from overall economic conditions and trends in broad industry categories. Diversifiable risks are those that affect the performance of an individual company independently of other companies. These are called diversifiable risks because they can be "diversified away" by including only a small fraction of stock in any one company in a portfolio of stocks of many companies.

The variance of return from the portfolio is much narrower than it would be if it consisted entirely of the stock of only one company. With a large number of companies represented in a portfolio, the contribution of the diversifiable risk of individual companies can be very small even if some or all of them are individually quite risky, because each company makes up only a small fraction of the overall portfolio and their returns are substantially uncorrelated.

There are two aspects to reviewing diversity in utility modeling. The first is whether it is considered at all since many models and modeling studies do not include diversity. The second aspect is how to include it in the analysis.

Diversity considers, at its simplest, both the expected outcome and the range of expected outcomes. A resource plan that focuses on natural gas-fired options may have a low cost under the base-case scenario, 
but a wide range of costs because of the uncertainty associated with future gas prices. A second resource plan that includes significant amounts of renewable resources may have a higher cost under the base-case scenario but could have a much smaller range of outcomes because it is not as sensitive to uncertain gas prices.

Diversity, therefore, considers both the base cost and the range, or variance, in the costs for alternative resource options. Both the costs and the range in costs would be considered in the selection of a resource plan. Utility planning studies that consider renewable resources should report both the base-case results and the range in results from the uncertainty analysis.

A more sophisticated method uses portfolio theory to combine the base costs and the range in costs by using probabilities and risk preferences, as described in the following section. ${ }^{32}$ This involves assessing the risk preference function and using it to determine whether a plan with a low price but a wide range of outcomes is preferred over a plan with a slightly higher price but a narrower range of outcomes. The theoretical development of risk preferences is presented in Appendix B.

\subsubsection{Modeling Techniques}

Scenario Analysis. One approach to evaluating diversity is to perform production simulation for a number of alternative plans under several fuel-price scenarios. MIDAS and other system models that have the capability to run multiple scenarios automatically can do almost all the computational work to calculate the diversity benefit. Two approaches can be used with these models. Both require separate multiplescenario model runs with and without the candidate project. It may be possible to use the same multiplescenario runs as one of the runs for all projects, as either the "with" run or the "without" run, depending on whether the project is or is not in the current iteration of the resource plan. One approach simply calculates the variance of total costs with and without the project and determines the diversity benefit from the difference in variances. The other approach calculates the incremental net benefit of the project in each scenario, calculates the covariance between net benefit and total production costs, and determines the diversity benefit from the covariance as described in the procedure above.

Portfolio Analysis. The following procedure, shown in Figure 4-4, outlines an approach for using portfolio theory to evaluate the fuel diversity benefits provided by each project in a set of candidate projects, assuming that each project is not large relative to the overall system.

Step 1. Construct a set of fuel-price scenarios. In many cases, three scenarios will be adequate-a base case, and high and low natural gas or world oil price scenarios. In constructing the high and low scenarios, care should be taken to adequately account for any significant linkages between fuel prices and energy purchase prices, including economy energy prices.

Step 2. For each fuel-price scenario, run the model to calculate the total production costs for each year over the planning horizon and take the present worth.

Step 3. For each candidate project:

a. Calculate the present worth of net benefits over the life of the project for each scenario.

32 Jacobs and Huntley (1992). 


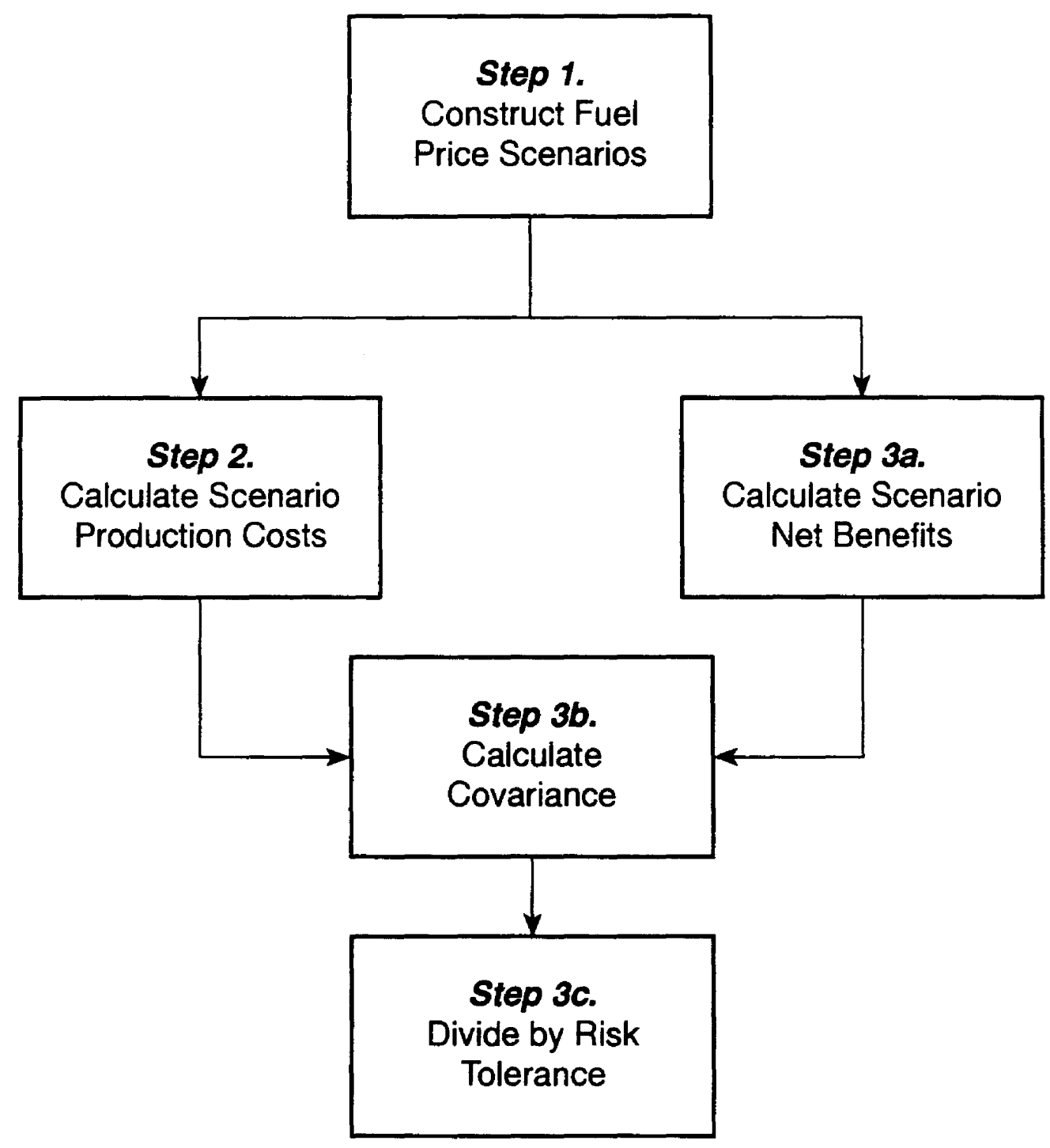

Figure 4-4. Calculation of diversity premium 
b. Use the probabilities of the fuel-price scenarios to calculate expected net benefits. Use the total production costs for each scenario to calculate the covariance between net benefits and total costs. The covariance is defined mathematically as the expected value of the product of the deviation of net benefits in a scenario from expected net benefits and the deviation of total costs from expected total costs. The covariance indicates the correlation between net benefits and total costs:

$$
\operatorname{Cov}(x, y)=\sum_{i}\left(x_{i}-\bar{x}\right)\left(y_{i}-\bar{y}\right) p_{i}
$$

where $x_{i}, y_{i}$, and $p_{i}$ are the values of net benefits, total production costs, and probability of scenario $i$.

c. Use the aggregate customer risk tolerance to calculate the diversity benefit. The aggregate customer risk tolerance is inversely related to risk aversion. It represents the trade-off between risk and expected value, as described in Appendix B.

Only one set of production cost runs in Step 2 is required to evaluate any number of projects in Step 3.

Some types of models could run the required scenarios automatically, while it would be necessary to manually perform the scenarios using other types of models. Various models use different approaches:

- Pure production costing models do not internally consider more than one scenario. The only way to analyze diversity is by manually performing a scenario analysis and combining the results of several runs.

- Decision-tree models can automatically run the alternative scenarios needed to analyze diversity, as well as other sensitivity cases. This can be an important improvement.

- Monte Carlo models also can simulate scenarios to provide data on diversity benefits.

MABS uses the portfolio approach to evaluate diversity benefits. MABS models three scenarios, representing high, medium, and low marginal costs. Each scenario is defined as a combination of a demand scenario and a natural gas price scenario. For example, the high marginal cost scenario is defined as a combination of high demand and high natural gas prices. MABS requires that a risk tolerance factor and the total production costs for the three scenarios be supplied when it is initially set up. When MABS is run for an individual project, the project fuel price is automatically adjusted as appropriate for each scenario. The diversity benefit is automatically calculated and displayed as a component of project net benefits.

\subsubsection{Issues}

Definition of the Portfolio. Three alternative definitions of the portfolio and the corresponding definitions of total system costs are:

1. The utility system-revenue requirements

2. The energy system-total cost of energy to customers (including outage costs and non-electric energy) 
3. The regional economy-regional gross domestic product.

The first definition is the simplest to evaluate. Calculating scenario revenue requirements is a routine exercise in utility planning. However, this narrow definition of the portfolio ignores the fact that there are likely other things affecting customers' economic well-being that are correlated with the prices they pay for electricity. These other things include the prices they pay for other fuels, such as gasoline and natural gas. Variations in fuel costs that consumers pay for indirectly, such as increased air fares resulting from higher jet fuel prices, are also relevant. The second definition encompasses these.

Energy costs are only a fraction of the overall economy. Variations in fuel costs may be swamped by other fluctuations in the economy resulting from abnormal weather, shifts in international trade balances, business cycle effects, or other factors. The third definition takes the perspective of the regional economy. To the extent that fluctuations in electricity prices are correlated negatively with fluctuations in gross domestic product (GDP), electricity price portfolio effects could be substantial and the diversity premium for non-fuel resources large. If electricity prices are uncorrelated with fluctuations in GDP, then the diversity premium is likely smaller.

Determination of the Risk Aversion Coefficient. The risk aversion coefficient represents the trade-off between expected value and variance. The concept implies a decision maker, either individual or aggregate. The following three perspectives may imply different levels of risk aversion:

1. Utility executives

2. Customers

3. Utility shareholders

4. Society.

The perspective selected must be consistent with the definition of the portfolio. The greatest risk aversion is likely to be found from the personal perspective of utility executives. However, evaluation of any of the three definitions of the portfolio above is inconsistent with the utility executives' personal perspective. An aggregate customers' perspective could be consistent with any of the three portfolio definitions. A societal perspective, to the extent that it is different from an aggregate customers' perspective, could be consistent with either the energy system or economy definition of the portfolio.

Assessment of the Risk Aversion Coefficient. The following are two approaches for assessing the risk aversion coefficient:

1. Customer surveys

2. Analysis of security market prices.

Customer surveys could be conducted in a manner similar to value-of-service reliability surveys. ${ }^{33}$ Questions and results obtained from surveys of business decision makers are described by MacCrimmon and Wehrung (1986). Statistical analysis of security market prices has been used to derive risk aversion coefficients for models of capital markets. ${ }^{34}$ Either approach could yield valid results.

RCG/Hagler Bailly (1990).

34 Pindyck (1988). 
Risk-Adjusted Discount Rates. Risk-adjusted discount rates are sometimes used in capital budgeting for evaluation of competitive projects. Projects with different levels of risk are assigned different discount rates. $^{35}$ Determining the proper discount rates is an issue.

The most comprehensive approach to determining risk-adjusted discount rates is by use of a decision tree. The decision tree is constructed to include all of the critical uncertainties. The utility's cost of capital is used for the discount rate throughout the decision-tree analysis. The expected value calculated from the decision tree is compared with the result from a single-scenario, base case analysis. The discount rate for the base-case analysis is adjusted to yield the same result as the expected value from the decision-tree analysis.

The decision analysis approach and risk-adjusted discount rates have been shown to be equivalent. ${ }^{36}$ Therefore, a multi-scenario approach weighted by probabilities as in MABS can capture the issues addressed by risk-adjusted discount rates. The direct decision analysis approach has the advantage of avoiding the intermediate step of determining risk-adjusted discount rates.

\subsubsection{Summary}

The first step in analyzing diversity is to recognize and analyze uncertainty. If planning is performed without significant consideration of uncertainty, many of the benefits of renewables are missed.

Although utility planning models are increasingly designed to analyze uncertainty, many are not explicitly designed to consider the benefits of diversity. Standard production costing models can only consider diversity benefits by performing manual sensitivity runs with further analysis by the modeler. Decisiontree models and Monte Carlo models can provide the necessary runs, but often are not designed to perform the calculations necessary to arrive at the diversity benefits.

In addition, most utility modeling studies do not consider diversity. Uncertainty may be considered in the studies, but the diversity benefits of renewables are not often tabulated and evaluated. We conclude, therefore, that utility planning models and studies may be deficient if diversity provides a significant benefit to customers.

The benefits of diversity depend on the magnitude of the risks. Under current assumptions about stable future prices, however, diversity appears to provide little additional benefit to customers. If fuel price or availability becomes more of a concern, the potential diversity benefits from renewable technologies will become more valuable and more important for inclusion in the analysis.

\subsection{Conclusion}

Various techniques exist for modeling the attributes of renewable resources. However, the state of the art is such that significant effort on the part of the analysis is required to evaluate any of the five key attributes considered in this section. Judgment, approximation, and, in some cases, manual effort to run multiple scenarios are all required for an adequate analysis. Further, no one model addresses all five of these attributes simultaneously. Therefore, the following section outlines a framework for integrating the results of several models to perform a comprehensive evaluation of renewable resources.

Weston and Brigham (1981); Awerbuch (1993). 


\subsection{A Framework for Evaluating Renewable Resources Using Current Models}

Section 4 reviewed the state of the art in modeling several attributes of resource options that are particularly relevant to the comparison of renewable resources and other options. Models exist that can account for each of these attributes. However, there is no one model or modeling system that adequately addresses all of these attributes together. Instead, the models must be combined to account for all of the potential benefits of renewable resources.

This section describes a framework for incorporating a rigorous analysis of all the relevant attributes into the IRP process using existing models with their current capabilities. This framework is flexible in that any of several available models may be used for various functions. In many cases, a utility can incorporate the model it currently uses for a particular function rather than adopt a new model in implementing this framework. Different models are used for different functions. Results from the different models are then integrated using a probabilistic cost-effectiveness model, which is described below.

\subsection{Integrated Strategy}

The product of the framework is an integrated strategy consisting of the following:

- A list of options that are included in the strategy

- A "script" or set of criteria that specifies the conditions under which each option will be developed and when.

The scope of candidate options is broad and includes:

- Generation, both utility- and non-utility-owned

- DSM

- Transmission

- Distribution.

A strategy is distinguished from a plan in that a plan specifies the resources and the dates when these resources will be developed under a single scenario, whereas a strategy covers a range of scenarios. The script spells out how resource commitments will be adjusted to respond to future evolution of the planning assumptions.

Options are differentiated by location. For example, separate options may be defined for photovoltaics in each of several different local subareas. Defining separate options in this way facilitates:

- Accounting for differences in resource potential and hourly profiles between subareas

- Evaluating the cost effectiveness of options separately in different subareas, thereby accounting for differences in both the resource and marginal costs between subareas

- Constructing a resource strategy consisting of resource options in the subareas in which they provide the greatest net benefits. 


\subsection{Integrated Strategy Development Process}

Figure 5-1 presents a broad conceptual overview of the framework. The process starts by identifying and screening options. It then performs system studies for a set of scenarios and develops a trial integrated strategy. Finally, it iterates through a sequence of incremental analyses of individual options to refine the trial strategy and obtain the final integrated strategy.

The framework uses both system-level studies and incremental analyses. The system-level studies evaluate the performance of the overall system at various levels of penetration of the candidate resources. These studies capture whatever saturation effects might exist, that is, the extent to which the benefits of a particular category of resources depend on the relative share that option holds in the utility's resource mix. The incremental analyses determine the incremental benefits of individual options or discrete blocks of resources. The results indicate whether a particular option belongs in the integrated strategy.

Figure 5-2 presents a more detailed view of the framework. On the far left are four tasks for identifying and screening the options in the four categories. These tasks produce sets of options in each of the four categories for possible inclusion in the integrated strategy. The options in each category are screened to avoid wasting effort in subsequent tasks on options that are clearly inapplicable, unfeasible, or uneconomic. The options are fully characterized in terms of capability and availability, costs, and other attributes. All costs are estimated and any constraints are identified. The screening is followed by separate tasks for performing detailed studies in each of the four categories for several scenarios. Separate tasks are shown for the four categories because different models are used for each category and the work is most likely performed by separate departments within a utility. On the basis of these studies, financial analyses are performed and marginal costs are evaluated. Response surface models, which are relatively simple algebraic models that approximate the behavior of more detailed models, are developed to summarize the results of the detailed studies, financial analyses, and marginal cost calculations.

An iterative process is initiated by developing a trial integrated strategy. A probabilistic cost-effectiveness analysis is performed for each option in the context of the trial integrated strategy. All options, including options that are in the current trial strategy and those that are not, are ranked according to the results of the probabilistic cost-effectiveness analysis. If there are significant inconsistencies between the rankings and the trial strategy, then the trial strategy is modified. If not, the process has converged and the trial strategy becomes the final integrated strategy.

\subsection{Tasks in the Integrated Strategy Development Process}

This subsection provides a more detailed discussion of the tasks in the integrated strategy development process shown in Figure 5-2.

Screen Demand-Side Options. This task involves assessing DSM potential and constructing candidate DSM programs. The primary models for this task are end-use demand forecasting, DSM potential assessment, and DSM cost-effectiveness models. To properly account for the location impacts of DSM options, DSM potential and hourly demand impacts should be assessed on a local subarea basis.

Screen Supply-Side Options. The primary models for this task are resource models that estimate the potential for generation from specific technologies in various areas. Other tools such as screening curves and engineering cost estimation methods may be used. To properly account for location impacts, renewable resource potential and hourly generation profiles should be evaluated on a local subarea basis. 


\begin{tabular}{|c|c|c|c|c|}
\hline $\begin{array}{l}\text { Screen } \\
\text { Options }\end{array}$ & $\begin{array}{c}\text { Perform } \\
\text { Scenario } \\
\text { System Studies }\end{array}$ & $\begin{array}{c}\text { Develop Trial } \\
\text { Integrated } \\
\text { Strategy }\end{array}$ & $\begin{array}{l}\text { Perform } \\
\text { Iterative } \\
\text { Incremental } \\
\text { Analysis }\end{array}$ & $\begin{array}{c}\text { Final } \\
\text { Integrated } \\
\text { Strategy }\end{array}$ \\
\hline
\end{tabular}




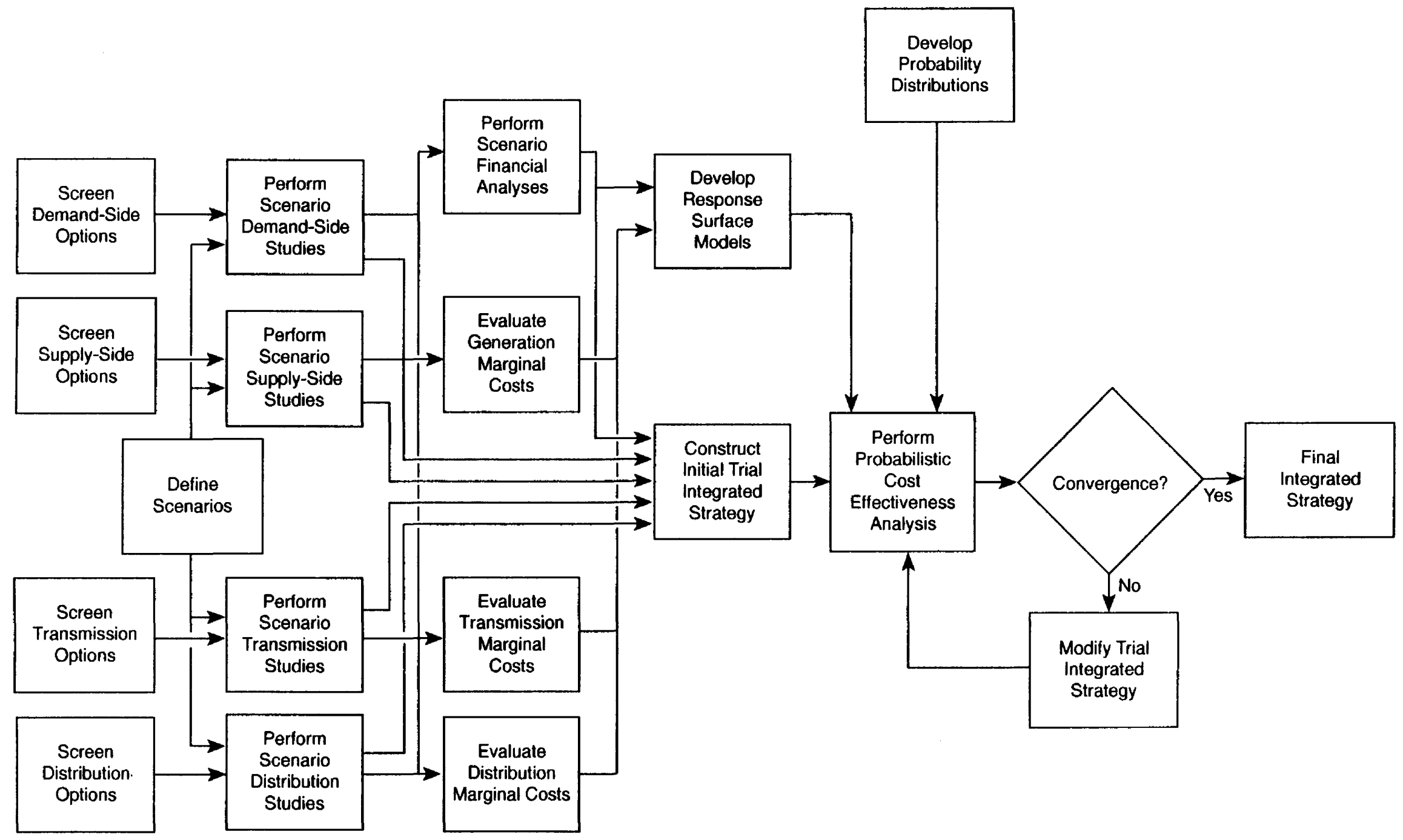


Screen Transmission Options. The set of candidate transmission projects is selected from a long list of candidate reinforcements identified in previous detailed studies.

Screen Distribution Options. As with transmission options, the set of candidate distribution projects is selected from a long list of previously identified options.

Define Scenarios. The result of this task is a set of scenarios representing the major uncertainties in the planning process. These major uncertainties usually include uncertainty in the demand forecast and general fuel price levels. They may also include uncertainties in the differential between the prices of different fuels and in the geographic distribution of demand growth, which may be particularly important for T\&D planning. Other key uncertainties may be the generation from particular resources such as hydro, and construction delays or cost overruns for major projects.

To maintain the feasibility of the process, it is important to minimize the number of scenarios defined at this point. At a later point in the process, it may be important for probabilistic analysis to have a larger number of scenarios. However, in this framework, the results for a larger number of scenarios are approximated using response surface models calibrated to a smaller number of scenarios. The smaller number of scenarios must be carefully selected to cover the uncertainties that have the most significant impact on the need for new resources or reinforcements and on the relative economics of various options.

Perform Scenario Demand-Side Studies. This task produces a DSM plan for each scenario, together with estimated costs. The DSM plan for a scenario is constructed by assembling the candidate demandside options that are cost effective on the basis of estimated marginal costs. The marginal costs are estimated from previous detailed studies. Marginal costs need not be particularly accurate at this stage. Rather, what is needed is an approximate level of DSM that will be economic in each scenario. This level will be deducted from pre-DSM demand to yield a level of net demand to be met by generation options. Feedback between DSM and generation will be incorporated later, in the iterative incremental analysis.

Perform Scenario Supply-Side Studies. This task yields a generation plan, evaluates generation reliability, and determines production costs for each scenario. The primary models for this task are detailed production simulation and generation reliability models. An expansion planning model also may be used in this task. However, it is not critical to have an optimal generation plan for each scenario at this point in the process; approximate plans are adequate. In fact, optimal resource plans may be unrealistic in some scenarios such as high or low demand. Scenario resource plans will eventually be merged into a trial integrated strategy, and the trial strategy will be optimized in the iterative incremental analysis.

There are two primary objectives for this task:

1. To test feasibility and develop intuitive understanding. The detailed production simulation and reliability analyses evaluate whether a given resource plan is actually feasible in a particular scenario. These analyses can identify situations in which there are unacceptable levels of unserved energy, or dump energy. Examination of capacity factors may identify resources that are underutilized or overutilized relative to a more optimal mix of resources. Examination of monthly or seasonal results may indicate that there are "problem" periods, which may or may not be helped by renewable resources or DSM options with their characteristic time profiles. It is hard to overstate the importance to the overall IRP process of the intuitive understanding gained in detailed analysis of multiple scenarios.

2. To establish a basis for the iterative incremental analysis process that will be used to develop the integrated strategy. The incremental analyses will use marginal costs and incremental financial 
measures that are derived in intermediate tasks from the production costs and reliability indices obtained in this task.

Perform Scenario Transmission Studies. This task produces a transmission plan for each scenario, together with costs. The primary models for this task are area demand forecasting and load flow models. Transient stability and transmission or composite reliability models might also be used here. The purposes of this task are to test feasibility and develop intuitive understanding and to establish a basis for subsequent incremental analyses.

This task may pose a significant analytical challenge. A high level of effort is required to develop a transmission plan for a single scenario using conventional transmission planning practices, hence the importance of keeping the set of scenarios small. However, it is important to consider multiple scenarios to address the impact of uncertainty on transmission needs. As with the scenario DSM and generation plans, it is not critical that the scenario transmission plans be optimal.

Perform Scenario Distribution Studies. This task produces a distribution plan for each scenario, together with costs. The purpose of this task is to establish a basis for subsequent incremental analysis. This task may go beyond the boundaries of traditional distribution planning in two ways:

1. Planning horizon. Traditional distribution planning typically has a shorter planning horizon than DSM, generation, or transmission planning. To evaluate all four categories of options on a consistent basis, the planning horizon of distribution planning must be extended.

2. Multiple scenarios. Traditional distribution planning considers only a base-case demand forecast for each local planning area. Some utilities may also consider a high-demand scenario. But to determine the impact of uncertainty on the need for distribution reinforcements, it is necessary to consider both high- and low-demand scenarios as well as base-case demand.

The primary models for this task are local area demand and feeder models.

Perform Scenario Financial Analyses. This task produces financial indices for the combined DSM, generation, transmission, and distribution plans constructed for each scenario. The objectives of this task are to test the financial feasibility of the combined plans and to develop intermediate results required for subsequent incremental analyses.

The primary model for this task is a financial/rates model. The key financial indicators to be obtained include:

- Electricity rates, both on a system average basis and by major customer class

- Interest coverage ratio.

Electricity rates are needed for several purposes:

- To check for substantial inconsistency with the rates assumptions used in creating the demand forecast

- To check whether any of the scenarios yield increases in rates that would be "unacceptable" in some way and might result in adverse regulatory action

- To provide a basis for evaluating lost revenues, if this component is to be included in the incremental analysis of DSM options. 
The interest coverage ratio is one indicator of the financial feasibility of a plan. Other indicators may also be examined.

Evaluate Marginal Generation Costs. This task produces marginal generation capacity and energy costs for each scenario. Marginal generation energy costs are calculated using a production simulation model.

Marginal generation capacity costs may be evaluated on the basis of either the incremental cost of capacity additions or the marginal economic benefit to customers of reducing unserved energy. The two approaches will yield the same result if the underlying resource plan is optimal. Most utilities use the incremental capacity cost approach, assuming that the resource plan is optimal. But the marginal unserved energy cost approach provides both a way to check the optimality of capacity additions and a way to determine marginal capacity costs when capacity additions are not optimal or when there are no capacity additions.

Both marginal generation capacity and energy costs are calculated using the results of model runs performed in the scenario supply-side studies, according to the utility's established practices. Some additional, but minor, post-processing may be required.

Evaluate Marginal Transmission Costs. This task produces marginal transmission capacity costs and losses for each scenario. These values are used in subsequent incremental analyses. Losses may be evaluated using an optimal power flow model. Marginal transmission capacity costs may be evaluated using either an optimal power flow model or the incremental savings of deferring the transmission plan in a scenario.

Evaluate Marginal Distribution Costs. This task produces marginal distribution capacity costs for each scenario. These values are used in subsequent incremental analyses. Marginal distribution capacity costs for a local area may be evaluated as the incremental savings of deferring the distribution plan for that area in a scenario. To properly account for location benefits, marginal T\&D costs must be evaluated on a local subarea basis, rather than on a system-wide average basis.

Develop Response Surface Models. This task produces a mechanism for adjusting the marginal costs to cover different scenarios and to account for changes in the integrated strategy as the iterative process proceeds. Here, response surface models are constructed to approximate the sensitivity of marginal generation capacity costs, marginal generation energy costs, marginal transmission capacity costs, and marginal distribution costs to changes in several independent variables. ${ }^{37}$ Two types of independent variables are included:

1. Planning uncertainties. The scenarios representing planning uncertainties are characterized by a small number of variables that capture the differences between the scenarios.

2. Plan capacity. The total capacity of the options in each category included in the integrated strategy for each scenario can be summarized by total capacity in various subcategories. Some of the scenarios for which detailed analysis was done will have different amounts of capacity in one or more of these subcategories.

The response surface models are constructed to approximate the sensitivity of marginal costs to all of the independent variables simultaneously. Inclusion of the independent variables for planning uncertainties enables the response surface models to be used to estimate marginal costs for any value or combination

37 Merrill and Schweppe (1984). 
of values of the planning uncertainties within the span of the scenarios for which detailed analysis was done. Inclusion of the independent variables for plan capacity enables the response surface models to be used to adjust marginal costs for changes in any of the options in the integrated strategy.

Response surface models also are constructed for rates if needed to calculate lost revenues and for total revenue requirements to capture portfolio effects.

An alternative to using response surface models is to re-evaluate marginal costs, rates, and revenue requirements using the detailed models at each pass through the iterative loop. However, this approach requires substantially more effort.

Construct Trial Integrated Strategy. The results of this task include an initial trial integrated strategy to begin the iterative process of developing the integrated strategy. The process for constructing the initial strategy is informal and heuristic rather than formal and algorithmic. It relies on simple rules of thumb, reserve margin targets, target resource mixes, and the like. The process is "informed" by the detailed analyses that have been performed up to this point, but there is not necessarily any formal connection. The objective of this task is to construct an initial strategy that is close to the final strategy to minimize the number of iterations required.

An important subtask is to define the generic structure of the script or the rules that trigger the construction of specific options. The simplest structure is based on the year-by-year values of demand. Either peak or energy demand can be used. The construction of an option is triggered when demand crosses over a specified threshold. The threshold is different for different options. The on-line date of an option is earlier in a scenario with more rapid demand growth because demand crosses over the threshold earlier. This approach is illustrated in Figure 5-3. A more complicated structure utilizes both peak and energy demand values, triggering base-loaded resources on the basis of energy demand and peaking resources on the basis of peak demand. Yet more complicated structures can be created by specifying different sets of thresholds for different fuel price regimes.

Once the generic structure is specified, the initial strategy is filled in. The initial strategy is constructed by considering several scenarios. These scenarios may be the same ones used for detailed analyses, a subset of those scenarios, or an entirely new set. For each scenario, a plan is created that includes options in all four categories and the dates at which they are to come on-line. The date at which construction must be triggered is obtained by working backward from the on-line date through the construction lead time. Given the various start-of-construction dates for a single option in different scenarios and the levels of the triggering variable, e.g., demand, at those dates, a threshold value is selected that is more or less consistent with these dates. Absolute consistency is not likely given the informality of the process to this point, but will be enforced in subsequent steps.

Develop Probability Distributions. The output of this task is probability distributions on each key planning uncertainty. Distributions can be constructed for other uncertainties such as costs or performance of specific options in addition to the uncertainties included as independent variables to the response surface models. In some cases, such as hydrological conditions, probability distributions can be constructed from historical data. In other cases, such as demand and fuel prices, probability distributions can be constructed simultaneously with the scenario specifications for detailed analysis. Direct assessment of expert judgment or Monte Carlo analysis can be used.

Perform Probabilistic Cost-Effectiveness Analysis. The result of this task is an incremental analysis of each candidate option in all four categories in order to rank the options. The incremental analysis uses the marginal generation, transmission, and distribution costs determined by detailed analyses to evaluate the incremental contribution to the current trial strategy. If an option is included in the current trial 


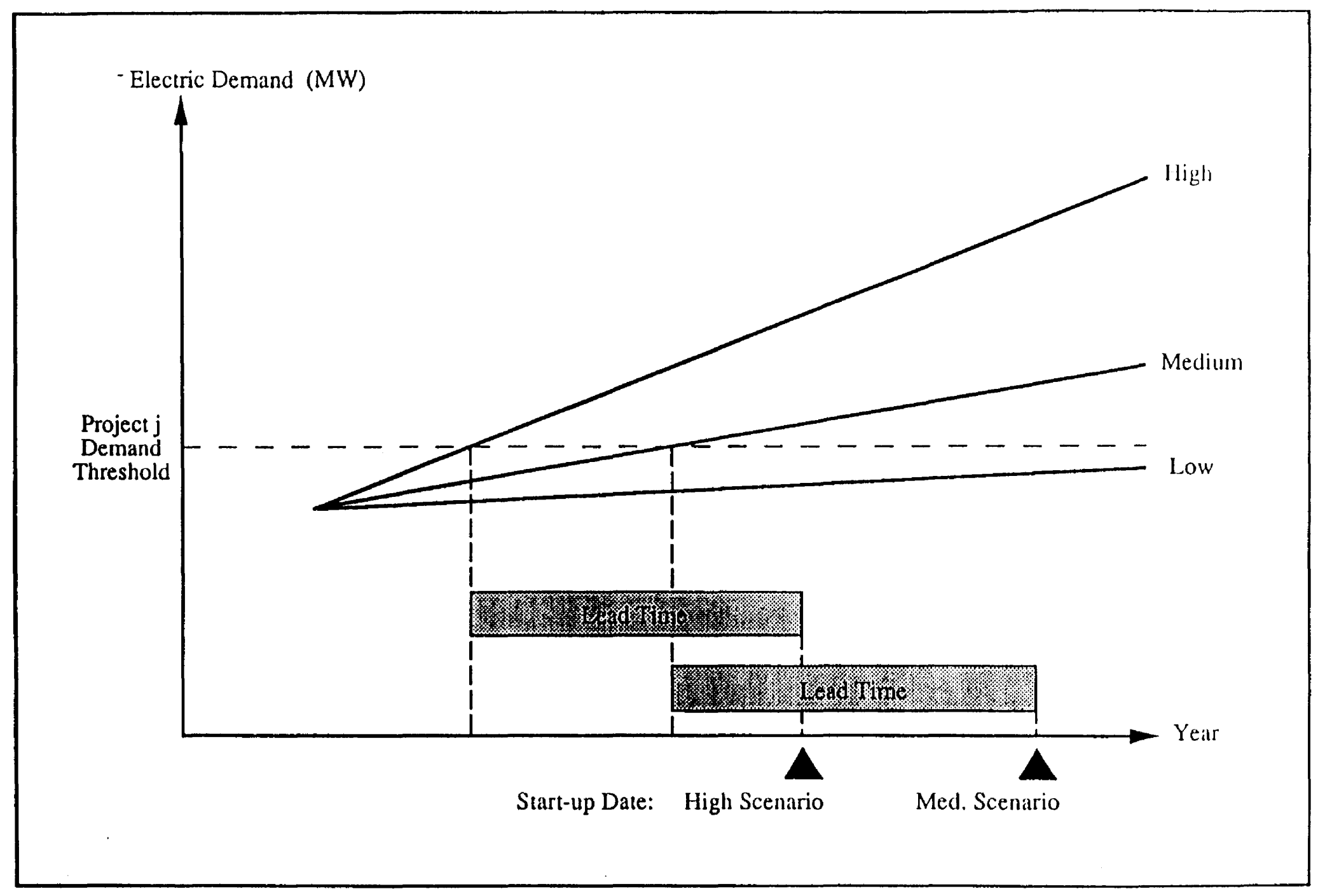


strategy, then the incremental analysis represents the amount by which total system costs would increase if that option were deleted from the strategy. If the option is not included in the current trial strategy, then the incremental analysis represents the amount by which total system costs would decrease if that option were added to the strategy. The results of probabilistic cost-effectiveness analysis indicate the direction in which the trial strategy should be modified in the iterative loop in Figure 5-2.

The primary model for this task is a probabilistic cost-effectiveness model such as MABS. Figure 5-4 illustrates the major components of such a model. The utility may create a custom spreadsheet model for this purpose or may use a probabilistic adaptation of another model such as the Delta model.

For each option, the incremental analysis is repeated for several scenarios representing the entire range of values and combinations of values of the planning uncertainties. The on-line date of an option is determined for each scenario on the basis of the script. If the option does not come on-line in a given scenario, then it does not provide any benefits. The net benefits for all scenarios are weighted by the probabilities to calculate expected net benefits. Also, the covariance between net benefits and total system costs is calculated to obtain the diversity premium.

The present value of net benefits in dollars may be normalized by lifetime capacity in kilowatt-years to obtain net benefits in dollars per kilowatt-year. The resulting value is used to rank the various options. Other ranking approaches could be used; the final integrated strategy will not substantially depend on the ranking approach, but the speed of convergence may depend on it.

Test Convergence. In this task, the results of the probabilistic cost-effectiveness analysis are compared with the current trial integrated strategy to determine whether the iterative process has converged. If all the options in the current strategy have positive net benefits, and if all the options that are not in the current strategy have negative or marginal net benefits, then the iterative process has converged. If there is an option in the current strategy that has negative net benefits, then the strategy can be improved by deleting it. If there is an option that is not in the current strategy that positive net benefits, then the strategy can potentially be improved by adding it.

There may be options that yield positive net benefits when evaluated against a trial strategy that does not include them, but negative net benefits when the current strategy includes them. These options are marginal. An argument could be made for excluding them from the integrated strategy. Further detailed analysis would be required before including them.

Modify Trial Integrated Strategy. This task produces a modified trial integrated strategy for evaluation in the next iteration. The trial strategy is modified according to the results of the probabilistic costeffectiveness analysis. If there are options that are not in the current trial strategy but would yield significant net benefits, they are added, starting with the ones with the highest value of net benefits per kilowatt-year. Likewise, options with significant negative net benefits are deleted. To minimize oscillation of the iterative process, a limit may be imposed on the maximum total capacity added or deleted in any one iteration.

Obtain Final Integrated Strategy. If the process has converged, then the current trial strategy becomes the final integrated strategy. This strategy minimizes expected total costs.

\subsection{Discussion}

The integration approach is applicable both to selecting the optimum combination of renewable resources and other options without set-asides and to selecting the renewable options that yield lowest total cost to meet a set-aside requirement. 


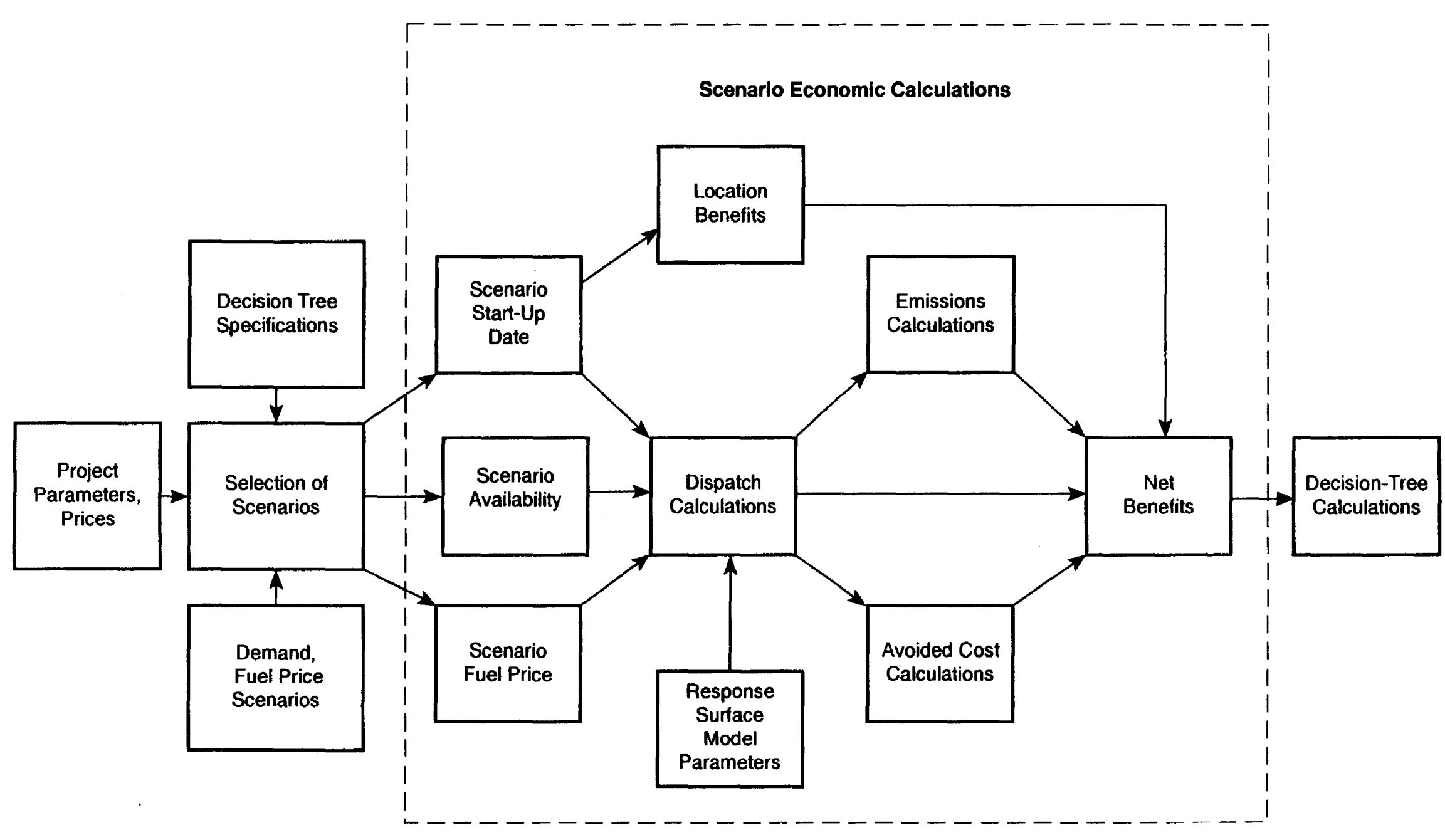


The integration approach is applicable to both large and small utilities. The level of effort required depends primarily on the amount of resource and location data to be developed, which is driven by the number of options and geographical areas considered. Smaller utilities will have fewer options and geographical areas to consider. Therefore, the level of effort required depends on the size of the utility, with a lesser level of effort required for smaller utilities.

\subsection{Summary}

The integrated strategy development process is a practical approach for incorporating a comprehensive analysis of renewable resources in IRP. It makes use of a utility's established models and planning practices to a large extent.

The approach uses both system studies to capture the cumulative effects of the penetration of various resource types into a utility's resource mix and incremental analyses to evaluate the incremental contribution of a specific option to the resource strategy. An iterative process with an embedded probabilistic cost-effectiveness analysis is used to optimize the integrated strategy.

The approach accounts for the key attributes of renewables, as described below.

Capability and Availability. The capability and availability of renewable and other resource options are fully accounted for in both the system studies and the incremental analyses. Care must be taken in conducting the detailed production simulations and reliability analyses to account for the intermittence and dependable profiles properly using the current capabilities of the models. The probabilistic costeffectiveness model must be constructed with sufficient temporal detail to capture the relevant time variations in the incremental analyses.

Location. The location benefits of various resources are captured by including marginal T\&D capacity costs in the calculation of net benefits in probabilistic cost-effectiveness analysis.

Modularity. Modularity is fully captured by using scenario-dependent, on-line dates in probabilistic costeffectiveness analysis, according to the script.

Diversity. Diversity benefits are fully accounted for in probabilistic cost-effectiveness by calculating the covariance between the net benefits from a project and total system costs.

Thus, the integrated strategy development process provides a comprehensive evaluation of the key attributes of renewable resources. 


\subsection{Conclusions}

The objective of IRP is to select a combination of utility investments to meet future demand for energy services at the lowest total cost within regulatory constraints. The types of investments to be considered include conventional generation options, renewable resources, and DSM options. Total costs include all utility costs that are passed on to the customer through rates and all other costs borne directly by the customer, such as conservation or renewable energy costs that are not covered by incentives paid by the utility. Total costs may include other societal costs as well. Comprehensive and consistent analysis of the various options, at an appropriate level of accuracy, is essential to obtain a resource plan that truly minimizes total costs. Otherwise, it is impossible to assure that the relative advantages and disadvantages of the options are weighed properly.

The introduction of renewable options into the planning process brings new issues and additional complexity. Utilities in some jurisdictions are including renewable resources in their resource plans on the basis of set-aside requirements mandated by their regulatory commissions. Set-asides are motivated in part by the perception that the full benefits of renewable resources are not adequately captured by current utility planning models and practices. The imposition of set-aside requirements short-circuits the utility planning process and whatever shortcomings it has that prevent it from properly accounting for the attributes of renewable resources. But this is only a short-term solution. In the future, finding the proper level of renewable resources will depend on developing planning methods that do capture these benefits.

This study reviews utility planning models with regard to their ability to account for the attributes of renewable resources. It makes recommendations about how utilities should use the current capabilities of models and about the direction of future work to advance the state of the art. The renewable resource attributes that currently present the greatest modeling challenges are:

- Capability

- Availability

- Location

- Modularity

- Risk diversity.

This study has focused on these five attributes, on their potential impacts on total costs, and on how they are modeled. In assessing the current state of the art, we looked at eleven models that meet one or more of the following criteria:

1. They are widely used by utilities.

2. They are generally available.

3. They are advanced in their treatment of these key attributes.

Section 6.1 summarizes our findings with regard to these key attributes. Section 6.2 describes a process for integrating the results of multiple models to perform a comprehensive analysis of renewable resource options in IRP. Section 6.3 contains our recommendations for future work in advancing the state of the art in modeling.

\subsection{Current Modeling Capabilities}

The attributes of renewable resource options need to be accounted for in both systemwide and incremental analyses. The aggregate effect of all of the renewable resources in the plan on the output and operating costs of other generation must be accounted for in systemwide analyses, while the incremental effect of 
a renewable resource project on system reliability and costs needs to be accounted for in incremental analyses of individual projects. Incremental analysis provides the basis for accepting or rejecting individual options in the resource plan, while systemwide analysis is a key component of revenue requirements and financial forecasting and provides the baseline for incremental analysis. Table 6-1, at the end of Section 6.3, summarizes our findings regarding the capabilities of the twelve models reviewed to accommodate the key attributes of renewable resources for both systemwide and incremental analyses.

Capability and Availability. Some renewable resources, such as geothermal and biomass, are quite like conventional options in their operation and effect on the rest of the system. But the capability and availability of other renewable options such as wind and solar are subject to both predictable variations and intermittence of the underlying energy source. The time-dependent nature of these resources must be properly accounted for in production simulation to capture their effect on the dispatch of other system generation and on overall production costs. These costs determine the direct value of renewable resource options and other options on the system.

Time-dependent resources can be modeled either as generation units or as load modifiers. When generation unit modeling is used in a load duration curve model, only a very limited level of detail is available for representing the predictable profile. This may be adequate for resources whose output is maximum during the hours of peak demand; otherwise, it is inadequate. Greater hourly detail may be possible with a chronological model. When resources are modeled as load modifiers, hourly profiles can be specified that account for both the predictable and random components.

Although none of the models that were examined here allow a user to easily represent the uncertainty associated with renewable power generation, the most complete treatment of capability and dispatchability is provided by EGEAS. The orthogonalization process in EGEAS permits a user to define an hour-byhour profile of energy delivery and associate a single forced outage rate with that profile. Unfortunately, the uncertainty in the peak hours is more critical than in other hours, and the best modeling approach may be simply to develop multiple profiles that reflect different assumptions about the timing of renewable generation and the degree of correlation with the system peak. These profiles would then serve as the basis of multiple scenarios that ultimately could be combined into expected results. Such a brute force method also would allow a planner to model the degree of correlation between separate renewable projects if the sites are affected by the same general weather patterns.

Other aspects of the capability and availability attributes include short-term fluctuation and multiplicity. Most planning models do not simulate short enough time periods to capture the issues or costs resulting from short-term fluctuation. However, short-term fluctuation of renewable generation is not likely to pose much of a problem for any utility unless resources with this characteristic become a significant portion of the utility's generating mix.

Multiplicity refers to the fact that many small power sources are likely to constitute a renewable project. Although multiplicity can result in greater generation reliability when only independent equipment-related outages are considered, it provides no such advantage when there is significant weather-related correlation of output from renewable resources at the same site.

Both the predictable and random components can be fully accounted for in incremental analysis of individual projects. The spreadsheet or other model used for incremental analysis should incorporate sufficient temporal detail to capture significant differences in seasonal or hourly profiles between the options under consideration. If there is significant correlation between separate options and if the aggregate number of these options is sufficient to cause non-negligible variation in system marginal costs, then it is important to account for this correlation. It can be accounted for by incorporating scenarios 
representing variation in the aggregate amount and making the output of the candidate option dependent on these scenarios.

In many cases, it is adequate to use the hourly expected output of an option for a set of representative days to account for uncertainty in the output. But the conservative approach of derating the output to zero or any value less than the expected output will generally result in ignoring a major portion of the benefits of the option.

Location. The location of resources can affect total costs in several ways. First, location determines whether any additional costs are required for interconnecting the resource to the system. Second, location determines the impact of a resource on total system losses. Third, distributed applications of renewable and other resources can defer $T \& D$ reinforcements and thereby decrease overall $T \& D$ costs. This effect must be accounted for in a full cost-benefit analysis. The most complete treatment of location is provided by the Delta model, which includes both marginal transmission and distribution capacity costs in evaluating the cost-effectiveness of options. These marginal costs are differentiated by time and location at the level of detail required to properly account for the location benefits provided by various resource options. MABS includes marginal transmission capacity costs, but not marginal distribution capacity costs. Therefore, MABS cannot capture any distribution benefits. Other models can account for transmission constraints in generation dispatch, and most models can account for losses.

Incorporation of location benefits requires marginal costs for T\&D differentiated by time and location. Established methods for determining marginal costs for T\&D on the basis of systemwide averages are not adequate. Emerging methods for determining marginal costs for $T \& D$ require the development of longterm $T \& D$ plans. This may require extension of the planning horizon for distribution, and perhaps transmission as well, at many utilities.

Modularity. The modularity of some renewable options, characterized by small size and short lead time relative to particular conventional options, provides advantages in tracking load growth and managing demand uncertainty. Modularity can help reduce total system costs in several ways, including reducing the amount of over-capacity that results when large resources are added, reducing the risk that a resource committed in advance of the need date will actually turn out not to be needed, and reducing AFUDC costs.

The economic benefits of modularity can be quantified using a multi-scenario analysis that captures differences in the way a utility adjusts its resource commitments over time in response to changes from the base-case demand forecast.

The most complete treatment of modularity is provided by the ISAAC model. The ISAAC model is explicitly designed to include the benefits of short lead times and can also handle multiple, small units. Most utility expansion analyses use what amounts to a deterministic forecast of the future, which will not provide any benefits to short-lead-time options. In ISAAC, short-lead-time benefits are examined in multiple expansion scenarios under a Monte Carlo growth framework. Lead times are also separated into pre-construction (permitting, licensing, and engineering) and construction times to more explicitly consider the two activities.

Diversity. Renewable options can diversify a utility's portfolio of energy sources. Diversification results in a narrower bandwidth of uncertainty in total system costs. An option provides diversification benefits if it is independent of the risks that are inherent in other types of resources that represent a large share of the total system cost. For example, diversification benefits can be provided to a system that has a large share of oil- or gas-fired generation by any option that does not burn oil or gas. Diversification benefits 
can also be provided by an option with zero fuel cost, whose risk is entirely related to capital and non-fuel operating costs.

An option's diversification benefits can be quantified using a combination of portfolio analysis and energy reliability analysis. Several of the models provide a partial analysis of diversity. Any of the production simulation models can be used to evaluate total production costs for a number of fuel price scenarios, which then can be weighted by scenario probabilities to calculate the expected value and variance of total production costs. Models that combine multiple scenario production simulation and probabilistic calculations, such as MIDAS and ISAAC, can do this automatically. The benefits of diversity can be determined by comparing the expected value and variance of total costs for alternative plans.

MABS is the only model that evaluates the diversity benefits of an individual resource option directly. But this capability could easily be added to any model that does an incremental analysis, such as Delta.

Some of these five attributes are relevant to options other than renewable resources. For example, location is important for conventional options as well as renewable options. DSM and smaller conventional generation options such as CTs and gen sets can be installed to provide location benefits similar to renewable DU options. T\&D costs should be accounted for in selecting large, medium, and small conventional options. Proper modeling of location benefits is important in evaluating all of these options.

Modularity benefits also can be provided by conventional options such as CTs and even CCs or cogeneration units for which pre-construction work is separated from construction work and is performed prior to a final decision on the project. In this way, the lead time between the final decision to go ahead with the project and its start-up date can be minimized. Proper modeling of modularity benefits is important in evaluating these conventional options relative to other conventional options that are larger or have longer lead times.

Diversity benefits may also be provided by some conventional options. For example, although coal is a fossil fuel, its fuel price is not subject to the same degree of volatility as oil and gas. Therefore, a candidate coal-fired unit can provide fuel diversity benefits to a system that is dominated by oil- or gasfired generation. Proper modeling of diversity benefits is important in evaluating the relative cost stability of non-oil, non-gas resources.

\subsection{Model Integration}

As summarized in Section 6.1, various methods have been implemented for incorporating the key attributes in different models. However, no one model completely addresses all of the key attributes simultaneously. In order to do a comprehensive evaluation of all the key attributes, it is necessary to use a combination of models.

A process for incorporating renewables in IRP using a combination of models was described in Section 5. This process uses a marginal approach to perform an incremental analysis of each of the candidate options. Marginal analysis accounting for all of the most important uncertainties is performed using a probabilistic cost-effectiveness model. The probabilistic cost-effectiveness model uses marginal costs derived using detailed models.

Using this approach, the capability and availability of renewable and other resource options are accounted for in both the systemwide and incremental analyses. The location benefits of various resources are captured by including marginal T\&D capacity costs in the calculation of net benefits in probabilistic costeffectiveness analysis. Modularity is captured by the use of scenario-dependent start-up dates. Diversity 
benefits are accounted for by calculating the covariance between the net benefits from a project and total system costs.

The integration approach is applicable both to selecting the optimum combination of renewable resources and other options without set-asides and to selecting the renewable options that yield lowest total cost to meet a set-aside requirement.

\subsection{Recommendations for Methodology Development}

This section presents our recommendations for high-priority work to enhance the capability of utilities to perform comprehensive evaluations of the benefits of renewable resources as part of their IRP processes. These recommendations are categorized by data requirements, uncertainty, DU planning, case studies, and workshops.

\subsubsection{Data Requirements}

A key requirement for incorporating renewable resources into IRP is data. Data are required on renewable resource potential and profiles, T\&D plans and costs, and subarea demand profiles. The following recommendations regard reducing the level of effort required to develop these data.

1. Develop simplified procedures to construct capacity and availability data for time-dependent resources in a way that takes full advantage of the current capabilities of models and adequately captures both the predictable and random components of these resources.

2. Develop guidelines for utilities to determine the appropriate level of effort for refining capacity and availability input data. These guidelines would indicate when further efforts are or are not cost-effective, based on value of information concepts.

\subsubsection{Uncertainty}

Uncertainty underlies three of the key attributes - availability, modularity, and risk diversity. Therefore, incorporating uncertainty into the analysis is critical for a complete evaluation of the costs and benefits of renewable resources. However, incorporating uncertainty into IRP is currently one of the greatest challenges for practitioners. The following recommendations regard enhancements for both extending and simplifying uncertainty analysis of renewable resources.

3. Add multiple-scenario capability or enhance existing multiple-scenario capabilities of production simulation models to include a start-up date decision rule for scenario-dependent start-up dates. This will enable these models to calculate modularity benefits.

4. Extend Delta to perform multiple-scenario analysis with the following features:

a. Response surface models for marginal costs, for both multiple scenarios and "dynamic" marginal costs

b. Start-up date decision rule for scenario-dependent start-up dates

c. Probability calculations to obtain expected values and variances

d. Calculation of the diversity premium. 
This will enable Delta to evaluate the effect of uncertainty on net benefits and to calculate modularity and diversity benefits. Although the incremental approach underlying Delta already enables it to evaluate even the smallest options, incorporation of uncertainty into the model is necessary to evaluate modularity and diversity benefits under uncertainty. The objective is not to transform Delta into a general purpose model that includes production simulation and other detailed modeling capabilities, but rather to make Delta a model that can integrate the results of other models.

\subsubsection{Distributed Utility Planning}

The location benefits of renewable resources can be evaluated using the methods of DU planning. The following recommendations regard enhancements to DU planning methodology. Recommendation (4) under uncertainty is also relevant here.

5. Develop simplified approaches to construct transmission and distribution plans. This will enable utilities to consider a larger number of local planning subareas and evaluate multiple scenarios to account for the effect of uncertainty on $T \& D$ investments.

6. Investigate the application of value-based approaches to distribution planning. This will enable distribution plans to achieve an economically optimal level of reliability and ensure that the marginal distribution capacity costs derived from the distribution plans provide economically efficient signals.

\subsubsection{Case Studies}

Broader application of methodological innovations is stimulated by the dissemination of utility case studies that can be studied and followed by other utilities. The following recommendations regard case studies to demonstrate the concepts and techniques described in this report.

7. Conduct utility case studies to demonstrate and refine the framework for combining the results of existing models, outlined in Section 5.

8. Perform case studies evaluating the relative importance of various attributes and examining improved approaches for considering renewable resources using standard utility planning models of two general types, single scenario models and models with decision analysis capabilities. The studies would examine alternative means of considering the benefits of modularity (short lead time) and diversity. The approaches developed in these studies could then be disseminated to utilities for inclusion in their planning studies. These case studies should cover various types of renewables and applications.

\subsubsection{Workshops}

Workshops are an effective means for promoting planning models and practices throughout the industry.

9. Conduct a workshop on utility planning for renewables. Invite utilities of all sizes and levels of sophistication. Include problems, issues, solutions, and industry needs in the workshop agenda. Publish a volume of workshop proceedings.

10. Organize an on-going forum of leading IRP practitioners from utilities, government, consulting, and universities to meet periodically and discuss theoretical and practical issues in IRP, particularly with regard to renewable resources. 


\begin{tabular}{|c|c|c|}
\hline Model & Capability and Availability & Location \\
\hline Delta & Monthly and hourly profile of capacity. Forced outage rate. & Full hourly load and marginal T\&D cost detail. \\
\hline DYNAMICS & Hourly profile of capacity. & None. \\
\hline $\begin{array}{l}\text { EGEAS/IRP } \\
\text { Workstation }\end{array}$ & $\begin{array}{l}\text { Explicit probability distribution combination of load and load modifier } \\
\text { nondispatchable resource using orthogonalization algorithm. Then } \\
\text { LDC model for up to } 39 \text { segments. Chronological model } \\
\text { forthcoming. }\end{array}$ & Version 7 includes subarea impacts. \\
\hline Elfin & $\begin{array}{l}\text { Chronological pre-processing of loads and load modifier units, then } \\
\text { LDC model with up to } 8 \text { segments. Can model renewables as } \\
\text { supply-side load modifier or generating unit. }\end{array}$ & $\begin{array}{l}\text { None explicitly, though losses related to location can be } \\
\text { included. }\end{array}$ \\
\hline IRP-Manager & $\begin{array}{l}\text { Chronologic dispatch and load modification. Renewables can } \\
\text { alternatively be modeled as generating units. }\end{array}$ & $\begin{array}{l}\text { None explicitly, though losses related to location can be } \\
\text { included. }\end{array}$ \\
\hline ISAAC & $\begin{array}{l}\text { Somewhat simplified production costing, energy only. Renewables } \\
\text { typically modeled as generating units. }\end{array}$ & $\begin{array}{l}\text { None explicitly, though losses related to location can be } \\
\text { included. }\end{array}$ \\
\hline MABS & Monthly and hourly profile of capacity. Forced outage rate. & Annual marginal transmission costs No distribution level \\
\hline MIDAS & $\begin{array}{l}\text { Somewhat simplified production costing. Renewables can be } \\
\text { modeled as load modifiers or as generating units. }\end{array}$ & $\begin{array}{l}\text { None explicitly, though losses related to location can be } \\
\text { included. }\end{array}$ \\
\hline PROMOD III & Monthly and hourly profile of capacity. Forced outage rate. & Multi-area capability captures transmission constraints. \\
\hline $\begin{array}{l}\text { PROSCREEN II/ } \\
\text { PROVIEW }\end{array}$ & Seasonal and hourly profile of capacity. Forced outage rates. & None. \\
\hline UPLAN III & $\begin{array}{l}\text { Chronological modeling using typical weeks. Renewables can be } \\
\text { included as load modifiers or as generating units. }\end{array}$ & $\begin{array}{l}\text { None explicitly, though losses related to location can be } \\
\text { included. }\end{array}$ \\
\hline
\end{tabular}




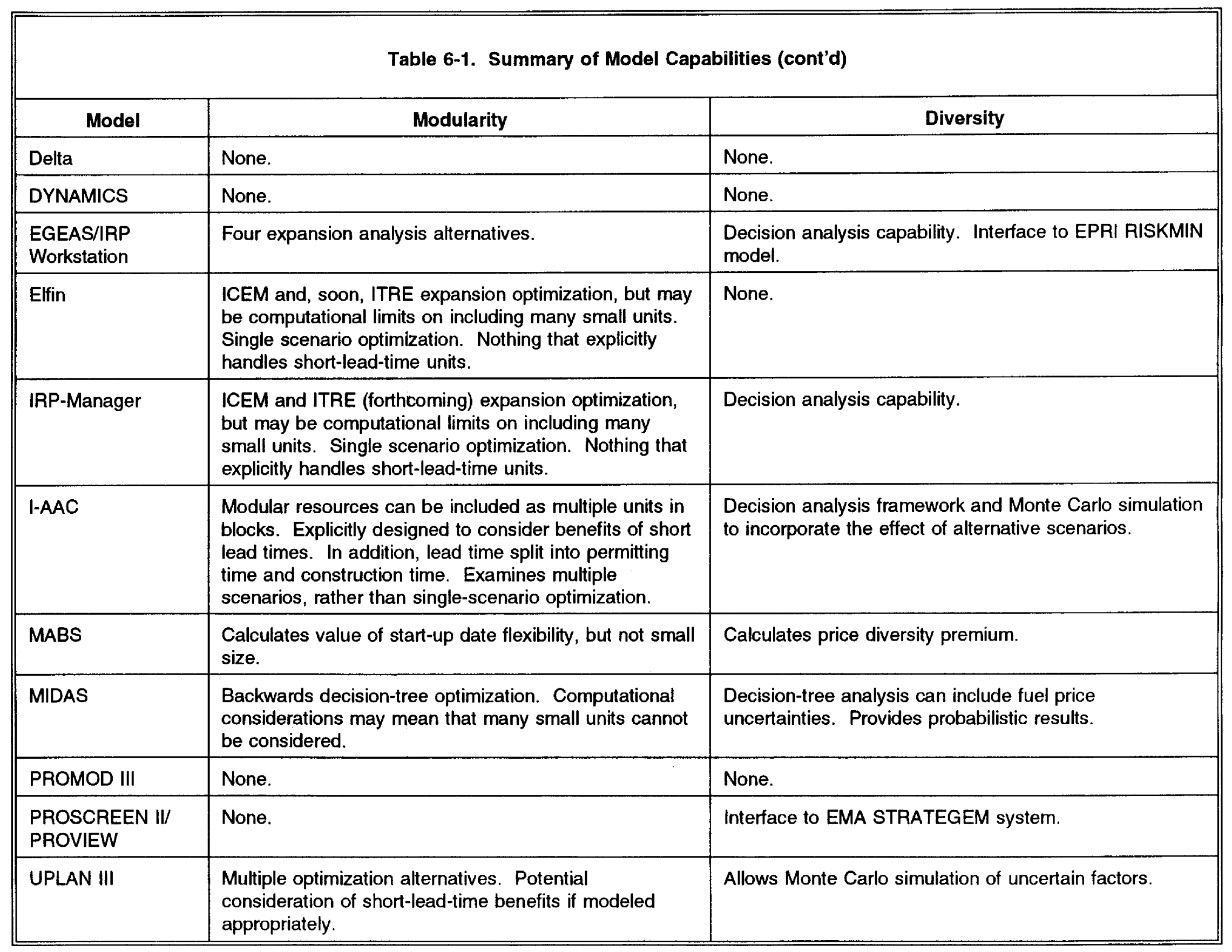




\subsection{References}

American Public Power Association. "Utility Resource Planning Software: A Compendium." Washington, DC: American Public Power Association, c. 1992.

Applied Decision Analysis, Inc. and Charles River Associates Inc. "Evaluating the Effects of Time and Risk on Investment Choices: A Comparison of Finance Theory and Decision Analysis." EPRI P-5028. Palo AIto, CA: EPRI, January 1987.

Awerbuch, Shimon. "The Surprising Role of Risk in Utility Integrated Resource Planning." Electricity Journal, Vol. 6, No. 3, April 1993, pp. 20-33.

Barakat \& Chamberlin, Inc. "'Best Current Practices' in Integrating DSM Into T\&D Planning. Proceedings From the Second Annual Workshop." EPRI TR-102955. Palo Alto, CA: EPRI, December 1993.

Belostotsky, Albert, Joel Klein, Pat McAuliffe, and Angela Tanghetti. Evaluation of Alternative Capacity Expansion Planning Methodologies, Phase III-Final Report, California Energy Commission, June 29, 1993, pp. 6-10.

Billinton, R., J. Satish, and J. Aweya. "Reliability Worth Evaluation in Electric Power Distribution Systems." The Third International Symposium on Electricity Distribution and Energy Management, Singapore, October 1993.

Bose, Anjan, and Paul M. Anderson. "Impact of New Energy Technologies on Generation Scheduling." IEEE Transactions on Power Apparatus and Systems, Vol. PAS-103, No. 1, January 1984, pp. 66-71.

Caramanis, Michael. "Analysis of Non-Dispatchable Options in the Generation Expansion Plan." IEEE Transactions on Power Apparatus and Systems, Vol. PAS-102, No. 7, July 1983, pp. 2098-2103.

Caramanis, Michael C., Richard D. Tabors, and Kumar S. Nochur. "The Introduction of Non-Dispatchable Technologies as Decision Variables in Long-Term Generation Expansion Models." IEEE Transactions on Power Apparatus and Systems, Vol. PAS-101, No. 8, August 1982, pp. 2658-2667.

Decision Focus, Inc. "Cost and Benefits of Over/Under Capacity in Electric Power System Planning." EPRI EA-927. Palo Alto, CA: EPRI, October 1978.

Decision Focus, Inc. "Load Management Strategy Testing Model." EPRI EA-2396. Palo Alto, CA: EPRI, May 1982.

Electric Power Research Institute. "TAG. Technical Assessment Guide. Volume 1: Electricity Supply-1989 (Revision 6)." EPRI P-6587-L, Volume 1, Revision 6. Palo Alto, CA: EPRI, November 1989.

Electric Power Software. "LMSTM Reference Guide." Minneapolis: Electric Power Software, Inc., February 1991.

El-Gassier, Mohamed, Allen Jones, Ren Orans, Daniel Shugar, and Alexandra Suchard. "Benefits of Distributed Generation in PG\&E's T\&D System: A Case Study of Photovoltaics Serving Kerman Substation." San Ramon, CA: Pacific Gas and Electric Company, August 1991. 
Energy and Environmental Economics and Pacific Gas and Electric Company. "Targeting DSM for Transmission and Distribution Benefits: A Case Study of PG\&E's Delta District." EPRI TR-100487. Palo Alto, CA: EPRI, May 1992.

Hamrin, Jan, and Nancy Rader. "Investing in the Future: A Regulator's Guide to Renewables." ORNL/Sub/95-X-SH985C. Washington, DC: National Association of Regulatory Utility Commissioners, February 1993.

Hirst, Eric. "A Good Integrated Resource Plan: Guidelines for Electric Utilities and Regulators." ORNL/CON-354. Oak Ridge, TN: Oak Ridge National Laboratory, December 1992.

Hobbs, Benjamin F., and Pravin Maheshwari. "A Decision Analysis of the Effect of Uncertainty upon Electric Utility Planning, Energy, Vol. 15, No. 9, 1990, pp. 785-801.

Jacobs, Jonathan M., and Thomas E. Huntley. "Valuation of Fuel Diversity." Testimony in California Energy Commission 1992 Electricity Report Proceeding, Docket No. 90-ER-92, prepared January 27, 1992.

Lamarre, Leslie. "The Vision of Distributed Generation." EPRI Journal, April/May 1993, pp. 6-17.

Logan, Douglas M. "Decision Analysis in Engineering-Economic Modeling." Energy, The International Journal, Vol. 15, No. 7-8, July-August 1990, pp. 677-696.

Ma, Fred S., and Leif Isaksen. "Impact of Dispersed Supply Management on Electric Distribution Planning and Operations." IEEE Transactions on Power Apparatus and Systems, Vol. PAS-98, No. 5, September-October 1979, pp. 1531-1539.

MacCrimmon, Kenneth R., and Donald A. Wehrung. Taking Risks. The Management of Uncertainty. New York: Free Press, 1986.

Marbek Resources Consultants Ltd. and Energy Systems Research Group/Tellus Institute. "Assessment of Existing DSM Models and Their Use and Applicability in Canadian Utilities." 819 U 706. Montreal, PQ: Canadian Electrical Association, October 1990.

Merrill, H.M., and F.C. Schweppe. "Strategic Planning for Electric Utilities: Problems and Analytic Methods." Interfaces, Vol. 14, No. 1, January-February 1984, pp. 72-83.

Milligan, Michael R., and Alan H. Miller. "The Value of Windpower: An Investigation Using a Qualified Production Cost Model." WindPower '93 Conference, San Francisco, CA, July 1993.

New England Electric System. "NEESPLAN 4." Westborough, MA: New England Electric System, November 1993.

Northwest Power Planning Council. "1991 Northwest Conservation and Electric Power Plan. Volumes I and II." 91-04 and 91-05. Portland, OR: Northwest Power Planning Council, April 1991.

Peña, Anna Karina. "PG\&E's Investigation of an Alternative to ICEM as a Resource Planning Method." Testimony in California Energy Commission 1992 Electricity Report Proceeding, Docket No. 90-ER-92, prepared January 27, 1992. 
Pindyck, Robert S. "Risk Aversion and Determinants of Stock Market Behavior." Review of Economics and Statistics, Vol. 70, No. 2, May 1988, pp. 183-190.

Quantitative Solutions. "Distributed Utility Valuation Project Monograph." EPRI TR-102807. Palo Alto, CA: EPRI, August 1993.

RCG/Hagler Bailly. "Cost-Benefit Analysis of Power System Reliability: Determination of Interruption Costs - Volume 1: Measurement Methods and Potential Applications in Reliability Cost-Benefit Analysis." Palo Alto, CA: EPRI, April 1990.

RCG/Hagler Bailly. "Value-Based Transmission Resource Analysis." EPRI TR-103587, Volumes I and II. Palo Alto, CA: EPRI, February 1994.

Shirmohammadi, Dariush, and Chifong L. Thomas. "Valuation of the Transmission Impact in a Resource Bidding Process." Paper No. 90WM252-7 PWRS. IEEE 1990 Winter Power Meeting.

Staschus, Konstantin, James Davidson, George Gross, Douglas Logan, Stella Perone, Dariush Shirmohammadi, and Alireza Vojdani. "A Multi-Attribute Evaluation Framework for Electric Resource Acquisition in California." Electric Power \& Energy Systems, Vol. 13, No. 2, April 1991, pp. 73-80.

Stone \& Webster Engineering Corp. "Electric Generation Expansion Analysis System. Volume 1: Solution Techniques, Computing Methods, and Results; Volume 2: Details of Solution Techniques, Data of Test Systems, and Glossary of Terms; Volume 3: Computer Program User's Manual; Volume 4: Programmer's Manual; Volume 5: Validation Manuar; Volume 6: Installation." EPRI EL-2561, Volumes 1-6. Palo Alto, CA: EPRI, August 1982-March 1984.

Temple, Barker \& Sloane, Inc. "Project Risk Analysis: A Case Study of Plant Life Extension." EPRI P-5087. Palo Alto, CA: EPRI, March 1987.

Temple, Barker \& Sloan, Inc. and M.S. Gerber \& Associates, Inc. "Multiobjective Integrated Decision Analysis System (MIDAS). Volumes 1 and 2." EPRI P-5402s-CCM, Volumes 1 and 2. Palo Alto, CA: EPRI, 1988.

Wan, Yih-huei, and Brian K. Parsons. "Factors Relevant to Utility Integration of Intermittent Renewable Technologies." NREL/TP-463-4953. Golden, CO: NREL, August 1993.

Western Area Power Administrtaion. "Western RPG Development Process Reviews 47 IRP Computer Software Models." Customer C\&RE Management Updated, 1992.

Weston, J. Fred, and Eugene F. Brigham. Managerial Finance. 7th ed. Hinsdale, IL: Dryden Press, 1981.

Yamayee, Zia A. "Modeling Intermittent Generation (IG) in a Monte-Carlo Regional System Analysis Model." IEEE Transactions on Power Apparatus and Systems, Vol. PAS-103, No. 1, January 1984, pp. 174-181. 


\section{Appendix A: Selection of Models for Review}

This appendix describes how the project team selected the models to review. These models are listed in Table 1-1.

First, we identified and contrasted the resource attributes associated with conventional supply-side resources, renewable energy technologies, and demand-side management options. These attributes are listed in Table 2-1 along with the types of models in which these attributes play a direct and significant role.

The twelve models were selected from among 110 planning models. The complete list of models was developed by examining results from several general model reviews and by drawing on the industry knowledge of both NREL and RCG/Hagler Bailly project participants. The following primary model reviews were used:

- American Public Power Association, Utility Resource Planning Software: A Compendium, 1992.

- Marbek Resources Consultants, Assessment of Existing DSM Models and Their Use and Applicability in Canadian Utilities, 1990.

- Western Area Power Administration, Model Review, 1991.

The process of selecting the short list involved the following:

- Determining which of the attributes in Table 2-1 currently present the greatest technical challenges for the appropriate comparison of renewable, conventional, and DSM options

- Determining the key model types associated with these attributes

- Segmenting the compiled list of models into these key model types

- Selecting one or more models from each of these segmented categories that are available, used by utilities, or judged to be among the most advanced models within the category.

In consultation with NREL, the project team identified five of the ten attributes displayed in Table 2-1 as presenting the greatest technical challenges for utility modeling:

- Capability-predictable profiles

- Availability-intermittence and availability diversity

- Location

- Modularity

- Diversity.

The other five attributes (efficiency, dispatchability, incentives, risks, and external costs) were deemed to be suitably addressed in current utility modeling methodolugies or were covered in several of the selected attributes. ${ }^{1}$

'For example, the attribute category of risk in Table 2-1 was associated with start-up delays and premature shutdowns. These risks can be suitably evaluated with existing utlity models; however, the risks associated with project capabilities, availabilities, and costs will be addressed within each of those selected attribute categories. 
An issue of particular interest related to capability and availability is the effect of renewables on the commitment and dispatch of other resources and the modeling of this relationship.

The project team identified 19 different types of modeling capabilities that could be used to categorize the models. Those 19 capabilities are defined in Table 3-1. The relationship between attributes and mode! types is displayed in Table 3-2.

After reviewing Table 3-2, the project team concluded that the five selected key attributes play a direct and significant role in the following six key model types:

- Project economic analysis

- Resource planning

- Production simulation

- Generation reliability

- Location benefits

- Uncertainty analysis.

Several of the key attributes also play a role in bulk power market models. However, the function of these models is to forecast bulk power market prices and quantities rather than to evaluate renewable options. Renewable resources play a role only to the extent that their aggregate quantity is sufficient to influence bulk power markets. However, this is not likely to be substantial (except in the case of hydro in some regions), given the overwhelming quantity of existing resources relative to even high penetrations of renewables into the mix of resource additions over typical utility planning horizons.

A number of other model types are also identified with the location attribute in Table 3-2. However, the relevant issues for renewables are captured in location benefits models.

In several cases, there were a number of similar models that were equally qualified for inclusion on the short list. However, because of these models' similarity, there was no additional benefit to including all of them on the short list. Therefore, the project team has selected representative models from these groups of similar models. 


\section{Appendix B: Technical Analysis of Risk Preference Functions}

The application of portfolio concepts to diversity in electric resource planning starts with the concept of risk preference from decision analysis. A decision maker's attitude toward risk is modeled by a risk preference function, which expresses the relative value of different values of monetary outcomes. Figure B-1 is a risk preference function representing a hypothetical customer's attitude toward various levels of his annual electricity bill. The horizontal axis is the dollar amount, $v_{c}$, of the customer's electricity bill; the vertical axis, $u\left(v_{c}\right)$, is the utility of the dollar amount, in the decision-theoretic meaning of utility. The function slopes to the right to reflect that increasing electricity costs are undesirable. The curvature of the function reflects the notion of decreasing marginal utility of wealth.

The value of $v_{c}$ for a future year is uncertain. Let this uncertainty be represented by a probability distribution $p\left(v_{c}\right)$. Let $E\left[v_{c}\right]$ and $\operatorname{Var}\left[v_{c}\right]$ denote the expected value and variance of $v_{c}$. The expected value of the utility of $v_{c}$ is called the expected utility of $v_{c}$ and is calculated as:

$$
E\left[u\left(v_{c}\right)\right]=\int u\left(v_{c}\right) p\left(v_{c}\right) d v_{c}
$$

The certain equivalent of $\mathrm{v}_{\mathrm{c}}$ is a dollar value $\mathrm{v}_{\mathrm{c}}{ }^{*}$ that has the same expected utility as the random outcome represented by the probability distribution $\mathrm{p}\left(\mathrm{v}_{\mathrm{c}}\right)$; that is:

$$
\mathrm{u}\left(\mathrm{v}_{\mathrm{c}} *\right)=\int \mathrm{u}\left(\mathrm{v}_{\mathrm{c}}\right) \mathrm{p}\left(\mathrm{v}_{\mathrm{c}}\right) \mathrm{dv_{ \textrm {c } }} \text {. }
$$

Intuitively, the customer is indifferent between the uncertain outcome of his portfolio and the certain value $\mathrm{v}_{\mathrm{c}}{ }^{*}$. The value of $\mathrm{v}_{\mathrm{c}}{ }^{*}$ can be calculated approximately by:

$$
\mathrm{v}_{\mathrm{c}} * \cong \mathrm{E}\left[\mathrm{v}_{\mathrm{c}}\right]-\frac{1}{2 \mathrm{r}} \operatorname{Var}\left[\mathrm{v}_{\mathrm{c}}\right]
$$

where $\mathrm{r}$ is the risk tolerance of the customer. The value of $\mathrm{r}$ is defined as:

$$
\mathrm{r} \equiv \frac{\mathrm{u}^{\prime}}{\mathrm{u}^{\prime \prime}}
$$

where $u^{\prime}$ and $u^{\prime \prime}$ are the first and second derivatives of $u$ at $v_{c}=E\left[v_{c}\right]$. The certain equivalent is approximately the expected value less a term that is proportional to the variance. The risk tolerance $r$ expresses the trade-off between the expected value and variance from the perspective of the customer. The customer would favor an action by the utility that would decrease the variance by an amount $\Delta \operatorname{Var}\left[\mathrm{v}_{\mathrm{c}}\right]$ so long as it does not increase the expected value by more than:

$$
\frac{1}{2 \mathrm{r}} \cdot \Delta \operatorname{Var}\left[\mathrm{v}_{\mathrm{c}}\right]
$$

So far, we have been examining the issue from the perspective of an individual customer. The same concepts apply to total system costs $\mathrm{v}$, with expected value $\mathrm{E}[\mathrm{v}]$ and variance $\operatorname{Var}[\mathrm{v}]$. Given a mechanism for allocating total costs between the customers and a risk preference function for each customer, an aggregate customer risk preference function $u(v)$ can be constructed from which the overall certain equivalent $\mathrm{v}^{*}$ can be calculated. 


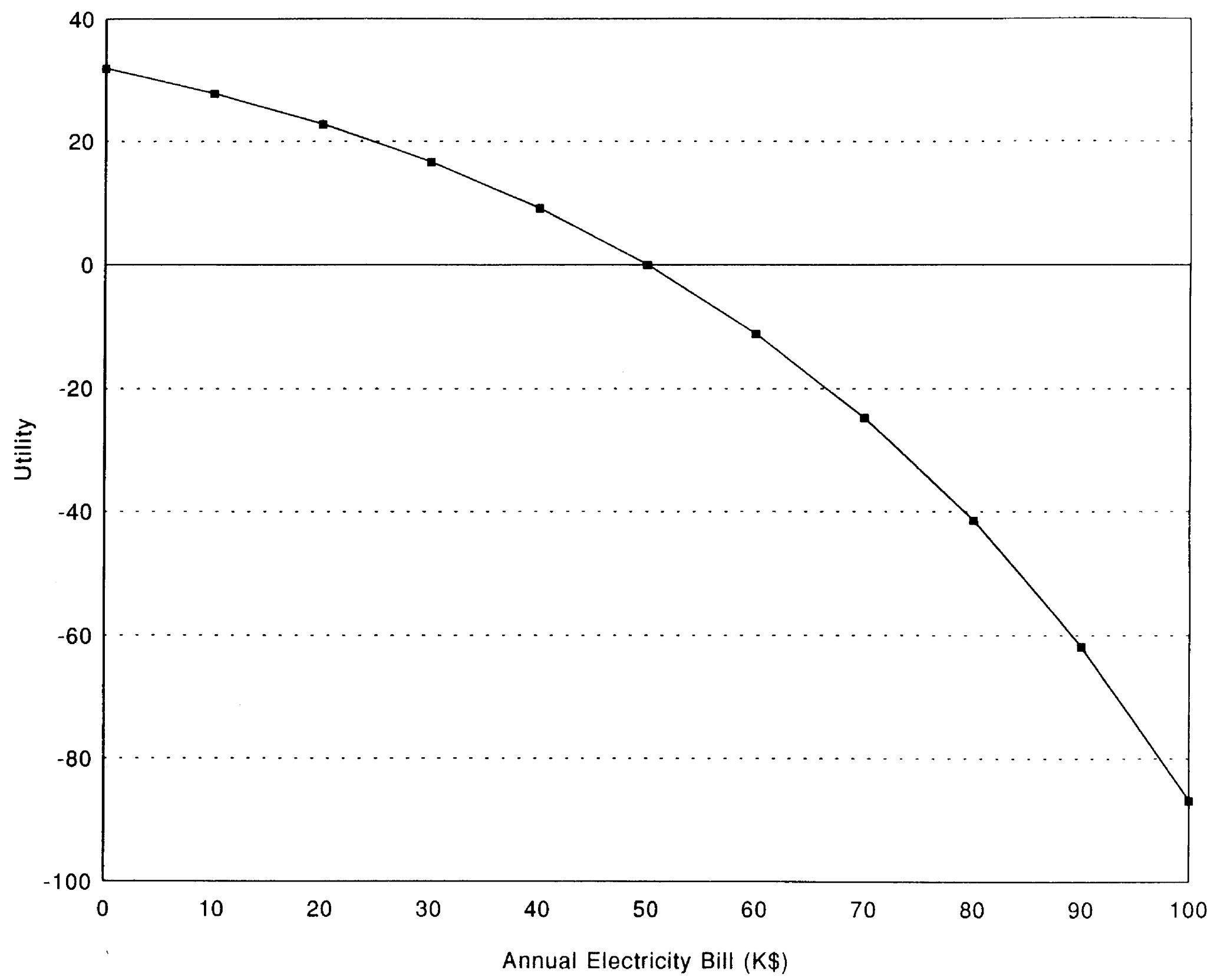

Figure B-1. Risk preference function for annual electric bill 
Now let us consider an individual project and the effect it has on the overall portfolio. Let s denote the net benefits of the project, $E[s]$ the expected net benefits, $\operatorname{Var}[\mathrm{s}]$ the variance of net benefits, and $\operatorname{Cov}[\mathrm{s}, \mathrm{v}]$ the covariance between the net benefits from the project and the cost of the total portfolio. The contribution of $s$ to the expected value and variance of the whole portfolio is:

$$
\begin{aligned}
\Delta \mathrm{E}[\mathrm{v}] & =\mathrm{E}[\mathrm{s}], \\
\Delta \operatorname{Var}[\mathrm{v}] & =\operatorname{Var}[\mathrm{s}]+2 \operatorname{Cov}[\mathrm{s}, \mathrm{v}]
\end{aligned}
$$

But if $s$ is small relative to the rest of the portfolio, the second term will dominate $\Delta \operatorname{Var}[v]$. Thus, the effect of the project on the certain equivalent of the portfolio is:

$$
\Delta \mathrm{v} *=\mathrm{E}[\mathrm{s}]+\frac{1}{\mathrm{r}} \operatorname{Cov}[\mathrm{s}, \mathrm{v}]
$$

The second term represents the diversity benefit of the project. 


\section{Appendix C: Descriptions of Models Reviewed}

The following discussion describes each model reviewed, provides a justification for its inclusion on the short list, and summarizes the comments that appear in various places in the report.

\section{Delta}

PG\&E and EPRI developed the Delta model to evaluate DSM options targeted to a specific local area. ${ }^{1}$ The model has subsequently been extended to renewable resources, and further efforts sponsored by PG\&E, EPRI, and NREL are currently under way to overcome particular shortcomings of the earlier work.

The Delta model consists of three principal sections, which are invoked in an iterative cycle:

1. Marginal costs

2. Evaluation

3. Ranking and implementation.

The marginal cost section calculates annual marginal $T \& D$ costs given a $T \& D$ investment plan using the present worth (PW) method. The PW method determines marginal T\&D costs on the basis of the incremental savings in the present worth of total $T \& D$ costs over the planning horizon, resulting from a reduction in net demand in the local planning area. The annual marginal T\&D costs are then allocated to some number, say 100 , of the highest peak hours in proportion to load.

Marginal T\&D costs are sensitive to the level of DSM and other DU options in two ways. First, the level of DSM and other DU options determines the number of years that T\&D reinforcements can be deferred. If any $T \& D$ reinforcements are deferred, the base $T \& D$ investment plan is changed on which annual marginal $T \& D$ costs are based. Second, the allocation of annual marginal T\&D costs between hours changes if the ratios of the hourly net loads change.

Marginal generation energy and capacity costs are taken as an input. Conceptually, marginal generation costs are also sensitive to the level of DU options. But if only one local planning is under consideration and if the local planning area is small relative to the rest of the system, then the range of net load resulting from implementing DU options is likely to be too small to cause significant variation in marginal generation costs.

The evaluation section performs cost-effectiveness evaluation of the individual DU options. The benefits of each option are calculated on the basis of the marginal generation (energy and capacity), transmission, and distribution costs passed from the marginal cost section. For each option, this section requires the hourly profile of capacity (for a generation option) or demand reduction (for a DSM option). The model determines the hourly dispatch of a dispatchable generation or load management option on the basis of incremental hourly operating cost and marginal energy and capacity cost. The net present value of benefits from an option can be calculated using any of the California Standard Practice cost-effectiveness tests.

The implementation section selects the DU options to include in the plan. The options are ranked on the basis of either net present value of benefits, benefit/cost ratio, or net benefits divided by a measure of peak load reduction. Increments of the highest ranked options are added to the plan in an iterative manner. First, an increment of the most cost-effective program is added. An increment may be either a portion

${ }^{1}$ Energy and Environmental Economics and Pacific Gas and Electric Company (1992). 
or the entire amount of the total potential of the program. Increments smaller than the entire amount are considered if it is possible that a saturation effect may cause the cost-effectiveness of the option to switch from positive to negative as a larger portion of the total potential is implemented.

Second, the net area load is adjusted to account for the impact of the option added. Third, the hourly spread of local T\&D costs is recalculated. Fourth, the options are re-ranked and the iterative process returns to the first step to add the next most cost-effective option.

Further discussion of the treatment of the key attributes in the Delta model follows.

Capacity/Availability. The Delta model takes 8,760-hour profiles. A forced outage rate can be used to represent any uncertainty in the output or load impact of a DU option. However, as described in Section 4.1, uncertainty can also be accounted for by constructing the 8,760-hour profile from typical days representing the profile of the option under different conditions. A shortcoming of the model is that it calculates the dispatch of dispatchable DU options only for the current year, then applies the same dispatch profile to every subsequent year throughout the life of that option. While subsequent DU devices may have different dispatch patterns, changes from year to year in dispatch for a particular device resulting from changes in the hourly profile of marginal costs are ignored.

Location. The location attribute is the reason for existence of this model. Location benefits are explicitly evaluated by the use of geographically differentiated marginal costs. A shortcoming of the model is that is does not currently handle more than one local planning area at a time. Local area marginal T\&D costs are derived on the basis of the local area T\&D investment plan. Annual marginal costs are allocated among the hours in a year on the basis of the hourly profile of local area demand.

Modularity. As an incremental model that uses marginal costs, the Delta model can handle even the smallest options. As described above, the Delta model can evaluate increments of a DU option that are only a portion of total potential. In this was the model can account for the benefit of small incremental size options in tracking load growth more closely. However, the Delta model has no capability for uncertainty analysis and therefore cannot evaluate the benefits of modularity under uncertainty.

Diversity. The Delta model does not have the capability for directly evaluating diversity benefits.

\section{DYNAMICS}

DYNAMICS is an EPRI model that was created to evaluate the benefits of energy storage systems and the impact of non-traditional energy sources on a utility system's operations. It is a short-term commitment model intended for use by utility dispatchers in determining appropriate commitment schedules, concluding cost-effective spot power transactions, and utilizing energy storage systems in an optimal manner. It can model a utility system from one hour up to five weeks. DYNAMICS provides for a detailed representation of dispatch constraints such as unit ramping limitations, hot start and cold start considerations, and spinning reserve requirements.

Capability/Availability. DYNAMICS allows a user to specify the same type of hourly load modifiers as can be defined in many of the other models. DYNAMICS does not currently have any capabilities that would represent potential uncertainty in getting energy from these load-modifier resources; however, some probabilistic features have been slated as future enhancements.

Location. Although DYNAMICS can evaluate transmission losses, it has no specific capabilities that address the location benefits of new resources. 
Modularity. In a very short-term sense, DYNAMICS is able to evaluate the reliability benefits associated with small, multiple units and can quantify this benefit in terms of operating cost savings due to smoother commitment scheduling. However, modularity in this project refers primarily to the longer-term issue of matching variable load growth conditions with the construction of small, modular units, and DYNAMICS is too short term of a model to contribute on this front.

Diversity. Given the very short time frame of the model, there is no probabilistic assessment of fuel prices or availability. All such parameters are assumed to be known with certainty.

\section{Electric Generation Expansion Analysis System (EGEAS) and IRP Workstation}

The Electric Generation Expansion Analysis System (EGEAS) was originally developed for EPRI in 1982 by Stone \& Webster Engineering Corporation and the Massachusetts Institute of Technology. ${ }^{2}$ EGEAS is a generation expansion optimization model that evaluates DSM and supply-side resources to determine optimal least-cost expansion plans. The model provides a ranked list of suboptimal plans that the user can examine to identify expansion plans that have better qualitative characteristics than the least-cost plan. EGEAS can also be used for reliability analysis: it can evaluate probabilistic reliability indices and estimate a utility's marginal cost of meeting reliability targets. One of the original features of EGEAS was its capability to model non-dispatchable technologies (NDTs) such as DSM and renewable resources.

EGEAS is at the heart of a broader system that Stone \& Webster Management Consultants, Inc. developed called IRP Workstation. IRP Workstation is a recent development that allows EGEAS to interact with other models, including the DSManager screening model, the RISKMIN risk analysis model, and FINANCE+, a financial planning and rate analysis module. This new system includes additional capabilities to assist utilities in performing integrated resource planning.

Capability/Availability. EGEAS/IRP Workstation is designed to handle renewable resources and DSM as NDTs. NDTs are modeled as load modifiers, though they could obviously be included as generating units. An advanced feature of EGEAS is to analyze NDTs that are interrelated with system demand. EGEAS uses the ELDC method for dispatch simulation. A chronological option is forthcoming. NDTs are assumed to have two availability inputs, energy related and equipment related. Energy-related availability is due to insolation or wind energy. The key feature of energy-related availability is that it can be interdependent with system load. EGEAS will accept, for example, insolation data to determine the interdependence of load and solar generation. Equipment-related availability is equivalent to standard generating unit forced outages and is independent of load. EGEAS uses an orthogonalization method that considers the probabilistic interdependence of load and availability of NDTs prior to developing its load duration curve.

NDTs and DSM impacts can be input to EGEAS/IRP Workstation with a full 8,760-hour load shape. For DSM programs, EPRI's DSManager program can be used to supply the impact estimates as well as for cost-benefit analyses. DSM data can also be fed to EGEAS from Synergic Resource Corporation's COMPASS model or from the utility's in-house data.

Location. Version 7 of the model considers locational impacts of new resources. The utility system can be subdivided, and resources can be assigned to the subdivisions for future analyses. Price elasticity impacts are measured, as well as T\&D impacts.

\footnotetext{
${ }^{2}$ Stone \& Webster Engineering Corp. (1982-1984).
} 
Modularity. EGEAS has four options for IRP: pre-specified pathway, screening curves, generalized benders (GB) decomposition, and dynamic programming. GB optimization uses continuous plant sizes, which may be useful in analyzing modular units, but can result in only an approximation of the optimal solution for most types of units. Dynamic programming retains the integer nature of units, but takes longer to run.

EGEAS includes decision analysis capabilities that would be useful in examining the impact of short lead times.

Diversity. EGEAS was designed to include consideration of uncertainty, and this capability has been enhanced in the IRP Workstation implementation. Multiple scenarios can be specified and automatically run. The results can be combined using scenario probabilities. Results can also be passed directly to EPRI's RISKMIN model. RISKMIN can be run to identify robust expansion plans and robust options and to calculate measures of riskiness.

\section{Elfin}

Developed by the Environmental Defense Fund, Elfin is a production simulation tool that has been promoted as the standard model for California utilities by that state's Public Utilities Commission (CPUC). ${ }^{3}$ Elfin uses the equivalent load duration curve method for dispatch simulation. The model incorporates two capacity expansion algorithms: the Iterative Cost-Effectiveness Methodology (ICEM) and the Iterative Test for Resource Evaluation (ITRE). Through the use of this methodology, an Elfin user can develop a capacity expansion plan from a set of potential DSM or supply-side resources. ELFIN also includes a financial model.

Capability/Availability. Elfin started as a load duration curve model that was slightly simpler and much less expensive than other available models. The model has, over the years, been significantly upgraded. An important upgrade was to include time-of-day considerations that can significantly improve the modeling of renewable resources and DSM. Another upgrade was adding the capacity to model energylimited units such as storage and hydro. Elfin can model up to 54 typical weeks per year.

Renewable resources can be modeled in Elfin as load modifiers or as generating units. When DSM or generating units are modeled as load modifiers, Elfin first adjusts the chronological load data and then develops the load duration curves. Elfin has separate load modifiers for demand-side resources and supply-side resources. Demand-side load modifiers are treated as direct reductions in load, before commitment and spinning reserve targets are calculated or annualized maintenance is scheduled. Supplyside load modifiers are included with other supply-side resources in calculations related to meeting commitment and spinning reserve targets and annual maintenance requirements. In addition, if userspecified transmission and distribution losses are modelled. energy requirements will be reduced more by demand-side load modifiers than by supply-side load modifiers, because supply-side resources must meet loads including T\&D losses.

When renewable resources are modeled as generating units, the units can be defined by time of day, but Elfin uses only the average capability within each simulation subperiod. If separate subperiods are defined, a separate load duration curve is developed for each subperiod. Elfin can use up to eight subperiods, but run time is directly proportional to the number of subperiods.

${ }^{3}$ Peña (1992); Belostosky et al. (1992). 
One weakness of Elfin is that it does not consider ramp rates in the model. The full effect of intermittence may therefore, be difficult to model explicitly using Elfin. Elfin does have spinning reserve and commitment capability, which could be adjusted to partially account for intermittence.

Location. The model does not have any capability to internally calculate effects related to location. The model can be provided, however, with loss factors related to location and with costs for location-related upgrades to the $T \& D$ systems.

Modularity. The model in either its ICEM or ITRE version can be run to consider adding units of small size. However, ITRE has several features which give it flexibility not found in ICEM. They include: 1) resources once added to an expansion plan can be deleted later if they are found not to be cost effective, 2) ITRE always analyzes the whole planning period in each iteration where ICEM builds a plan year by year, starting from the beginning of the planning period, 3) ITRE's marginal cost based implementation can evaluate large numbers of options in a short time frame.

There may be a practical limitation on the Elfin/ICEM model's ability to evaluate modular alternatives, however, because evaluating each alternative requires running the production costing submodel a number of times. Thus, the evaluation of a number of small alternatives could require many hours of run-time. Including sufficient alternatives to allow Elfin/ICEM to select small-sized units to match load more closely could require many more hours to run than if only larger units were considered.

ITRE is capable of adding several resources based on marginal cost estimates before having to do another simulation. Elfin/ITRE has many user-specified options for specifying level of detail in various simulations in order to be able to run capacity expansion optimization in a reasonable period of time.

The model performs single scenario analysis; the ICEM and ITRE approaches select a plan for one set of assumptions. Analyzing alternative scenarios and uncertainties requires manual specification of multiple runs of the model.

Diversity. The model will not automatically combine the results of different scenarios, but it is designed to easily run different scenarios. Every input category includes a scenario identifier and the scenario to be run is specified in the command file. Running high, medium, and low assumptions for demand and fuel price forecasts is a standard procedure for the California utilities, for example.

An enhancement to the model would be the ability to automatically run multiple scenarios with probabilities assigned to the scenarios, and have the results combined to arrive at an expected cost.

\section{IRP-Manager}

IRP-Manager is a relatively new integrated resource planning and strategic analysis model developed by EPRI and supported by Electric Power Software, Inc. I IRP-Manager includes a graphical user interface, a relational database management system, a decision analyis (DA) module, and a module that performs iterative resource selection. The DA module supports interative decision tree definition, automatically constructs data components into scenarios, and presents a wide range of results. The entire model, including the iterative resource selection module, is devigned for analyzing multiple objectives and perspectives.

\footnotetext{
${ }^{4}$ Decision Focus, Inc. (1982); Electric Power Software (1991).
} 
At the core of IRP-Manager is an enhanced, faster version of the former LMSTM production simulation engine, which conducts a chronological demand-supply simulation and fully integrates customer and utility data across demand, supply, finance, and rates modules. IRP-Manager's centralized database design provides direct data linkages with several EPRI and non-EPRI models, including EPRI DSManager, EPRI HELM, and EPRI EGEAS. Planned near-term enhancements include an expanded iterative resource selection technique, similar to ITRE or CAPEX.

Capability/Availability. The chronological dispatch methodology applied by IRP-Manager provides a more detailed and explainable analysis of renewable resources than possible with pure load duration curve models. True hourly marginal costs and dispatch of supply and load control resources can be viewed interactively and analyzed in detail if desired.

IRP-Manager applies either three, four, or seven "typical daytypes" each month (seven daytypes representing a typical week). Monthly results are determined by the number of individual days in the month represented by each typical day. The daytypes could be applied to account for variation in production from renewables, where that is a focus of the analysis.

Because of the chronological nature of the model, renewable resources can be modeled in detail on an hourly basis if desired, and tracked through all results reports. The user has the option of modeling renewables as load modifiers, energy-limited generating units, or interchanges. Most generating unit parameters can be altered monthly if desired; load and interchange data can be altered hourly if desired.

Location. IRP-Manager adjusts the impact of each resource for T\&D losses. This is useful for DSM and renewable projects that are located at the load center or that avoid transformation losses, and is useful for accounting for remote generation. Percent losses are input to the model on an annual, monthly, or hourly basis, as desired. Asset and operating expense accounts can be applied to model T\&D costs; it is planned that the automated calculation of T\&D costs as a function of load level will be added in 1994 .

Modularity. The chronological simulation employed by IRP-Manager accurately represents even small increments of capacity such as renewable resources and DSM. Small increments of capacity cannot "get lost in the noise" of a large system, as is often the case with load duration curve modeling techniques.

Although iterative resource selection techniques support the modeling of more unique resource options than does dynamic programming, these simulations may take a considerable amount of time if an especially large pool of unique resources is considered. Various modeling techniques are available in IRPManager to reduce run-time requirements, including grouping of resources and simplified generating unit capacity and availability modeling. As of this writing, the vendor is implementing end-effects logic and other techniques to further reduce run-time in these situations.

Diversity. IRP-Manager includes a decision analysis ability. The decision analysis framework can be specified to run different scenarios for load growth and fuel costs, for example, and combine the results. This is one of the new features included in the model and indicates a growing concern and interest in this type of analysis.

\section{ISAAC}

The Bonneville Power Administration (BPA), the Northwest Power Planning Council, and the Northwest utilities developed the Integrated System for Analysis of Acquisitions (ISAAC). ${ }^{5}$ It is a decision

\footnotetext{
${ }^{5}$ Northwest Power Planning Council (1991), Volume II, Part II, pp. 939-953.
} 
analysismodel that examines the benefits of acquiring different types of resources in meeting uncertain demand. A Monte Carlo process is used to generate and analyze the effects of different load levels and hydro conditions that may occur in each year of the study. The model is used by BPA and the Northwest Power Planning Council.

The model features an automatic algorithm for updating the resource plan in response to changes in load as the simulation steps through time. This algorithm could be useful in evaluating the benefits of modularity. However, this algorithm may be regarded as an approximation of a decision analysis approach.

ISAAC is a rather aggregated model because it is designed to model the entire Pacific Northwest. Three or four groups of utilities or planning parties are modeled, typically investor-owned utilities, government utilities, and BPA. Resources are aggregated into one of six categories: nuclear, low-operating-cost coal, high-operating-cost coal, simple-cycle combustion turbines, combined-cycle combustion turbines, and load reducing resources.

The model, as implemented in the Pacific Northwest where hydro and fish are important considerations, includes four seasons: September through December, January through April, May, and June through August.

Capability/Availability. Currently, only energy loads are represented (i.e., there is no peak information in the model). Non-dispatchable resources such as renewables and conservation are typically modeled as load reduction resources with seasonally shaped energy contributions. Hydro resources are simulated as one aggregate unit with hydro conditions randomly selected based on probabilities associated with the 102year water record.

Location. The model does not explicitly analyze locational impacts of new resources.

Modularity. The model can handle modular resources. Even though it is designed to deal with aggregated blocks of resources, it selects individual units from within these blocks. Supply curves are defined by specifying the number of units available, and the model selects the appropriate number of blocks to add.

Another feature of the ISAAC model that appears unique is that resource addition decisions are made in two steps: permitting and construction. The first decision is to start the pre-construction activities on a unit-permitting, licensing, and engineering design. If this phase is successfully completed in the model, the option moves to an inventory account. Units can be held in inventory for several years, but may also fall out of the inventory account if construction is not started within a specified time period. The second decision is to start construction of a project from the inventory of available projects. This approach further demonstrates the benefits of short lead time projects and, in some respects, is a more sophisticated approach than the one actually used by most utilities.

Diversity. The model includes a decision analysis framework and Monte Carlo simulation to incorporate the effect of alternative scenarios. Many considerations are explicitly modeled in a probabilistic framework. The factors that are modeled using probabilistic considerations include:

- Load growth (excluding the aluminum industry)

- Aluminum industry load

- Fuel price (both fixed and variable)

- Successful completion of resource permitting 
- Loss of resources in inventory

- Expected and actual amount of a particular type of resource available.

The most important of these is load growth, but fuel prices are also modeled with a detailed uncertainty analysis. Note that the model has probabilities for successful completion of the permitting phase of a project and for failure once a project is in inventory, but not for successful construction. The assumption is that all the potential for failure occurs in the permitting and inventory phases. Once a project has successfully negotiated these hurdles, it is assumed with certainty that it will complete the construction phase.

There are interdependencies among some of the fuel costs, so that fuel costs for gas-fired combustion turbines, combined cycle facilities, and cogeneration units all move in a related manner.

\section{MABS}

The Multi-Attribute Bidding System (MABS) is a spreadsheet model for evaluating the net benefits of candidate projects; it was developed by PG\&E, SDG\&E, and SCE as part of a broader effort to reform the resource bidding procedure imposed by the California Public Utilities Commission. ${ }^{6}$ Some of the principles guiding the development of MABS were:

- Consideration of attributes other than price. The bid evaluation framework must accommodate other attributes and convert them to dollar values for comparison to price.

- Price signals. The relative values and weights assigned to various attributes should be able to be interpreted as price signals reflecting the economic value of various options to the utility.

- Flexibility. Both the price structure and the evaluation framework should be sufficiently flexible to accommodate a broad range of resource options, operating characteristics, and financial requirements.

- Self-scoring. A project developer must be able to use the bid evaluation framework to optimize his bid before submitting it.

MABS was implemented as a Lotus 1-2-3 spreadsheet for distribution to prospective bidders with a solicitation.

MABS is unique among the 11 models reviewed in that it performs an incremental analysis based on marginal costs to determine the net benefits of an individual project. All of the other models are systemwide models. Incremental analysis can be performed with the other models only by taking the differences between multiple model runs.

MABS evaluates the following seven components:

- Capability benefits

- Energy and controllability benefits

- Location

- Price diversity

- Start date flexibility

\footnotetext{
${ }^{6}$ Staschus, et al. (1991).
} 
- Project viability

- Environmental impact.

Although many of these components have been quantified using a simple point-scoring system in other utilities' bidding processes, they nevertheless have a real economic impact on the utility. MABS attempts to estimate the economic value of each of the components to allow them to be traded off consistently against price.

Capability/Availability. Capability and availability are modeled in the course of evaluating capacity and energy benefits. Capacity benefits are calculated on the basis of marginal generation capacity costs accounting for forced outages, maintenance requirements, and the hourly and seasonal profile of capacity. In evaluating energy benefits, the model accounts for different levels of dispatchability. Generation from a base-loaded resource is limited only by capacity and availability. Energy limited resources are assigned to the hours with highest marginal energy cost. The capacity factor of a fully dispatchable resource is estimated on the basis of a marginal cost duration curve to determine the fraction of hours that marginal costs are higher than the variable energy cost of the resource. Curtailable resources is modeled as shut down for up to the maximum number of curtailable hours if it is economic to do so. The value of the generation from a resource is determined from system marginal energy costs.

Location. The location of a resource is accounted for in two ways:

- Losses. The effect of a resource on total system losses depends on location.

- System reinforcement adjustment costs. The effect of a resource on requirements for transmission reinforcements depends on location. A resource may either accelerate or defer a reinforcement.

Both components are determined on the basis of marginal values estimated from optimal power flow sensitivity analysis using the LOCATION model. ${ }^{7}$

Diversity. MABS calculates the net benefits of a project for each of three different natural gas price scenarios, then estimates the covariance between net benefits and total system production costs to determine the price diversity benefit. MABS follows the procedure described in Section 4.4.

Modularity. MABS evaluates the benefits of short lead times and start date flexibility. MABS calculates the net benefits of a project for each of three different demand scenarios. If the project offers start date flexibility, then maximum acceleration and deferral are assumed in the high and low demand scenarios, respectively. MABS explicitly displays the gain in net benefits that results from acceleration in the high scenario and the reduction in negative net benefits that results from deferral in the low scenario. Generally, a resource with shorter lead time can offer great start date acceleration. MABS can evaluate projects of any size, except projects so large that the validity of system marginal costs may be a concern. But MABS does not explicitly evaluate any modularity benefits resulting from small unit size.

\section{MIDAS}

The original Multi-objective Integrated Decision Analysis Model (MIDAS) was developed by M.S. Gerber \& Associates for EPRI. ${ }^{8}$ Subsequent updates to the user interface and simulation system comprise

\footnotetext{
${ }^{7}$ Shirmohammadi and Thomas (1990).

${ }^{8}$ Temple, Barker \& Sloane, Inc. and M.S. Gerber \& Associates, Inc. (1988).
} 
a newer model called MIDAS Gold. This tool allows a user to formulate resource planning problems in a decision tree where different nodes in the tree represent either planning uncertainties (e.g., high/low loads, high/low fuel prices) or planning decisions. MIDAS Gold simulates the utility system's loads, resources (thermal, energy limited, DSM, contract purchases, economy interchange), emissions, finances, and rate impacts for each path or scenario, of the decision tree. Users define objectives (revenue requirements, total resource test, average rates, societal test, etc.) which are created after the simulation. MIDAS Gold then calculates the expected value of alternative resource strategies based upon future uncertainty.

Capability/Availability. MIDAS Gold has a load modifier capability. Thus, renewable resources can be modeled as generating units or as reductions from load. MIDAS Gold can also reflect uncertainty associated with cost, technical versus actual performance, demand, or any other input variable as part of the analysis.

The model also includes energy limited units, which are often used to model hydroelectric units. Small units can be included through the multiple unit specification. MIDAS Gold allows for mutually exclusive resources such as those built in phases, or with evolving technical characteristics, and capital replacement patterns associated with technologies such as fuel cells.

The production costing method within MIDAS Gold is aggregated and fast rather than detailed. It does include tracking of five emission types, fuel inventorying, and fuel use of up to three fuel sources per generating unit.

Location. MIDAS does not explicitly develop or consider locational factors.

Modularity. MIDAS explicitly models sequential decision making, which is particularly useful in evaluating the benefits of modularity.

Diversity. MIDAS Gold combines the results of multiple scenarios within a decision analysis framework to develop resource strategies according to user defined objectives. MIDAS Gold performs one simulation year in between 1-2 seconds, which permits the evaluation of hundreds of scenarios in an overnight run. Results from the model may be viewed, customized, exported in a general presentation tool called a Results Matrix. Then, alternative objectives may be compared to determine the optimal choice at each decision node without having to re-simulate the model.

MIDAS also provides information on the riskiness of decisions. It provides information on risk exposure so that utilities can manage their risk. The model develops risk profiles in addition to the most likely or expected outcome. MIDAS Gold also calculates the expected value of perfect information (EVPI) and value of control. EVPI examines the value of obtaining better, or perfect, information about planning uncertainties; while, value of control quantifies the benefit of resolving an uncertainty in a resource plan.

\section{PROMOD IV}

EDS/Energy Management Associates (EMA) first developed PROMOD in the 1970s and the model has come to be widely used throughout much of the utility industry. PROMOD IV is a production simulation model with three dispatch options for assessing the effects of unit availabilities on utility system operations: 1) a Booth-Baleriaux probabilistic convolution technique, 2) an hourly chronological Monte Carlo dispatch technique, and 3) an hourly chronological Monte Carlo technique with transmission 
constraints. ${ }^{9}$ There is both a single-area and a multi-area version of the program. The single-area version focuses on the dispatch of an individual utility without any transmission constraints. The multi-area version allows one to model an entire interconnected power pool and account for inter-utility economy power interchange and area-to-area transmission limitations.

Capability/Availability. The most commonly selected time period for PROMOD IV's simulation is a typical week - a 168-hour representation that is meant to approximate a utility system's operations for each month. Thus, system loads are developed that contain 168 hourly values for each month; each hourly value represents the average system demand over that particular hour. However, the model also has a weekly dispatch option that allows the user to model all 8,760 hours in a year.

As is the case with most production simulation models, PROMOD IV allows the user to define renewable resources as either load modifiers or generating units. Load modifiers can be defined on an hourly basis and are added to (in a system sale) or subtracted from (in a power purchase or a renewable project) the system loads before dispatching the utility's generating resources. In the case of the convolution dispatch option, PROMOD IV segments the week into three subperiods, based on the user's designation: weekday, weeknight, and weekend. After the hourly loads have been modified, they are segregated into three subperiods and sorted into three load duration curves. Generating units are dispatched against the load duration curves by piece-wise linear convolution. Units are modeled in terms of blocks of capacity that represent the different operating levels at which a unit can generate power. A unit can have up to seven blocks, and each block can have a different availability designated for it.

The commitment of units in the dispatch process involves a look-ahead scheduling mechanism that determines the probability that the unit will be needed during high-load periods. In combination with user-specified commitment targets, this scheduling results in the initial commitment of resources. Subsequently, additional units may be committed during the dispatch process to maintain adequate spinning reserves. In the multi-area version of PROMOD IV, commitment constraints can be specified for each area, for a cluster of areas, and for the entire power pool.

Each resource (whether a load modifier or a generating unit) can be designated as contributing toward the system's commitment target in one of three ways: 1) it is non-firm and does not contribute any capacity to the target, 2) it contributes the amount of capacity that is available during the system peak hour, or 3 ) it contributes its maximum capacity (regardless of what hour that occurs in). There currently is no way to weight a resource with a partial commitment percentage that would reflect a dispatcher's level of confidence in relying on the resource. This all-or-nothing process forces the user to consider a renewable resource as either entirely dependable or entirely undependable in its impact on the commitment process.

Dispatch is modeled separately for each of three different subperiods for each month. A user can derate a generating unit or make it entirely unavailable in any subperiod. This could allow a user to specify, for example, a renewable unit that was only available during the daytime. The probabilistic dispatch process addresses generating unit forced outages only; there is no analogous availability factor that can be specified for load modifiers.

Location. PROMOD IV's multi-area version allows a user to analyze and assess the benefits of locating new generating resources (such as renewables) in geographic areas that are bumping their transmission

\footnotetext{
${ }^{9}$ The majority of this section's discussion applies to PROMOD IV's probabilistic convolution dispatch technique. The model's hourly chronological Monte Carlo dispatch techniques involve similar issues to those discussed in the UPLAN and IRP-Manager sections.
} 
import limits. However, a user cannot use PROMOD directly to model the deferral of T\&D investments associated with new generation in such areas.

Modularity. PROMOD IV is a single-scenario simulation tool. Therefore, it does not provide the user with an easy means of assessing the benefits of modularity. Instead, the analysis would have to be done with several runs and would rely on outside financial and rate analysis. PROMOD IV could be used to compare the operational ramifications of having excess capacity (e.g., because the construction of a large unit was followed by lower-than-expected load growth). Another simulation could examine the construction of several smaller units that more closely matched the new load growth pattern. However, the modularity benefits of the smaller resources would depend on the probability of a down-turn in projected loads and the financial and regulatory ramifications of surplus capacity. These issues cannot be analyzed with PROMOD IV.

Diversity. PROMOD IV does not have any explicit scenario development and analysis capabilities. Issues like diversity would have to be examined through multiple runs of the model and subsequent tabulation and analysis of the results.

\section{PROSCREEN IIVROVIEW}

PROSCREEN/PROVIEW, also an EMA product, is a comprehensive, modular, integrated resource planning tool that is used by over 80 utilities. As a screening model, it uses a simpler and faster dispatch simulation methodology (the cumulant technique) than the more-detailed method used in PROMOD III. PROSCREEN also has modules for end-use load forecasting and price elasticity impacts, capital accounting, and financial/rate analysis. In addition, it includes PROVIEW, a dynamic programming-based resource optimization tool. Dynamic programming is an efficient optimization technique that effectively examines all feasible generation expansion plans over a specific time period and selects the least-cost plan(s). However, the size of the optimization problem increases exponentially with the number of available resources, so one must be careful to limit the pool of resources to a manageable number.

Capability/Availability. PROSCREEN provides the user with many of the same capabilities as were discussed in the PROMOD section. PROSCREEN load representations are also based on a 168-hour typical week. This typical week can be specified for up to 12 seasons per year. Therefore, the PROSCREEN user has the flexibility to define monthly or quarterly dispatch periods or just a single annual dispatch period. In running PROVIEW, some users may be inclined to consolidate their seasons into an annual period to speed up the optimization. Unfortunately, this compromises seasonally significant information such as the seasonal profiles of demand or of renewable generation, as it would in any model. Whereas conventional generating unit availability may not be substantially affected by seasonal issues (annual maintenance requirements notwithstanding), renewable resources often exhibit seasonal fluctuations in generation.

A PROSCREEN user can segment a typical week into two or more subperiods. This feature allows a user to model renewables as generating units and control the time of day when the resource's generation might be available. Units are defined in at most two blocks. This may reduce the value of modeling renewables as generating units since one cannot designate different availabilities for more than two different levels of resource generation.

What PROSCREEN loses in less detailed production simulation, it gains in the fact that it is a full IRP model with comprehensive financial and rate analysis modules. The system has a scenario storing and comparison capability that can be linked to either Supertree or DPL, two decision analysis programs. This linkage allows a user to evaluate the impacts of renewable generation uncertainty. 
Location. The model does not explicitly model locational impacts of new resources. There is no multiarea feature in the PROSCREEN system. However, one can represent T\&D investments in the capital expenditure module. The user can manually delay or delete these investments when selecting specific resources.

Modularity. Because PROVIEW bases its optimization on a single, exogenous load forecast, the model cannot be easily used to evaluate the benefits of resource modularity. The PROSCREEN financial and rate modules, however, could be run under different load forecasts with different resource additions to assess the potential financial and regulatory consequences of building too much capacity versus meeting erratic and variable load growth with smaller, modular resources. Nonetheless, there is no automatic process that performs this analysis. The separate runs would have to be set up and executed by the user.

Also, PROVIEW runs can become unmanageably time-consuming if one models too many small resource additions. Such additions can result in a massive proliferation of feasible dynamic programming states. If the user is not careful, PROVIEW will be forced to trim feasible states from the optimization problem (or take an inordinate amount of time) in attempting to evaluate all of these states.

Diversity. As noted earlier, the system has a scenario storage and comparison capability that can be linked with Supertree or DPL. This linkage allows a user to automatically assess renewable resource diversity benefits.

\section{UPLAN III}

UPLAN is an integrated utility planning tool that includes production simulation, capacity expansion, financial/rate analysis, and uncertainty analysis capabilities. UPLAN was developed by LCG Consulting. Unlike some of the industry's older resource planning models, UPLAN was designed from the start to run on a PC. Its user-friendly interface makes it a popular planning system.

The model uses either ELDC or hourly chronological dispatch simulation, allowing a user to accurately model utility system operating constraints such as resource ramp rates and minimum downtimes. Although there are several hourly chronological dispatch models used throughout the utility industry (e.g., POWERSYM, ENPRO, POLARIS), UPLAN is one of the most widely used of the chronological models. UPLAN can use either typical weeks for its chronological simulation or the entire year $(8,760$ hours). Typical weeks can be used to shorten the run time if many years or scenarios are to be analyzed.

Capability/Availability. Chronological models such as UPLAN may have advantages over load duration curve models in modeling the commitment and dispatch of renewable resources. Chronological models may be able to more accurately model the time-of-day related capacity and energy of renewable resources such as solar and wind. They can also directly model the effect of changes in natural demand as well as requirements on other resources due to intermittence of renewable resources. These effects may be masked somewhat in load duration curve models.

Renewable resources could be modeled as either load modifiers or as generating units. Modeling them as generating units in UPLAN is appropriate if the resource has some capability to be dispatched. The load modifier approach requires detailed data on the load shape of the renewable resource. If the load modifier alternative is selected, it is possible in UPLAN to directly include uncertainty levels on the load modifier. UPLAN allows the capacity to vary monthly and by time of day, which is a potentially useful feature for modeling renewables as either generating units or load modifiers.

As a PC-based system, UPLAN has convenient graphics capabilities to examine and modify loads. 
Location. The model does not explicitly model locational impacts of new resources.

Modularity. UPLAN includes a dynamic system optimization module to determine the selection of plant additions that result in the minimum cost system. Alternative expansion scenarios can be interactively evaluated. The UPLAN approach can examine alternatives with fixed capacity sizes, variable capacity, or a mix of fixed and variable alternatives. The variable size approach used in UPLAN could be used, for example, to determine the number of modular units required to match the planning criteria of the utility for each year in the future. This feature is an advantage for considering renewable resources, compared to many planning models.

UPLAN also considers lead time in its planning analysis. Because its uncertainty analysis operates year by year, UPLAN results can provide an indication of the benefits of short lead time options.

Diversity. UPLAN includes an uncertainty analysis capability of critical variables such as system demand, impact of load modifier alternatives, unit in-service dates, and fuel costs. It is designed to perform Monte Carlo simulations based on input high, medium, and low values of selected input variables such as demand growth rates. It reports the expected results as well as the range of results. These results can be analyzed to determine the variance of the results and the change in the variance due to changing certain assumptions.

In UPLAN, the Monte Carlo simulations for factors like system demand operate annually, so that changes in load growth over the forecast horizon are possible. The use of annual growth rates allows the benefits of short lead time options to be examined. Rather than only following a high, medium, or low path for the entire forecast horizon, the growth rates can vary from high to low each year. Generation expansion plans that appear good under a high growth case, for example, may not be as good under conditions of varying growth. This type of uncertainty analysis allows UPLAN users to examine the benefit of shortlead-time options like renewables. 


\section{Appendix D. Models Considered for Review}

Table D-1 presents a comprehensive list of the models that were considered for evaluation in this project. Each model's vendor and its primary capabilities are displayed.

\begin{tabular}{|c|c|c|}
\hline Model Name & Vendor & Primary Capabilities \\
\hline ADM-2 Version 4.1 & ADM Associates, Inc. & $\begin{array}{l}\text { End-Use Demand Forecasting } \\
\text { DSM Potential Assessment }\end{array}$ \\
\hline ADMDOE & ADM Associates, Inc. & $\begin{array}{l}\text { End-Use Demand Forecasting } \\
\text { DSM Potential Assessment }\end{array}$ \\
\hline AGEND & Quantum Consulting & $\begin{array}{l}\text { End-Use Demand Forecasting } \\
\text { DSM Potential Assessment } \\
\text { (Agriculture) }\end{array}$ \\
\hline A-LESP & U.S. Naval Civil Engin. Lab & DSM Potential Assessment \\
\hline $\mathrm{ARCH}$ & Lawrence Berkeley Lab & DSM Potential Assessment \\
\hline ARGUS & Argonne National Lab & Energy Sector Model \\
\hline ASSESS2 & TechPlan Associates & DSM Potential Assessment \\
\hline BENCHMARK & EPRI & Production Simulation \\
\hline BEST Profiler & Quantum Consulting & DSM Potential Assessment \\
\hline CEDMS & Jerry Jackson \& Associates & End-Use Demand Forecasting \\
\hline CIRTOU & Christensen Associates & $\begin{array}{l}\text { DSM Potential Assessment } \\
\text { Financial/Rates }\end{array}$ \\
\hline CMAFS & Synergic Resource Corp. & $\begin{array}{l}\text { End-Use Demand Forecasting } \\
\text { DSM Potential Assessment }\end{array}$ \\
\hline COMET & Quantum Consulting & $\begin{array}{l}\text { End-Use Demand Forecasting } \\
\text { DSM Potential Assessment }\end{array}$ \\
\hline COMMEND 3.2 & Regional Economic Research & $\begin{array}{l}\text { End-Use Demand Forecasting } \\
\text { DSM Potential Assessment }\end{array}$ \\
\hline COMPASS & Synergic Resource Corp. & $\begin{array}{l}\text { DSM Cost-Effectiveness } \\
\text { Analysis }\end{array}$ \\
\hline COMPLEAT & $\begin{array}{l}\text { American Public Power } \\
\text { Association }\end{array}$ & $\begin{array}{l}\text { DSM Cost-Effectiveness } \\
\text { Analysis } \\
\text { Resource Planning } \\
\text { Production Simulation } \\
\text { Financial/Rates } \\
\text { Uncertainty Analysis }\end{array}$ \\
\hline COMTECH & Regional Economic Research & $\begin{array}{l}\text { DSM Potential Assessment } \\
\text { DSM Cost-Effectiveness } \\
\text { Analysis }\end{array}$ \\
\hline COOLAID & Regional Economic Research & $\begin{array}{l}\text { DSM Potential Assessment } \\
\text { DSM Cost-Effectiveness } \\
\text { Analysis }\end{array}$ \\
\hline
\end{tabular}




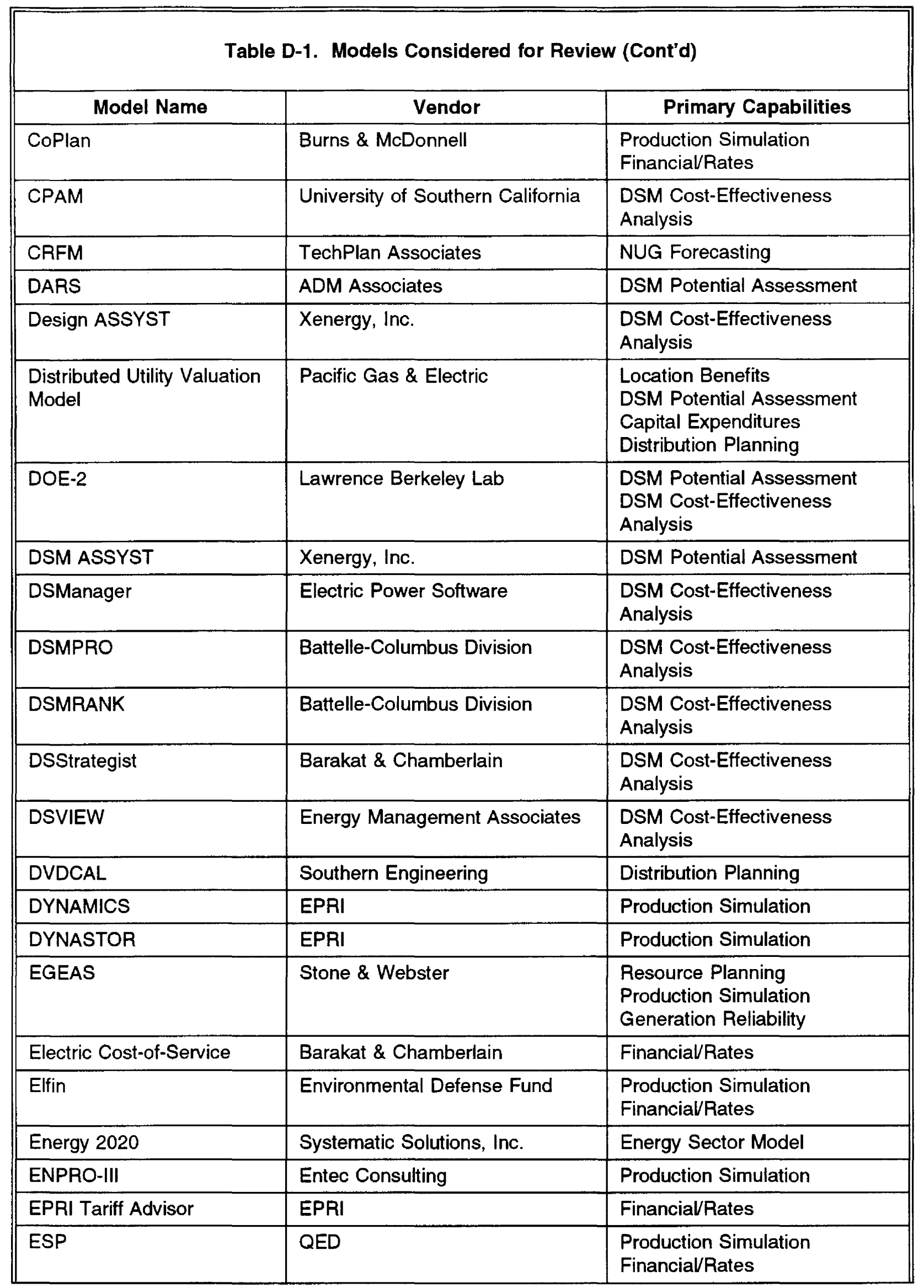




\begin{tabular}{|c|c|c|}
\hline Model Name & Vendor & Primary Capabilities \\
\hline ETEMPS & McDaniels Research Ltd. & DSM Potential Assessment \\
\hline EUTAP & TechPlan Associates & $\begin{array}{l}\text { DSM Cost-Effectiveness } \\
\text { Analysis }\end{array}$ \\
\hline FA\$T 123 & Polydyne, Inc. & Project Economic Analysis \\
\hline $\mathrm{FIN}$ & M.S. Gerber \& Associates & Financial/Rates \\
\hline FORTELL & EPRI & $\begin{array}{l}\text { Econometric Demand } \\
\text { Forecasting }\end{array}$ \\
\hline FUELMIX / CONTRACTMIX & EPRI & $\begin{array}{l}\text { Project Economic Analysis } \\
\text { Uncertainty Analysis }\end{array}$ \\
\hline FUTURE & Pacific Gas \& Electric & $\begin{array}{l}\text { Project Economic Analysis } \\
\text { Uncertainty Analysis }\end{array}$ \\
\hline GEMS & Decision Focus, Inc. & $\begin{array}{l}\text { Production Simulation } \\
\text { FinanciaVRates }\end{array}$ \\
\hline HELM & ICF, Inc. & End-Use Demand Forecasting \\
\hline HELP & Quantum Consulting & End-Use Demand Forecasting \\
\hline INDEPTH & EPRI & $\begin{array}{l}\text { Econometric Demand } \\
\text { Forecasting }\end{array}$ \\
\hline INFORM 1.0 & EPRI & End-Use Demand Forecasting \\
\hline IPEP & Wisconsin Power \& Light & $\begin{array}{l}\text { DSM Cost-Effectiveness } \\
\text { Analysis } \\
\text { Project Economic Analysis }\end{array}$ \\
\hline IPM (ICF) & ICF, Inc. & $\begin{array}{l}\text { Production Simulation } \\
\text { Resource Planning }\end{array}$ \\
\hline IPM (Quantum Consulting) & Quantum Consulting & DSM Potential Assessment \\
\hline IRP-Manager/LMSTM & Electric Power Software & $\begin{array}{l}\text { Production Simulation } \\
\text { DSM Cost-Effectiveness } \\
\text { Analysis }\end{array}$ \\
\hline ISAAC & Bonneville Power Administration & Production Simulation \\
\hline ISTUM & Simon Fraser University & $\begin{array}{l}\text { End-Use Demand Forecasting } \\
\text { DSM Potential Assessment }\end{array}$ \\
\hline LCPM & Applied Energy Services & $\begin{array}{l}\text { End-Use Demand Forecasting } \\
\text { NUG Forecasting } \\
\text { Production Simulation } \\
\text { FinanciaVRates }\end{array}$ \\
\hline Load Planner & Xenergy, Inc. & End-Use Demand Forecasting \\
\hline LoadShaper & Morgan Systems Corporation & DSM Potential Assessment \\
\hline LoadView & Quantum Consulting & End-Use Demand Forecasting \\
\hline LPV & ADM Associates & End-Use Demand Forecasting \\
\hline
\end{tabular}




\begin{tabular}{|c|c|c|}
\hline Model Name & Vendor & Primary Capabilities \\
\hline $\begin{array}{l}\text { MABS (Multi-Attribute } \\
\text { Bidding System) }\end{array}$ & Pacific Gas \& Electric & $\begin{array}{l}\text { Project Economic Analysis } \\
\text { Uncertainty Analysis }\end{array}$ \\
\hline $\begin{array}{l}\text { MAPS (Multi-Area } \\
\text { Production Simulation) }\end{array}$ & General Electric & $\begin{array}{l}\text { Production Simulation } \\
\text { Bulk Power Market }\end{array}$ \\
\hline $\begin{array}{l}\text { MAPS (Marketing Activity } \\
\text { Planners) }\end{array}$ & $\begin{array}{l}\text { National Rural Electric } \\
\text { Cooperative Association }\end{array}$ & DSM Potential Assessment \\
\hline Market Manager & SRC Systems & $\begin{array}{l}\text { DSM Cost-Effectiveness } \\
\text { Analysis }\end{array}$ \\
\hline MIDAS & $\begin{array}{l}\text { EPRI } \\
\text { (M.S. Gerber \& Associates) }\end{array}$ & $\begin{array}{l}\text { Uncertainty Analysis } \\
\text { Production Simulation } \\
\text { Financial/Rates }\end{array}$ \\
\hline MostValue & Case Western Reserve University & $\begin{array}{l}\text { DSM Cost-Effectiveness } \\
\text { Analysis }\end{array}$ \\
\hline OPTIONS & $\begin{array}{l}\text { lowa Association of Municipal } \\
\text { Utilities }\end{array}$ & $\begin{array}{l}\text { DSM Cost-Effectiveness } \\
\text { Analysis }\end{array}$ \\
\hline Over/Under & EPRI & $\begin{array}{l}\text { Generation Reliability } \\
\text { Uncertainty Analysis }\end{array}$ \\
\hline $\mathrm{P}+$ & P Plus Corporation & $\begin{array}{l}\text { DSM Cost-Effectiveness } \\
\text { Analysis } \\
\text { Production Simulation }\end{array}$ \\
\hline PM-DAM & Bonneville Power Administration & $\begin{array}{l}\text { Bulk Power Market } \\
\text { Resource Planning } \\
\text { Uncertainty Analysis }\end{array}$ \\
\hline POLARIS & Decision Focus, Inc. & Production Simulation \\
\hline PowerCoach & Strategic Decisions Group & $\begin{array}{l}\text { Project Economic Analysis } \\
\text { Uncertainty Analysis }\end{array}$ \\
\hline $\begin{array}{l}\text { PowerPlan } \\
\text { POWRPLAN }\end{array}$ & Burns \& McDonnell & Production Simulation \\
\hline POWERSYM-Plus & Energy and Control Consultants & $\begin{array}{l}\text { Production Simulation } \\
\text { Generation Reliability }\end{array}$ \\
\hline PowerWatch 1.0 & Demand Side Software, Inc. & Energy Use Monitoring \\
\hline POWRPRO & Black \& Veatch & Production Simulation \\
\hline PROMOD III & Energy Management Associates & $\begin{array}{l}\text { Production Simulation } \\
\text { Generation Reliability }\end{array}$ \\
\hline $\begin{array}{l}\text { PROSCREEN II/ } \\
\text { PROVIEW }\end{array}$ & Energy Management Associates & $\begin{array}{l}\text { Resource Planning } \\
\text { Production Simulation } \\
\text { Capital Expenditures } \\
\text { Financial/Rates }\end{array}$ \\
\hline PROSIM & Henwood Energy Services, Inc. & $\begin{array}{l}\text { Production Simulation } \\
\text { Generation Reliability }\end{array}$ \\
\hline PSS/E & Power Technologies, Inc. & Load Flow Analysis \\
\hline
\end{tabular}




\begin{tabular}{|c|c|c|}
\hline Model Name & Vendor & Primary Capabilities \\
\hline RE-SHAPE & Battelle-Columbus Division & DSM Potential Assessment \\
\hline RECAP & Xenergy, Inc. & End-Use Demand Forecasting \\
\hline RECONDA V2.0 & Christensen Associates & End-Use Demand Forecasting \\
\hline REDMS & Jerry Jackson \& Associates & $\begin{array}{l}\text { End-Use Demand Forecasting } \\
\text { DSM Cost-Effectiveness } \\
\text { Analysis }\end{array}$ \\
\hline REEPS 2.1 & EPRI & $\begin{array}{l}\text { End-Use Demand Forecasting } \\
\text { Econometric Demand } \\
\text { Forecasting }\end{array}$ \\
\hline RELIEF & Christensen Associates & DSM Potential Assessment \\
\hline RELOAD 2.1 & Synergic Resource Corp. & End-Use Demand Forecasting \\
\hline RETOU-PC & Christensen Associates & DSM Potential Assessment \\
\hline RISKMIN & EPRI & Uncertainty Analysis \\
\hline RPSM & Washington State University & $\begin{array}{l}\text { DSM Cost-Effectiveness } \\
\text { Analysis }\end{array}$ \\
\hline SAGE & Decision Focus, Inc. & Production Simulation \\
\hline SAM & Decision Focus, Inc. & Production Simulation \\
\hline SHAPES-PC & Battelle-Columbus Division & End-Use Demand Forecasting \\
\hline STARRSS & RCG/Hagler Bailly & Uncertainty Analysis \\
\hline $\begin{array}{l}\text { Stone \& Webster Screening } \\
\text { Model }\end{array}$ & Stone \& Webster & $\begin{array}{l}\text { DSM Cost-Effectiveness } \\
\text { Analysis }\end{array}$ \\
\hline SYSREL & Argonne National Lab & $\begin{array}{l}\text { Production Simulation } \\
\text { FinancialRates }\end{array}$ \\
\hline TELPLAN & EPRI & $\begin{array}{l}\text { Production Simulation } \\
\text { Financial/Rates }\end{array}$ \\
\hline Thermo-Stor 100 & Demand Side Software, Inc. & DSM Potential Assessment \\
\hline TIGER & Florida Power Corporation & $\begin{array}{l}\text { Generation Reliability } \\
\text { Production Simulation } \\
\text { FinancialRates }\end{array}$ \\
\hline TrakLoad & SRC Systems & DSM Potential Assessment \\
\hline TRNSYS 12.2 & $\begin{array}{l}\text { Solar Energy Lab } \\
\text { University of Wisconsin }\end{array}$ & DSM Potential Assessment \\
\hline TRELSS & EPRI & Composite Reliability \\
\hline UPLAN III & LCG Consulting (Lotus) & $\begin{array}{l}\text { Resource Planning } \\
\text { Production Simulation } \\
\text { FinancialRates }\end{array}$ \\
\hline UPM & EPRI & $\begin{array}{l}\text { Production Simulation } \\
\text { Project Economic Analysis } \\
\text { FinanciaVRates }\end{array}$ \\
\hline
\end{tabular}




\begin{tabular}{||l|l|l||}
\hline \multicolumn{2}{|c||}{ Table D-1. Models Considered for Review (Cont'd) } \\
\hline \multicolumn{1}{|c||}{ Model Name } & \multicolumn{1}{|c|}{ Vendor } & \multicolumn{1}{c|}{ Primary Capabilities } \\
\hline WASP & Tennessee Valley Authority & $\begin{array}{l}\text { Production Simulation } \\
\text { Resource Planning }\end{array}$ \\
\hline $\begin{array}{l}\text { WESCOUGER / } \\
\text { WESPRIDE / Automatic } \\
\text { Generation Planning (AGP) }\end{array}$ & $\begin{array}{l}\text { ABB/Advance Systems } \\
\text { Technology }\end{array}$ & $\begin{array}{l}\text { Production Simulation } \\
\text { Resource Planning }\end{array}$ \\
\hline XenCAP & Xenergy, Inc. & DSM Potential Assessment \\
\hline
\end{tabular}




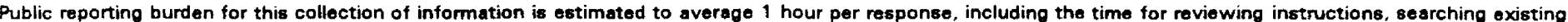

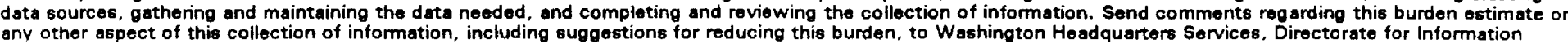

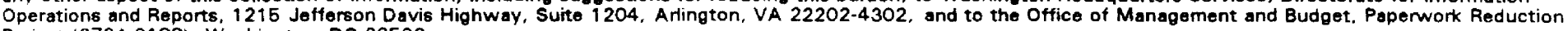
Project (0704-0188). Washington, DC 20503.
1. AGENCY USE ONLY (Leave blank)
2. REPORT DATE,
3. REPORT TYPE AND DATES COVERED
June 1994
Subcontractor report

4. TITLE AND SUBTITLE

Modeling Renewable Energy Resources in Integrated Resource Planning

5. FUNDING NUMBERS

AS1 15440

6. AUTHOR(S)

D. Logan, C. Neil, and A. Taylor

7. PERFORMING ORGANIZATION NAME(S) AND ADDRESS(ES)

RCG/Hagler, Bailly, Inc.

8. PERFORMING ORGANIZATION

P.O. Drawer 0

Boulder, CO 80306-1906 REPORT NUMBER

National Renewable Energy Laboratory

1617 Cole Boulevard

Golden, CO 80401-3393

10. SPONSORING/MONITORING AGENCY REPORT NUMBER

TP-462-6436

Subcontract No.

AAE-3-13371-01

11. SUPPLEMENTARY NOTES

12a. DISTRIBUTION/AVAILABILITY STATEMENT

National Technical information Service

U.S. Department of Commerce

5285 Port Royal Road

Springfield, VA 22161 12b. DISTRIBUTION CODE

UC 233

13. ABSTRACT (Maximum 200 words)

This subcontract report examines the capabilities of utility planning models to address key issues in choosing between renewable resources and other options. Including renewable energy resources in integrated resource planning requires that utility planning models properly consider the relevant attributes of various renewable resources in addition to the conventional supply-side and demand-side options. The current trend toward regulatory set-asides is motivated in part by the perception that the capabilities of current utility planning models do not address renewable resources adequately. Finding the proper level of renewable resources in a utility's resource mix will depend on developing planning methods that capture the benefits renewables offer. The study recommends how utilities should use the current capabilities of some models and suggests the direction of future work.

SUBJECT TERMS

utility planning models; integrated resource planning; renewable energy resources

15. NUMBER OF PAGES

114

\begin{tabular}{l} 
16. PRICE CODE \\
\hline
\end{tabular}

17. SECURITY CLASSIFICATION OF REPORT unclassified
18. SECURITY CLASSIFICATION OF THIS PAGE unclassified
19. SECURITY CLASSIFICATION OF ABSTRACT unclassified 